\title{
Designing Microstructure through Reverse Peritectoid Phase Transformation in $\mathrm{Ni}_{3} \mathrm{Mo}$ Alloy
}

\author{
Ibrahim Y. Khalfallah \\ Thesis submitted to the faculty of \\ Virginia Polytechnic Institute and State University \\ in partial fulfillment of the requirements for the degree of \\ Master of Science \\ in \\ Materials Science and Engineering \\ Alexander O. Aning, Chair \\ William T. Reynolds \\ Carlos T. A. Suchicital
}

December $7^{\text {th }}, 2016$

Blacksburg, VA

Keywords: Bulk Processing, Reverse Peritectoid, Age Hardening, $\mathrm{Ni}_{3} \mathrm{Mo}$ Alloy

Copyright 2016, Ibrahim Khalfallah 


\title{
Designing Microstructure through Reverse Peritectoid Phase Transformation in $\mathrm{Ni}_{3} \mathrm{Mo}$ Alloy
}

\author{
By \\ Ibrahim Khalfallah
}

\begin{abstract}
High-energy ball milling and powder metallurgy methods were used to produce a partially alloyed nickel and molybdenum of $\gamma-\mathrm{Ni}_{3} \mathrm{Mo}$ composition (Ni-25at.\%Mo). Milled powders were cold-compacted, sintered/solutionized at $1300^{\circ} \mathrm{C}$ for $100 \mathrm{~h}$ sintering followed by quenching. Three transformation studies were performed. First, the intermetallic $\gamma-\mathrm{Ni}_{3} \mathrm{Mo}$ was formed from the supersaturated solution at temperatures ranging between $600^{\circ} \mathrm{C}$ and $900^{\circ} \mathrm{C}$ for up to $100 \mathrm{~h}$. The $100 \%$ stable $\gamma-\mathrm{Ni}_{3} \mathrm{Mo}$ phase was formed at $600^{\circ} \mathrm{C}$ after $100 \mathrm{~h}$, while aging at temperatures ranging between $650^{\circ} \mathrm{C}$ and $850^{\circ} \mathrm{C}$ for $25 \mathrm{~h}$ was not sufficient to complete the transformation. The $\delta$-NiMo phase was observed only at $900^{\circ} \mathrm{C}$ as cellular and basket strands precipitates.

Second, the reversed peritectoid transformation from $\gamma-\mathrm{Ni}_{3} \mathrm{Mo}$ to $\alpha-\mathrm{Ni}$ and $\delta$-NiMo was performed. Supersaturated solid solution samples were first aged at 600C for 100h followed by quenching to form the equilibrium $\gamma-\mathrm{Ni}_{3} \mathrm{Mo}$ phase. After that, the samples were heat treated between $910^{\circ} \mathrm{C}$ and $1050^{\circ} \mathrm{C}$ for up to $10 \mathrm{~h}$ followed by quenching. Regardless of heat-treatment temperature, samples heat-treated for shorter times exhibited small precipitates of $\delta$-NiMo along and within grain boundaries of $\alpha-\mathrm{Ni}$ phase, and it coarsened with time. Third, the transformation
\end{abstract}


from the supersaturated solution $\alpha-\mathrm{Ni}$ to the peritectoid two-phase region was performed. The samples were aged between $910^{\circ} \mathrm{C}$ and $1050^{\circ} \mathrm{C}$ for up to $10 \mathrm{~h}$ followed by quenching. Precipitates of $\delta$-NiMo were observed in the $\alpha$-Ni matrix as small particles and then coarsened with aging time. In all three cases, hardness values increased and peaked in a way similar to that of traditional aging, except that the peak occurred much rapidly in the second and third cases. In the first case, hardness increased by about $113.6 \%$ due to the development of the new phases, while the hardness increased by $90.5 \%$ and $77.2 \%$ in the second and third cases, respectively. 


\title{
Designing Microstructure through Reverse Peritectoid Phase Transformation in $\mathrm{Ni}_{3} \mathrm{Mo}$ Alloy
}

\author{
By \\ Ibrahim Khalfallah \\ General Audience Abstract
}

Mechanical milling and powder processing methods were used to produce $\mathrm{Ni}-25 \mathrm{at} . \% \mathrm{Mo}$ alloy. Nickel and molybdenum powders were milled for $10 \mathrm{~h}$, pressed, and then sintered at $1300^{\circ} \mathrm{C}$ for $100 \mathrm{~h}$ followed by quenching. Three different phase transformation studies were performed. The goal of the first study was to investigate the formation of $\gamma-\mathrm{Ni}_{3} \mathrm{Mo}$ phase from the solid solution $\mathrm{Ni}$ at temperatures ranging between $600^{\circ} \mathrm{C}$ and $900^{\circ} \mathrm{C}$ followed by quenching. The $100 \% \gamma-\mathrm{Ni}_{3} \mathrm{Mo}$ phase was formed at $600^{\circ} \mathrm{C}$ after $100 \mathrm{~h}$. In the second study, the formation of $\alpha-\mathrm{Ni}$ and $\delta$-NiMo from $\gamma-\mathrm{Ni}_{3} \mathrm{Mo}$ phase was performed. The heat treatments were done between $910^{\circ} \mathrm{C}$ and $1050^{\circ} \mathrm{C}$ for up to $10 \mathrm{~h}$ followed by quenching. The $\gamma-\mathrm{Ni}_{3} \mathrm{Mo}$ phase was not stable at temperatures between $910^{\circ} \mathrm{C}$ and $1050^{\circ} \mathrm{C}$. Small precipitates of $\delta$-NiMo along and within grain boundaries of $\alpha$-Ni phase were observed, and they coarsened with time. The third study included the formation of $\alpha-\mathrm{Ni}$ and $\delta$-NiMo from solid solution $\mathrm{Ni}$. The heat treatments were performed between $910^{\circ} \mathrm{C}$ and $1050^{\circ} \mathrm{C}$ for up to $10 \mathrm{~h}$ followed by quenching. Precipitates of $\delta$-NiMo were observed in the $\alpha$-Ni matrix. In all three cases, hardness value increased and peaked with heat treatment times as particles coarsened. In the first case, hardness increased by about $113.6 \%$ due 
to the development of the new phases, while the hardness increased by $90.5 \%$ and $77.2 \%$ in the second and third cases, respectively. 


\section{Acknowledgements}

First and foremost, I would like to thank ALLAH who has given me the will to achieve this work and pursue my dream. I could never have done this work without the faith I have in ALLAH, the Almighty.

Firstly, I would like to express my sincere gratitude to my academic father and academic advisor Dr. Alex O. Aning. Without his patience, teaching, guidance, and motivation, this thesis could have not been accomplished. I cannot adequately express my thanks for his help and interest in seeing me not only obtain my degree, but also succeed in my life.

Beside my advisor, I would like to thank my thesis committee members (i) Dr. William Reynolds, for his patience, helpful discussions, and guidance, (ii) Dr. Carlos Suchicital, for his insightful comments and help in writing. Without their help and guidance, it would be difficult for me to accomplish this work. My sincere thanks also go to Dr. Karen P. DePauw, Vice President and Dean for Graduate Education of Virginia Tech and Dr. David Clark, Department Head of The Virginia Tech's Materials Science and Engineering Department for providing financial support. Without their help, I would not have achieved my dream.

I would also like to thank Dr. Aning's research group: Hesham Elmkharram, Mohamed Mohamedali, Jonathan Angle, and James Tang for helpful discussions and great company. Last but not least, I would like to thank my family and friends for helping and supporting me throughout my study journey. 


\section{Table of Contents}

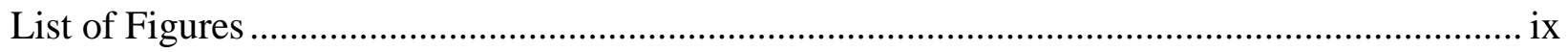

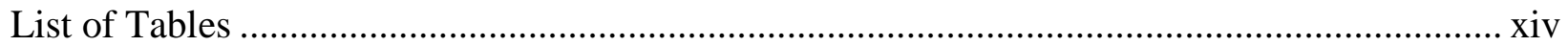

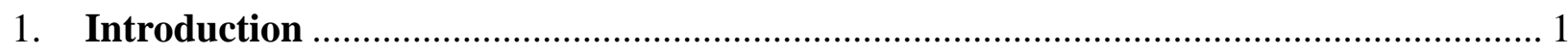

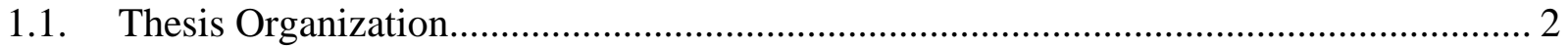

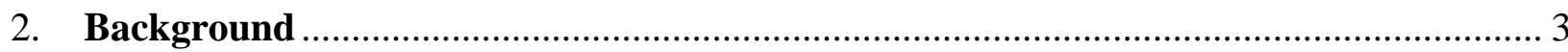

2.1. Microstructural Engineering of Metals ………….......................................................... 3

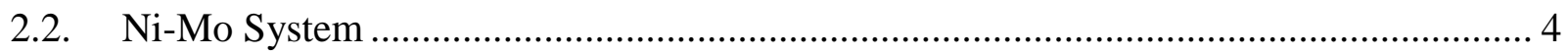

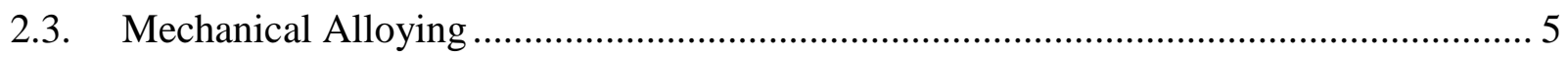

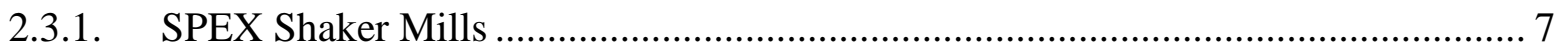

2.4. Powder Compaction and Sintering Methods........................................................... 8

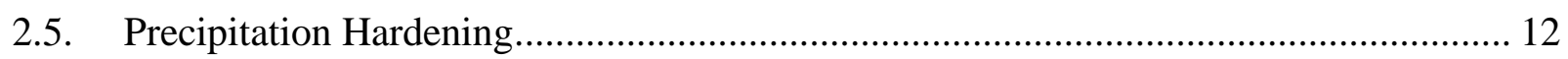

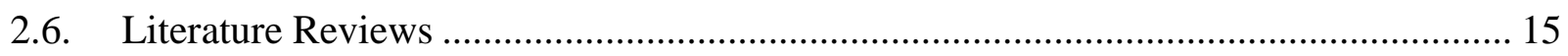

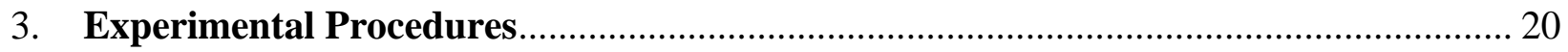

3.1. Sample Preparation ......................................................................................... 20

3.2. Heat-treatment Steps ……………………………............................................ 22

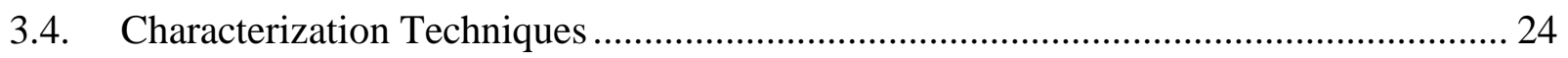

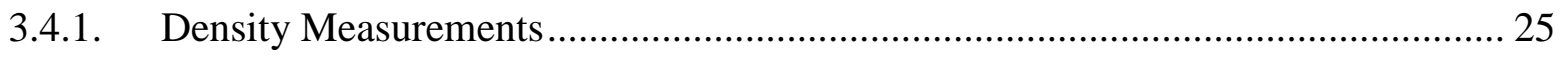

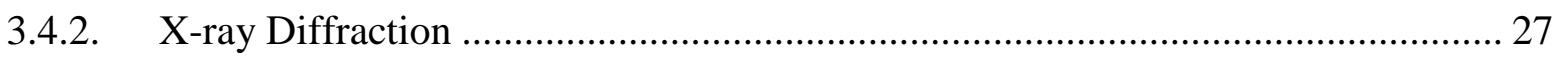

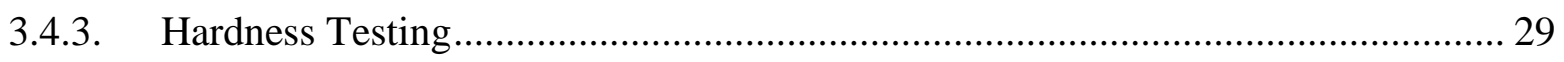

3.4.4. Scanning Electron Microscopy (SEM) ……………………………………....... 29

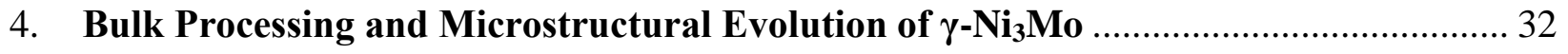

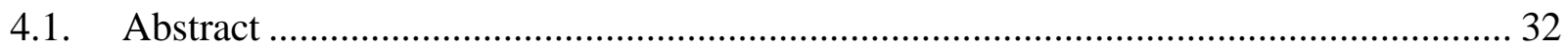

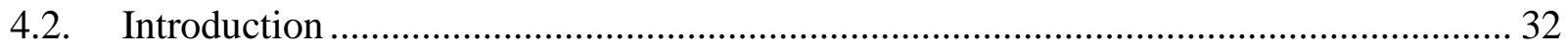

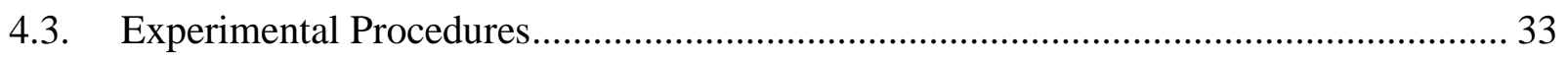




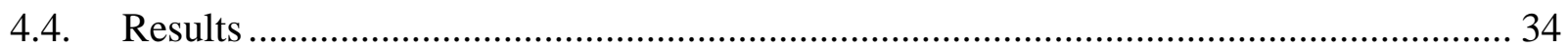

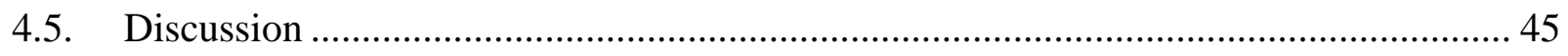

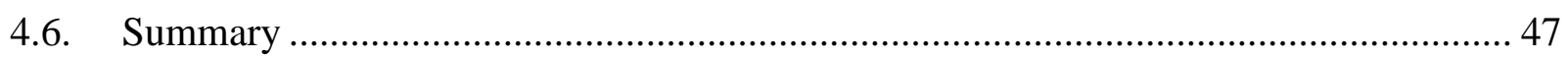

5. Reverse Peritectoid Phase Transformation in $\mathrm{Ni}_{3} \mathrm{Mo}$ Alloy ………….......................... 50

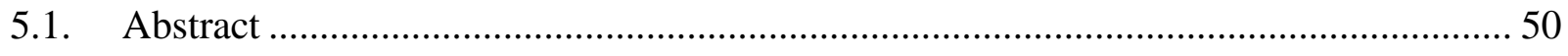

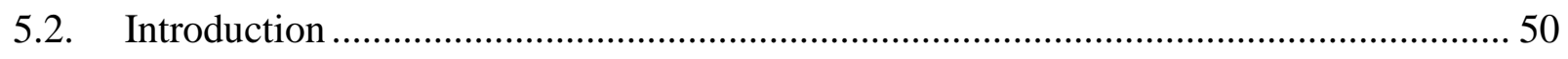

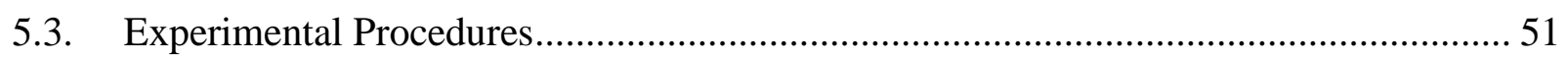

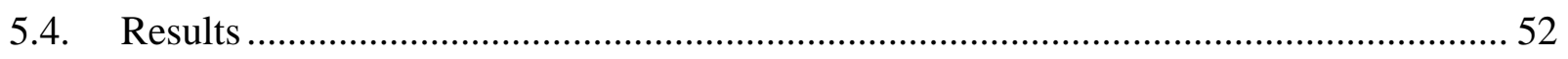

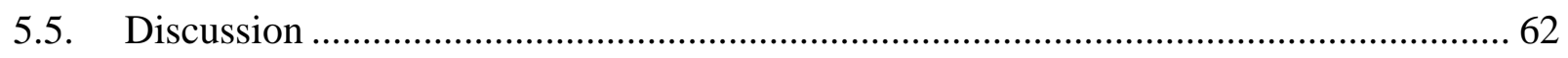

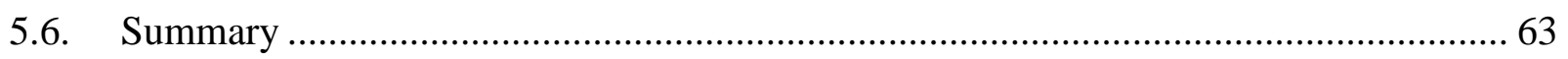

\section{Transformation of Supersaturated $\alpha$-Ni Solid Solution in the Peritectoid Two Phase}

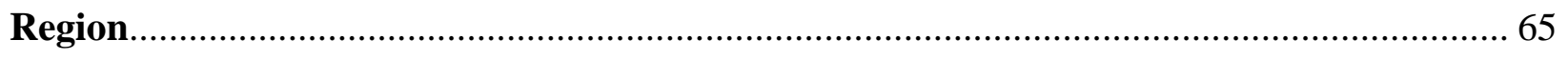

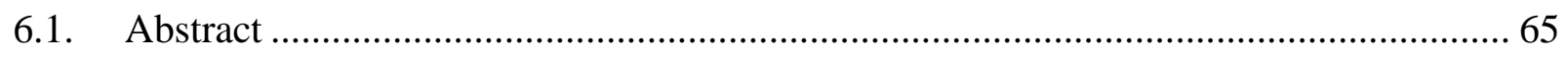

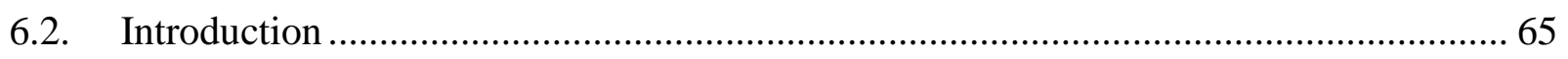

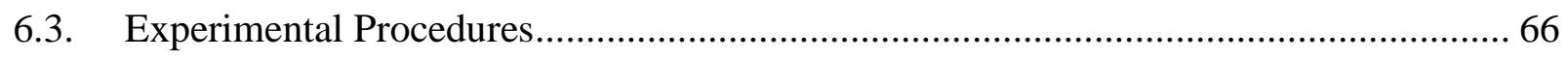

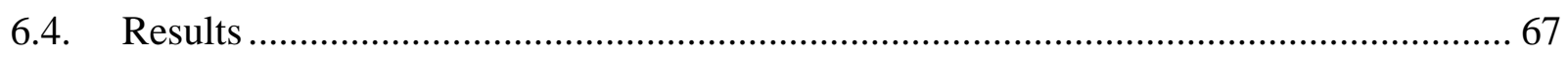

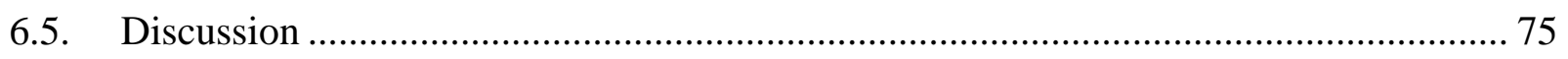

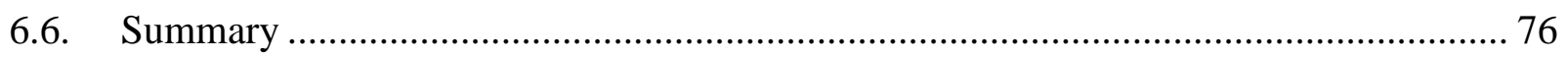

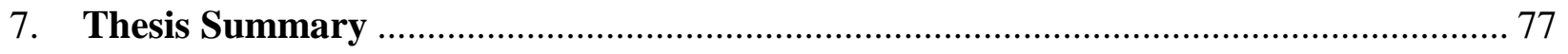

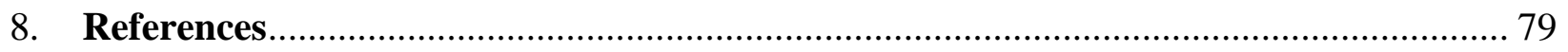




\section{List of Figures}

Figure 2.1 Ni-Mo binary equilibrium phase diagram [10] .................................................... 5

Figure 2.2 (a) SPEX 8000 shaker mill, (b) tungsten carbide vial, lid, gasket and balls ............... 8

Figure 2.3 Schematics of (a) cold isostatic pressing (CIP), (b) cold uniaxial pressing steps (www.

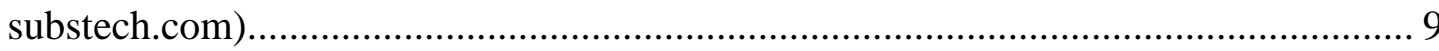

Figure 2.4 Schematics of (a) spark plasma sintering, (b) combustion driven compaction, and (c)

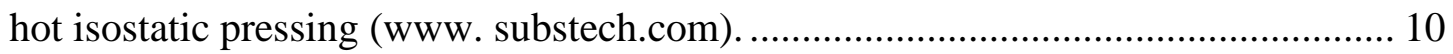

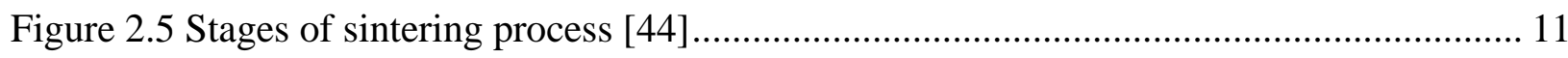

Figure 2.6 The aluminum-rich end of the $\mathrm{Al}-\mathrm{Cu}$ phase diagram showing the three steps in the age-hardening heat treatment and the microstructures that are produced [46] .......... 13

Figure 2.7 A typical one -peak precipitation hardening curve, shows the relationship between yield stress and aging time, includes three stages, underaging, peak strength, and

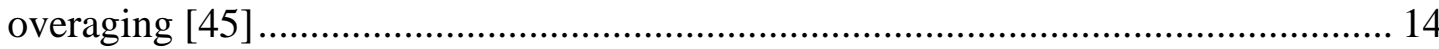

Figure 2.8 Micrograph of Ni-24.4at\%Mo alloy quenched from $\alpha$-region and then annealed at $860^{\circ} \mathrm{C}$ for $1 \mathrm{~h}$ after quenching from $\alpha$-region. A region $\mathbf{A}$ consists of $\mathrm{Ni}_{2} \mathrm{Mo}$ and $\beta$ $\mathrm{Ni}_{4} \mathrm{Mo}$ in the short-range-ordered matrix. A region $\mathbf{B}$ consists of $\gamma-\mathrm{Ni}_{3} \mathrm{Mo}$ which

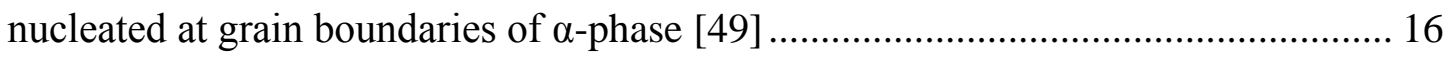

Figure 2.9 Micrograph of $\mathrm{Ni}-24.4 \mathrm{at} \% \mathrm{Mo}$ alloy quenched from $\alpha$-region and then annealed at $860^{\circ} \mathrm{C}$ for $550 \mathrm{~h}$. A region A (bands) consists of fcc lattice. A region B consists of $\gamma-$ $\mathrm{Ni}_{3} \mathrm{Mo}$ [49] 16

Figure 2.10 Histogram summarizing the coherent phase solvus with dissolution temperature.

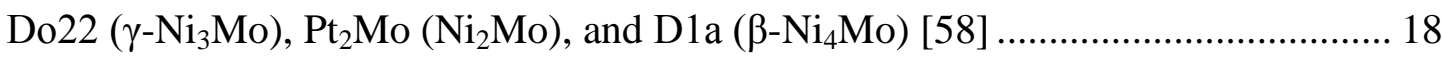

Figure 3.1 Tube furnace ( Lindberg Blue M (Model\# 54233)) ............................................... 21

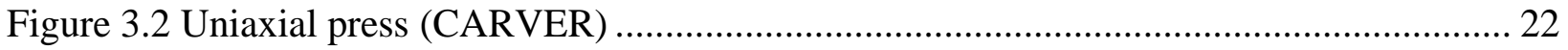

Figure 3.3 Uniaxial steel mold set and compacted samples .............................................. 22

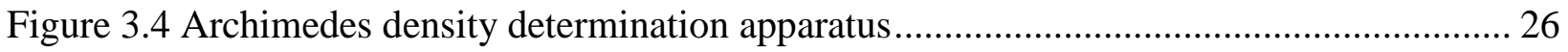

Figure 3.5 Density measurements of green compacted and sintered samples as a percentage of the theoretical value plotted with respect to sintering time. After $25 \mathrm{~h}$ the samples were quenched, re-compacted, and sintered. This step was repeated for a total of $100 \mathrm{~h}$

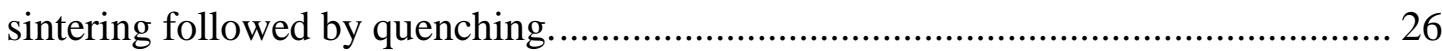


Figure 3.6 XRD (PANalytical X'Pro PW 3040 diffractometer) (A) an X-ray source, (B) nickel filter, (C) $10 \mathrm{~mm}$ mask, (D) $1^{\circ}$ anti-scatter slit, (E) sample holder, (F) $\mathrm{X}^{\prime}$ accelerator $\mathrm{X}$-ray detector. 27

Figure 3.7 Atomic \% of molybdenum in nickel as a function of lattice parameter [64] ............. 28

Figure 3.8 Vickers microhardness tester (LECO DM-400) ............................................... 29

Figure 3.9 Vickers indentation and measurement of impression diagonal (www.twi-global.com) 30

Figure 3.10 Environmental Scanning Electron Microscope (FEI Quanta 600 FEG) .................. 31

Figure 4.1 Partial phase diagram of Ni-Mo system with the heat-treatment steps: (1) sintering/solutionized at $1300^{\circ} \mathrm{C}$ for total $100 \mathrm{~h}$; (2) quenching; (3) aging at temperatures between $600^{\circ} \mathrm{C}-900^{\circ} \mathrm{C}$ for up to $100 \mathrm{~h}$ followed by quenching. ............ 34

Figure 4.2 XRD profiles of (a) Ni and Mo blended powder. (b) Mechanically Alloyed for 10h by using SPEX mill. (c) Sintered/Solutionized sample at $1300^{\circ} \mathrm{C}$ for a total of $100 \mathrm{~h}$

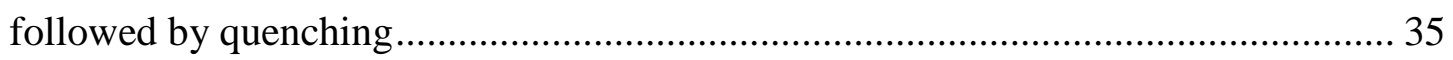

Figure 4.3 XRD patterns of Ni-25at.\%Mo alloy isothermally aged at $600^{\circ} \mathrm{C}$ for: (a) $15 \mathrm{~min}$; (b)

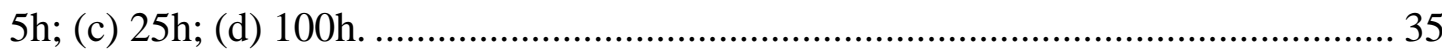

Figure 4.4 XRD profiles of Ni-25at.\%Mo alloy isothermally aged at $850^{\circ} \mathrm{C}$ for: (a) $30 \mathrm{~min}$; (b)

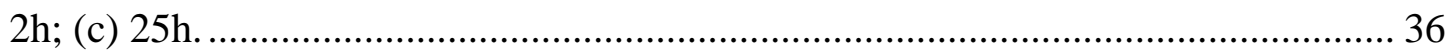

Figure 4.5 XRD profiles of Ni-25at.\%Mo alloy isothermally aged at $900^{\circ} \mathrm{C}$ for (a) $30 \mathrm{~min}$, (b) $2 \mathrm{~h}$, and (c) $25 \mathrm{~h}$. 37

Figure 4.6 Composition of solid solution $\alpha-\mathrm{Ni}$ determined from the existing solubility data [64] and X-ray data. 38

Figure 4.7 Optical micrograph of Ni-25at.\%Mo alloy sintered/solutionized at $1300^{\circ} \mathrm{C}$ for $100 \mathrm{~h}$ followed by rapid quenching the microstructure showed equiaxed and twined grains of solid solution $\alpha-\mathrm{Ni}$ phase (the black regions are spherical voids). Etchant: $\mathrm{FeCl}_{3} 5 \mathrm{~g}$, $\mathrm{HCl} 100 \mathrm{ml}$, and $10 \mathrm{ml} \mathrm{H}_{2} \mathrm{O}$. 38

Figure 4.8 SEM micrographs of Ni-25at.\%Mo alloy isothermally aged at $600^{\circ} \mathrm{C}$ for: (a) $2 \mathrm{~h}$ showing a microstructure of twinned grains of $\alpha-\mathrm{Ni}$ phase and the precipitates of $\gamma$ $\mathrm{Ni}_{3} \mathrm{Mo}$ along the grain boundaries; (b) $5 \mathrm{~h}$ consisting of $\alpha$-Ni grains and $\gamma-\mathrm{Ni}_{3} \mathrm{Mo}$ precipitates along the grain boundaries; (c) $100 \mathrm{~h}$ consisting of the equilibrium $\gamma$ - 
$\mathrm{Ni}_{3} \mathrm{Mo}$ phase. The voids are not included in these smaller fields of views. Etchant: $\mathrm{FeCl}_{3} 5 \mathrm{~g}, \mathrm{HCl} 100 \mathrm{ml}$, and $10 \mathrm{ml} \mathrm{H}_{2} \mathrm{O}$. 40

Figure 4.9 SEM micrographs of Ni-25at.\%Mo alloy isothermally aged at $850^{\circ} \mathrm{C}$ for: (a) $30 \mathrm{~min}$ showing a microstructure of $\alpha$-Ni phase and precipitates of $\gamma-\mathrm{Ni}_{3} \mathrm{Mo}$ along and within the grain boundaries; (b) $25 \mathrm{~h}$ consisting of $\alpha-\mathrm{Ni}$ and $\gamma-\mathrm{Ni}_{3} \mathrm{Mo}$ phase according to the XRD data. The black regions are voids. Etchant: $\mathrm{FeCl}_{3} 5 \mathrm{~g}, \mathrm{HCl} 100 \mathrm{ml}$, and $10 \mathrm{ml}$ $\mathrm{H}_{2} \mathrm{O}$. 41

Figure 4.10 SEM micrographs of Ni-25at. $\%$ Mo alloy aged at $900^{\circ} \mathrm{C}$ for :(a) 30 min consisting of mixture of $\gamma-\mathrm{Ni}_{3} \mathrm{Mo}$ and $\delta$-NiMo precipitates along and within the grain boundaries of $\alpha$-Ni phase; (b) $2 \mathrm{~h}$ consisting of $\delta$-NiMo precipitates along and within the grain boundaries of $\alpha-\mathrm{Ni}$ phase; (c) $25 \mathrm{~h}$ consisting of a basket weave strands of $\delta$-NiMo within the grain boundaries of $\alpha-\mathrm{Ni}$ phase. The black regions are voids. Etchant: $\mathrm{FeCl}_{3} 5 \mathrm{~g}, \mathrm{HCl} 100 \mathrm{ml}$, and $10 \mathrm{ml} \mathrm{H}_{2} \mathrm{O}$. 43

Figure 4.11 Microhardness of Ni-25at.\%Mo alloy aged plotted against aging time. 44

Figure 4.12 Schematic diagram summarizing the phase transformation of Ni-25at.\%Mo alloy during aging between $600^{\circ} \mathrm{C}-900^{\circ} \mathrm{C}$ (y-axis) and different aging times (x-axis)....... 49

Figure 5.1 Partial phase diagram of Ni-Mo system with the heat-treatment steps: (1) sintering/solutionized at $1300^{\circ} \mathrm{C}$ for total $100 \mathrm{~h}$; (2) quenching; (3) aging at $600^{\circ} \mathrm{C}$ for $100 \mathrm{~h}$ followed by quenching; (4) heat-treatment to $\alpha-\mathrm{Ni}-\delta$-NiMo followed by

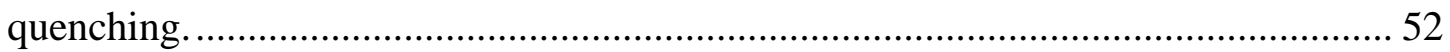

Figure 5.2 XRD patterns of the heat-treated sample at $910^{\circ} \mathrm{C}$ for (a) $5 \mathrm{~min}$, (b) $30 \mathrm{~min}$, (c) $2 \mathrm{~h}$,

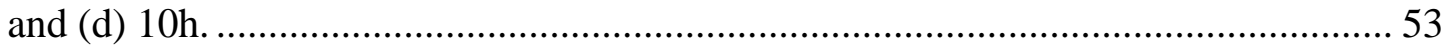

Figure 5.3 XRD patterns of the heat-treated sample at $970^{\circ} \mathrm{C}$ for (a) $5 \mathrm{~min}$, (b) $30 \mathrm{~min}$, (c) $1 \mathrm{~h}$, and (d) $10 \mathrm{~h}$. 53

Figure 5.4 XRD patterns of the heat-treated sample at $1050^{\circ} \mathrm{C}$ for (a) $5 \mathrm{~min}$, (b) $30 \mathrm{~min}$, (c) $2 \mathrm{~h}$, and (d) $5 \mathrm{~h}$

Figure 5.5 SEM micrographs of Ni-25at.\%Mo alloy isothermally aged at $600^{\circ} \mathrm{C}$ for $100 \mathrm{~h}$ consisting of grains of $\gamma-\mathrm{Ni}_{3} \mathrm{Mo}$. The voids are not included in these smaller fields of views. Etchant: $\mathrm{FeCl}_{3} 5 \mathrm{~g}, \mathrm{HCl} 100 \mathrm{ml}$, and $10 \mathrm{ml} \mathrm{H}_{2} \mathrm{O}$. 55

Figure 5.6 SEM micrographs Ni-25at.\%Mo alloy heat-treated at $910^{\circ} \mathrm{C}$ for: (a) $5 \mathrm{~min}$, (b) $1 \mathrm{~h}$, and (c) $10 \mathrm{~h}$. These micrographs are consisting of precipitated particles of $\delta$-NiMo 
(white) in the $\alpha$-Ni matrix (gray). Black reigns are voids. Etchant: $\mathrm{FeCl}_{3} 5 \mathrm{~g}, \mathrm{HCl}$

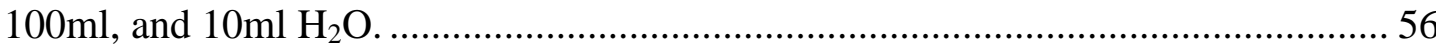

Figure 5.7 SEM micrographs of Ni-25at.\%Mo alloy heat-treated at $970^{\circ} \mathrm{C}$ for (a) $5 \mathrm{~min}$, (b) 30 min, (c) $2 \mathrm{~h}$, and (d) $10 \mathrm{~h}$. These micrographs are showing the development of the precipitation of $\delta$-NiMo (white) along and within the grain boundaries of $\alpha-\mathrm{Ni}$ (gray). All black regions are voids. Etchant: $\mathrm{FeCl}_{3} 5 \mathrm{~g}, \mathrm{HCl} 100 \mathrm{ml}$, and $10 \mathrm{ml} \mathrm{H}_{2} \mathrm{O}$............ 59

Figure 5.8 SEM micrographs of heat-treated specimens at $1050^{\circ} \mathrm{C}$ for (a) $5 \mathrm{~min}$, (b) $30 \mathrm{~min}$, (c) $2 \mathrm{~h}$, and (d) $5 \mathrm{~h}$. These micrographs are showing precipitated particles of $\delta$-NiMo (white) in an $\alpha$-Ni matrix (gray). Black regions are voids. Etchant: $\mathrm{FeCl}_{3} 5 \mathrm{~g}, \mathrm{HCl}$ $100 \mathrm{ml}$, and $10 \mathrm{ml} \mathrm{H}_{2} \mathrm{O}$. 61

Figure 5.9 Microhardness of heat-treated samples plotted against heat-treatment time. 62

Figure 5.10 Schematic diagram summarizing the phase transformation of $\gamma-\mathrm{Ni}_{3} \mathrm{Mo}(\mathrm{Ni}$ 25at.\%Mo alloy) during heat treatment between $910^{\circ} \mathrm{C}-1050^{\circ} \mathrm{C}$ (y-axis) and different heat treatment time (x-axis). 64

Figure 6.1 Partial phase diagram of Ni-Mo system with the heat-treatment steps: (1) sintering/solutionized at $1300^{\circ} \mathrm{C}$ for total $100 \mathrm{~h}$; (2) quenching; (3) aging at temperatures between $910^{\circ} \mathrm{C}-1050^{\circ} \mathrm{C}$ for up to $10 \mathrm{~h}$ followed by quenching. 66

Figure 6.2 XRD patterns of Ni-25at.\%Mo alloy aged at $910^{\circ} \mathrm{C}$ for: (a) $5 \mathrm{~min}$, (b) $30 \mathrm{~min}$, (c) $2 \mathrm{~h}$, and (d) $10 \mathrm{~h}$ 67

Figure 6.3 XRD patterns of Ni-25at.\%Mo alloy aged at $970^{\circ} \mathrm{C}$ for: (a) $5 \mathrm{~min}$, (b) $30 \mathrm{~min}$, (c) $2 \mathrm{~h}$, and (d) $10 \mathrm{~h}$ 68

Figure 6.4 XRD patterns of Ni-25at.\%Mo alloy aged at $1050^{\circ} \mathrm{C}$ for: (a) $5 \mathrm{~min}$, (b) $30 \mathrm{~min}$, (c) $2 \mathrm{~h}$, and (d) $5 \mathrm{~h}$ 68

Figure 6.5 SEM micrograph of Ni-25at.\% Mo alloy sintered at $1300^{\circ} \mathrm{C}$ for a total $100 \mathrm{~h}$ followed by quenching consisting of annealing twins and equiaxed grains (the black regions are voids). Etchant: $\mathrm{FeCl}_{3} 5 \mathrm{~g}, \mathrm{HCl} 100 \mathrm{ml}$, and $10 \mathrm{ml} \mathrm{H}_{2} \mathrm{O}$.

Figure 6.6 SEM micrographs of Ni-25at.\% Mo alloy aged at $910^{\circ} \mathrm{C}$ for: (a) $5 \mathrm{~min}$; (b) $2 \mathrm{~h}$; (c) $10 \mathrm{~h}$. The microstructures are consisting of precipitates of $\delta$-NiMo along and within the grain boundaries of $\alpha-\mathrm{Ni}$ (the black regions are voids). Etchant: $\mathrm{FeCl}_{3} 5 \mathrm{~g}, \mathrm{HCl}$ $100 \mathrm{ml}$, and $10 \mathrm{ml} \mathrm{H}_{2} \mathrm{O}$. 
Figure 6.7 SEM micrographs of Ni-25at.\% Mo alloy aged at $970^{\circ} \mathrm{C}$ for: (a) $5 \mathrm{~min}$; (b) $5 \mathrm{~h}$. The microstructures are showing precipitates of $\delta$-NiMo along and within the grain boundaries of $\alpha-\mathrm{Ni}$ (the black regions are voids). Etchant: $\mathrm{FeCl}_{3} 5 \mathrm{~g}, \mathrm{HCl} 100 \mathrm{ml}$, and $10 \mathrm{ml} \mathrm{H}_{2} \mathrm{O}$.

Figure 6.8 SEM micrographs of Ni-25at.\% Mo alloy aged at $1050^{\circ} \mathrm{C}$ for: (a) $5 \mathrm{~min}$; (b) $2 \mathrm{~h}$; (c) 5h. The microstructures are consisting of $\delta$-NiMo along and within the grain boundaries of $\alpha-\mathrm{Ni}$ (the black regions are voids). Etchant: $\mathrm{FeCl}_{3} 5 \mathrm{~g}, \mathrm{HCl} 100 \mathrm{ml}$, and $10 \mathrm{ml} \mathrm{H}_{2} \mathrm{O}$. 73

Figure 6.9 Microhardness of Ni-25at.\% Mo alloy aged plotted against aging time. 74

Figure 6.10 Schematic diagram summarizing the phase transformation of the supersaturated $\mathrm{Ni}$ 25at.\% Mo alloy during heat treatment between $910^{\circ} \mathrm{C}-1050^{\circ} \mathrm{C}(\mathrm{y}$-axis) and different heat treatment times (x-axis). 76 


\section{List of Tables}

Table 3.1 Summary of the heat-treatment conditions and purposes ...................................... 23

Table 3.2 Summary of the full heat-treatment matrix between $600^{\circ} \mathrm{C}$ and $900^{\circ} \mathrm{C} \ldots \ldots \ldots \ldots \ldots . . . . . . . .24$

Table 3.3 Summary of the full heat-treatment matrix between $910^{\circ} \mathrm{C}$ and $1050^{\circ} \mathrm{C}$................. 24 


\section{Chapter One}

\section{Introduction}

The material's microstructures are the connection between its processing techniques and its resulting properties. The microstructure of metal alloys can be modified by mechanical deformation or heat-treatment, to improve their properties. Understanding the thermodynamics of an alloy formation, which is reflected in its phase diagram, and selecting the appropriate processing technique may lead to design a new microstructure with excellent properties [1]. There are many processing techniques that have been used to modify metal alloy microstructures to enhance the performance and broaden its applications. These processes include but are not limited to selective laser melting (SLM) [2, 3], mechanical alloying (MA) [4, 5], ultra-fast annealing (UFA) [6, 7], and precipitation hardening [8, 9]. These processing techniques have been developed either to refine the microstructure or to disperse particles in the microstructure, and both can lead to improving strength and toughness of the alloy.

Typical microstructural design in metal alloys usually includes cooling the alloy from a single phase region, e. g. austenite, to a multiple phase region, e. g. ferrite and cementite. This kind of heat treatment is determined by the alloy's phase diagram. With information from the equilibrium phase diagram of Ni-Mo system, it is possible to engineer its microstructure in various ways. The Ni-Mo phase diagram shows three intermetallic phases $\beta-\mathrm{Ni}_{4} \mathrm{Mo}, \gamma-\mathrm{Ni}{ }_{3} \mathrm{Mo}$, and $\delta$-NiMo. In 1970, a fourth intermetallic phase $\mathrm{Ni}_{2} \mathrm{Mo}$ was discovered, and it is not shown in the Ni-Mo phase diagram [10]. The $\mathrm{Ni}_{3} \mathrm{Mo}$ alloy is unique because it forms a solid solution at high temperatures and a supersaturated solid solution after quenching. Thus, the $\mathrm{Ni}_{3} \mathrm{Mo}$ alloy heat-treated in several ways to alter its microstructure may lead to enhanced properties.

The present work deals with the processing of bulk Ni-25at.\%Mo alloy (stoichiometric $\gamma$ $\mathrm{Ni}_{3} \mathrm{Mo}$ ) using mechanical alloying and powder metallurgy methods. This work also seeks to 
understand the microstructural evolution during aging of the supersaturated solid solution $\alpha-\mathrm{Ni}$ above and below the peritectoid temperature and their associated hardness.

\subsection{Thesis Organization}

This thesis is organized as follows. Following this introductory part is Chapter two. Chapter two includes background information on microstructural engineering in metal, Ni-Mo system, mechanical alloying, powder compaction and sintering methods, precipitation hardening, and related work. Chapter three describes the experimental procedures as well as the characterization techniques employed. Chapters four through six are written as journal articles. Chapter four discusses bulk processing and microstructural evolution of $\gamma-\mathrm{Ni}_{3} \mathrm{Mo}$. Chapter five discusses reverse peritectoid phase transformation in $\mathrm{Ni}_{3} \mathrm{Mo}$ alloy. Chapter six discusses the transformation of the supersaturated $\alpha-\mathrm{Ni}$ solid solution in the peritectoid two-phase region. Chapter seven summarizes the conclusions, followed by a list of references. 


\section{Background}

\subsection{Microstructural Engineering of Metals}

The microstructure of most metal alloys would include multiple phases, which differ in their properties. Designing the microstructure of the metal alloys is one of the large areas of research today. Both materials and the processing techniques must be taken into account to obtain the microstructure of interest. Some of the processing techniques that are commonly utilized to obtain specific microstructures include severe plastic deformation (SPD) [11, 12], rapid solidification processing (RSP) [13, 14], and precipitation hardening [15, 16].

Severe plastic deformation has been used to produce metal alloys with extraordinary properties. The main objective of this fabrication method is to produce ultra-fine grained metals, which can be done by introducing an ultra-large plastic strain into a bulk metal [17]. Several severe plastic deformation processes have been developed such as high-pressure torsion (HPT) [18], accumulative roll-bonding (ARB) [19], equal channel angular pressing (ECAP) [20], and mechanical alloying (MA) [21-23]. Very small average grain size (less than $1 \mu \mathrm{m})$ with high angle misoriented grain boundaries can be produced using these processes, which leads to developing high mechanical strength.

Rapid solidification processing involves rapid extraction of thermal energy during the transition from a liquid state at a high temperature. The cooling rate associated with this process is in the range of $10^{5}$ to $10^{6} \mathrm{Ks}^{-1}$, while the cooling rate of conventional solidification is in the range of $10^{2} \mathrm{Ks}^{-1}[14]$. In this process, a sample is heated up to a high temperature for a few minutes and then rapidly quenched to room temperature. The quenching medium can be water, liquid nitrogen, or brine solution [24]. Rapid solidification processing has been used to make a large volume fraction of stable dispersed second phase, which improves the high-temperature 
mechanical strength of aluminum alloys [14]. This fabrication process has also been used to improve the properties of other alloys [25-28]. In the late 1960s, rapid solidification was used on nickel-based alloys to accomplish microstructural homogeneity for improved properties; at the time the alloy was powder processed and then consolidated to form engine disc components [26]. On copper-based alloys, the rapid solidification process has been used on shape memory alloys, high-strength alloys, and amorphous alloys [14].

Precipitation hardening was first discovered in 1911 by A. Wilm. Wilm [29] reported that after heating an aluminum alloy containing $\mathrm{Cu}, \mathrm{Fe}$, and $\mathrm{Si}$ to a temperature below its melting point followed by quenching, its hardness increased with time at room temperature. Today the aim of this process is to enhance alloys strength by coherent precipitates that impede dislocation movement. Precipitation hardening is typically achieved by the following steps: (i) solution heat treatment, (ii) quenching, and (iii) aging heat treatment [15]. This strengthening method will be further discussed in Section 2.5.

\subsection{Ni-Mo Alloy System}

The binary equilibrium phase diagram of Ni-Mo system is shown in Fig. 2.1. This phase diagram shows three equilibrium intermetallic phases $\beta-\mathrm{Ni}_{4} \mathrm{Mo}, \gamma-\mathrm{Ni}{ }_{3} \mathrm{Mo}$, and $\delta$-NiMo. The metastable $\mathrm{Ni}_{2}$ Mo phase was discovered in 1970 by Van et al. [30] and is not shown in the NiMo phase diagram of Fig. 2.1. Both the intermetallic $\gamma-\mathrm{Ni}_{3} \mathrm{Mo}$ and $\beta-\mathrm{Ni}_{4} \mathrm{Mo}$ form when an alloy with a composition ranges between 20 and 25 at. $\%$ Mo cooled slowly from the single phase region $(\alpha-\mathrm{Ni})$. The critical temperatures $\beta-\mathrm{Ni}_{4} \mathrm{Mo}$ and $\gamma-\mathrm{Ni}_{3} \mathrm{Mo}$ are $870^{\circ} \mathrm{C}$ and $910^{\circ} \mathrm{C}$, respectively. The $\delta$-NiMo is a high-temperature intermetallic phase. Composition (at.\%Mo), structure, space group, and lattice parameters of $\beta-\mathrm{Ni}_{4} \mathrm{Mo}, \gamma-\mathrm{Ni}_{3} \mathrm{Mo}, \mathrm{Ni}_{2} \mathrm{Mo}$, and $\delta$-NiMo are shown in Table 2.1. 


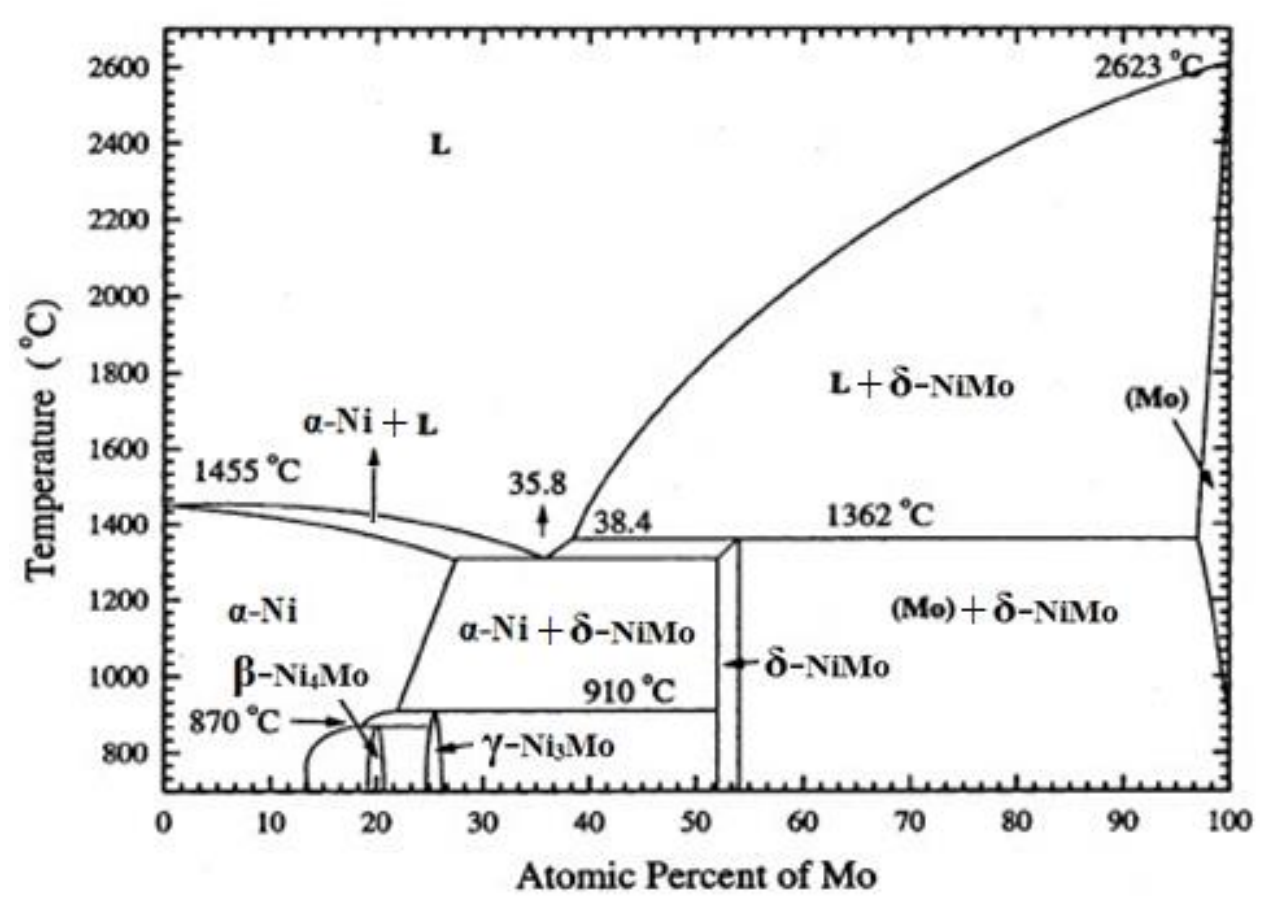

Figure 2.1 Ni-Mo binary equilibrium phase diagram [10]

Table 2.1 Summary of phase properties of Ni-Mo system [30].

\begin{tabular}{|c|c|c|c|c|c|c|}
\hline \multirow[t]{2}{*}{ Phase } & \multirow{2}{*}{$\begin{array}{l}\text { Composition } \\
\text { (at.\%Mo) }\end{array}$} & \multirow[t]{2}{*}{ Structure } & \multicolumn{3}{|c|}{ Lattice parameter $\AA$} & \multirow{2}{*}{$\begin{array}{l}\text { Space } \\
\text { group }\end{array}$} \\
\hline & & & $\mathrm{a}$ & $\mathrm{b}$ & $\mathrm{c}$ & \\
\hline$\alpha-\mathrm{Ni}$ & 0 to $28^{\#}$ & Face-centered cubic & 3.524 & 3.524 & 3.524 & $F m \overline{3} m$ \\
\hline$\beta-\mathrm{Ni}_{4} \mathrm{Mo}$ & 20 & Body-centered tetragonal & 5.727 & 5.727 & 3.566 & $I 4 / m$ \\
\hline$\gamma-\mathrm{Ni}_{3} \mathrm{Mo}$ & 25 & Hexagonal close packing & 5.064 & 4.224 & 4.448 & Pmmm \\
\hline $\mathrm{Ni}_{2} \mathrm{Mo}$ & 20 to52.5 & Body-centered orthorhombic & 2.492 & 7.475 & 3.524 & - \\
\hline$\delta$-NiMo & 51 to 52.5 & Orthorhombic & 9.108 & 9.108 & 8.852 & $P 2_{1} 2_{1} 2_{1}$ \\
\hline Mo & 98.9 to $100 *$ & Body-centered cubic & 3.147 & 3.147 & 3.147 & $\mathrm{Immm}$ \\
\hline
\end{tabular}

${ }^{\#}$ At $1309^{\circ} \mathrm{C}$. $*$ At $1362^{\circ} \mathrm{C}$

\subsection{Mechanical Alloying}

In 1966, at the International Nickel Company, mechanical alloying (MA) was developed by Benjamin and his colleagues [31]. MA is a powder processing technique that produces extremely high homogeneous materials that start from mixed elemental powder mixtures. The MA process has received much attention as a useful technique for processing equilibrium, nonequilibrium, and composite materials [32]. The powder particles are repeatedly cold-welded, 
fractured, and re-welded through high-energy ball milling [33]. The MA process can be successfully carried out in both high-energy mills and low-energy mills. The high-energy mills include a vibratory, centrifugal, attritor, and planter-type ball mills, whereas the low-energy mills include ball and rod mills [31].

There are several factors affecting the MA process, which can make a significant difference in the product's phase or microstructure. The milling parameters that have an effect on the final constitution of the powder are [31]:

- Type of mill (e.g., low-energy and high-energy mills)

- Milling time

- Milling environment (e.g., wet or dry milling)

- Charge ratio (milling medium-to-powder ratio)

- Milling temperature

- Type of milling medium (e.g., balls or rods)

- Milling atmosphere (e.g., an inert gas, argon, or liquid nitrogen)

- The materials of the milling tools (e.g., stainless steel, tungsten carbide, and ceramics)

The MA process variables are not independent, and they need to be optimized to achieve the desired product microstructure. For example, the milling time depends on many different process variables, such as charge ratio, the temperature of milling, type of mill, etc. With increasing the charge ratio and milling time, more energy will be transfer to the milled powder [31]. Milling time has a direct effect on the fracture and welding as well as diffusion processes during milling [34]. Kinetic energy of the milling balls increases the temperature, and this can have an effect on the process. The increase in temperature during milling results in an increase of the diffusivity of the component in the powder [32]. 
The most common materials used for the grinding medium are tungsten carbide and steels (stainless, hardened, tempered, and tool). The grinding medium's density should be high enough to create a high impact force on the powder, and milling medium's hardness higher than the powder being milled. The density of the grinding medium enhances the kinetic energy transferred to the powder. Alloying occurs due to the impact forces that are exerted on the powder. Thus, it is important to leave enough space for the milling medium and the powder to move freely in the milling container [32]. MA of metals is normally conducted under vacuum or in an inert atmosphere such as argon or helium to minimize oxidation [33]. The milling medium must be chosen carefully to reduce contamination from the milling medium; when possible the milling medium with composition similar to that of the powder [31].

\subsubsection{SPEX Shaker Mills}

A SPEX-shaker-mill is one of the types of high-energy mills commonly used for laboratory investigations. Because of the high velocities $(\sim 5 \mathrm{~m} / \mathrm{s})$ of the balls inside the vial, a SPEX mill is considered a high-energy mill type. High impact forces can be obtained using SPEX-shaker-mill that is because of its high frequency (about $1200 \mathrm{rpm}$ ) and high amplitude (about $5 \mathrm{~cm}$ ) of vibration. The common sort of SPEX mill has one vial, which is secured by a clamp and swung back and forth in infinity sign $(\infty)$ as it moves. The vial contains the charge (powder and balls) with capacity about $10-20 \mathrm{~g}$ of the powder. During the swing back and forth action, the powder particles are flattened between the balls or between a ball and the vial walls [31]. The drawback of a SPEX mill is that the powder somehow cannot be fully milled when it is compacted in the vial corners. A typical SPEX-shaker-mill, tungsten carbide vial, and grinding balls are shown in Fig. 2.2. 

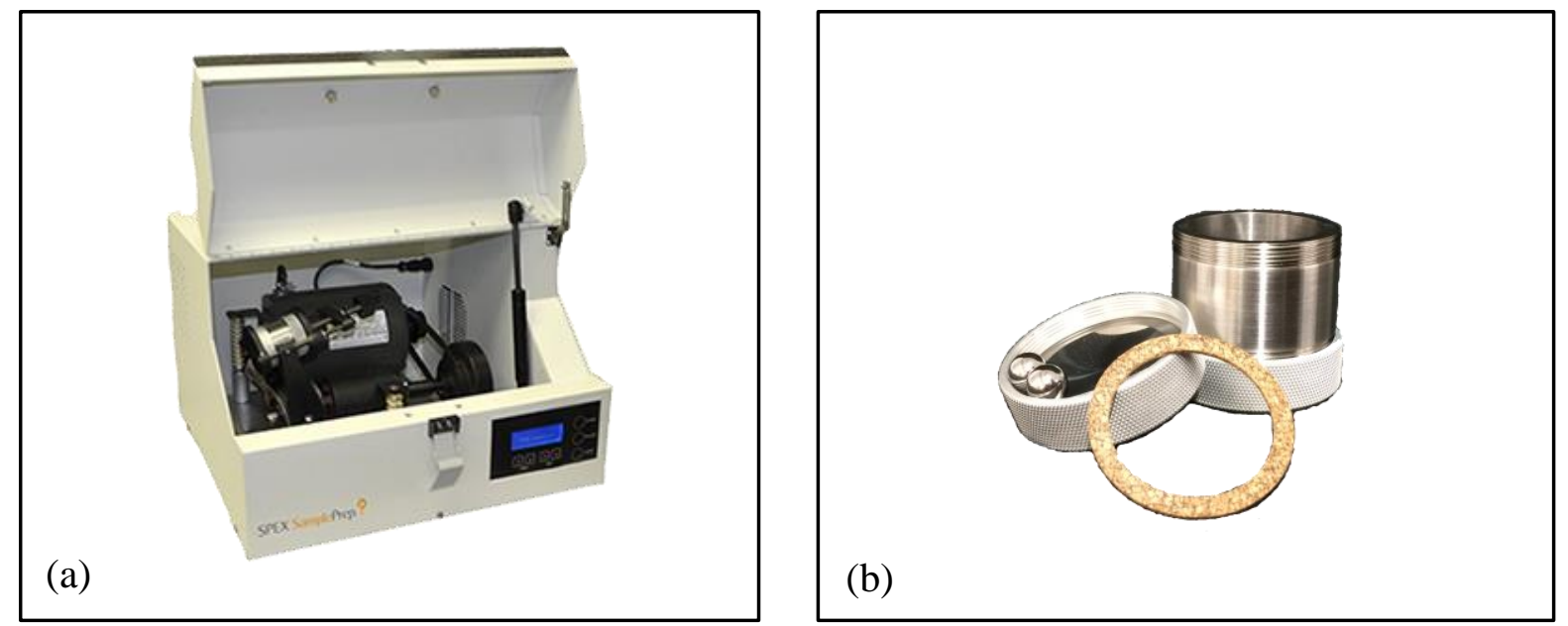

Figure 2.2 (a) SPEX 8000 shaker mill, (b) tungsten carbide vial, lid, gasket and balls

\subsection{Powder Compaction and Sintering Methods}

After processing, the powder is compacted and then sintered to have a bulk shape. Compaction of powders is a route that is used in industry to produce parts from polymers, metals, and ceramics. In general, as a first step the powder mixture (with a binder or lubricant) is compacted via isostatic pressing or cold/hot uniaxial compaction. Then the compact is sintered at elevated temperatures (around $0.6 \%$ to $0.8 \%$ of melting temperature) and controlled atmosphere, where diffusion mass transport processes become appreciable [35].

A cold compaction process is carried out using a cold isostatic pressing (CIP) or cold uniaxial. No sintering is achieved during this kind of compaction because they are carried out at room temperature $[35,36]$. CIP utilizes the pressure of a liquid or gas that applies pressure on a flexible rubber mold compressing the processed powder as shown in Fig. 2.3a. The main advantage of CIP over cold uniaxial method is that high homogenous and dense green bulk samples can be obtained [36].

A cold uniaxial pressing includes pouring a mixture of powders and a binder or lubricant in a steel die and then pressing the mixture between lower and upper punches as shown in Fig. 
2.3b. One of the main advantages of the uniaxial pressing is the ability to press large and different shapes. Also, the uniaxial pressing can produce parts with high productivity but with low quality as compared with CIP [37]. Repeating compaction after sintering when the uniaxial pressing is used that helps to improve the densification of the bulk materials. This approach is used in this work.

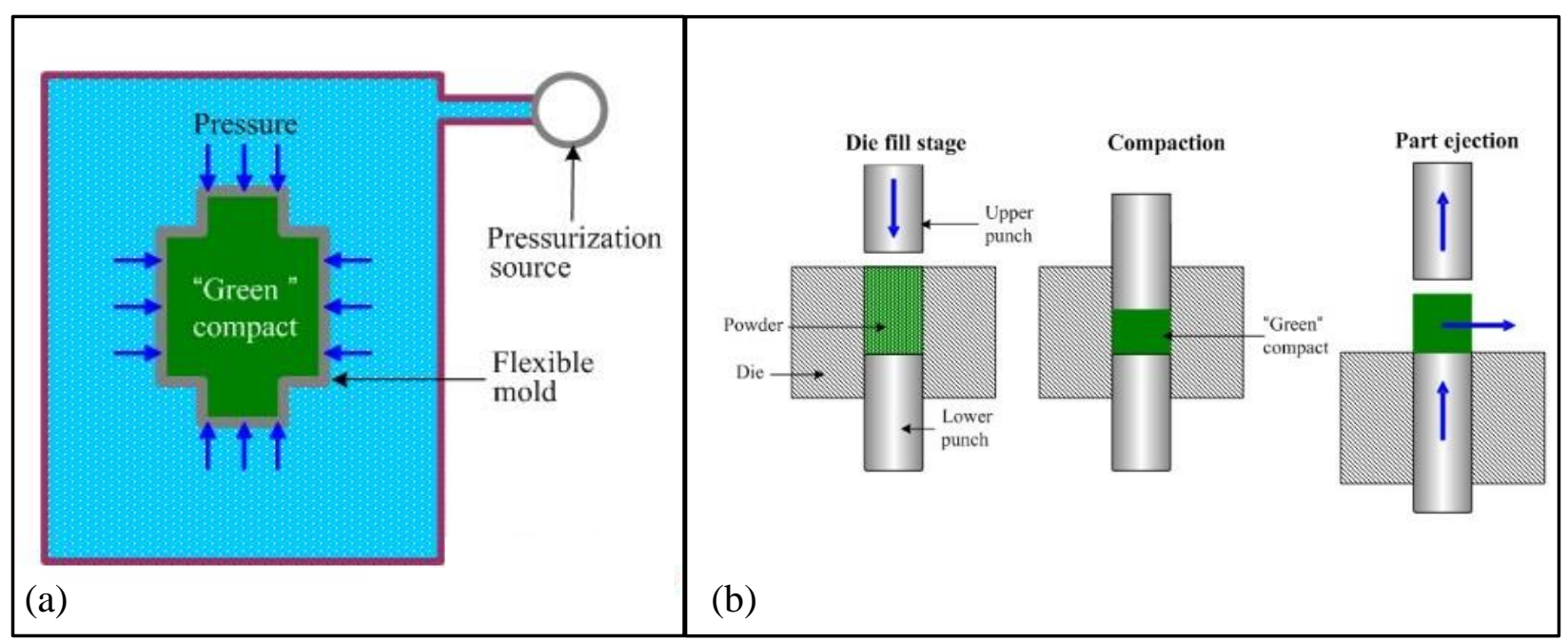

Figure 2.3 Schematics of (a) cold isostatic pressing (CIP), (b) cold uniaxial pressing steps (www. substech.com).

Hot compaction is like cold compaction, but it is done simultaneously applying a sintering temperature [38]. The most common hot compaction methods are spark plasma sintering (SPS) [37, 39], hot isostatic pressing (HIP) [40], and combustion driven compaction (CDC) [41]. The spark plasma sintering (SPS) is a newly developed technique utilizing uniaxial pressure featuring high heating rate (up to $1000^{\circ} \mathrm{C} / \mathrm{min}$ ) due to a pulse of DC current up to 8000A. SPS makes it possible to sinter powders at a low temperature, short isothermal holding time, and get almost fully dense bulk samples [42]. Fig. 2.4a shows a schematic diagram of spark plasma sintering system. 
Combustion driven compaction (CDC) utilizes released energy by igniting the natural gas and air. The natural gas $\left(\mathrm{CH}_{4}\right)$ and air after combustion generate a sudden high pressure that drives the press motion. This type of sintering technique provides in the moderate (100 to 1000 tons) to the more extreme ( $>1,000,000$ tons) pressures as needed for powder consolidation [41]. A schematic diagram of combustion driven compaction is seen in Fig. 2.4b. Hot isostatic pressing (HIP) likes CIP except that the heat is applied during the pressurization, and the mold deforms at high temperature shaping the part [43]. Fig. 2.4c illustrates the schematic diagram of hot isostatic pressing. HIP is considered to be one of most promising sintering techniques for producing fine grains and dense bulk materials.

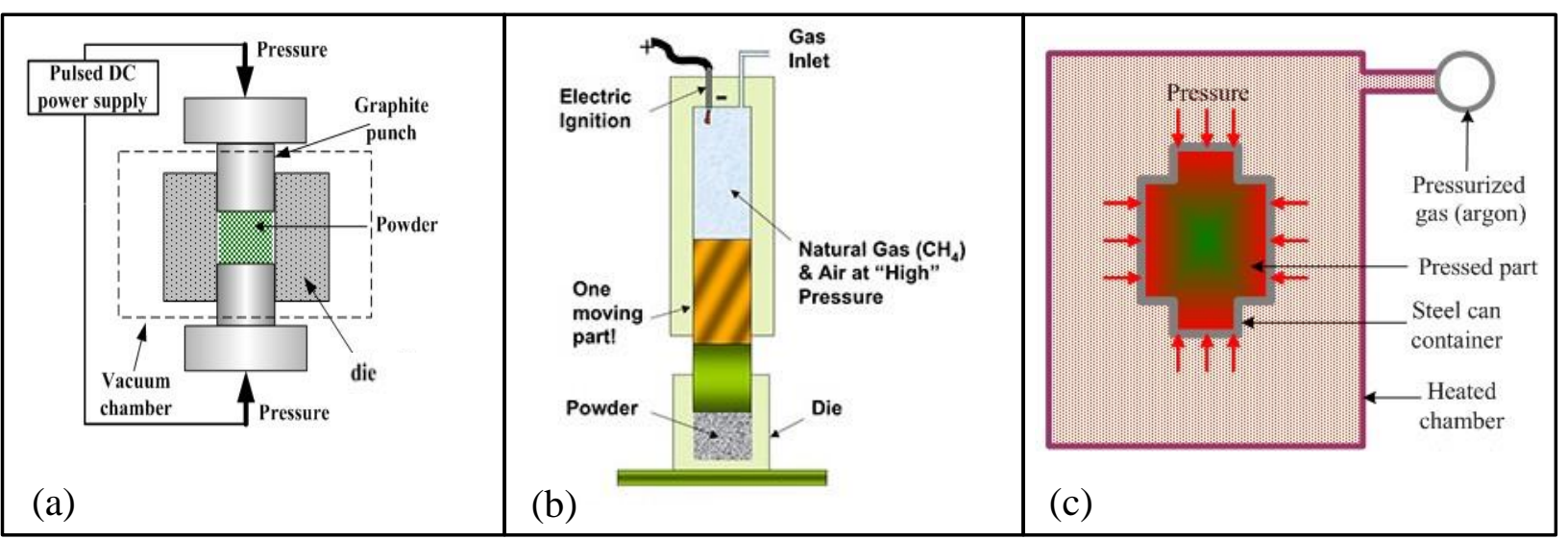

Figure 2.4 Schematics of (a) spark plasma sintering, (b) combustion driven compaction, and (c) hot isostatic pressing (www. substech.com).

Sintering is a major process in the manufacture of polymer, metals, and ceramics. In general, the sintering process involves consolidation by heating the compacted powder to a high temperature but below the melting temperature of the material, soaking for a desired length of time, and then cooled. During the sintering process, energy is provided, which helps the individual powder particles to bond together. It was reported that the green compact shrinks by around 40 vol. \%, during the sintering process [44]. 
The categories of sintering are solid solution sintering, liquid phase sintering, and viscous sintering. Here, the focus is on solid solution sintering. The solid-state sintering process passes through three different stages as illustrates in Fig. 2.5. In the initial stage, the powder particles join to the neighboring powder particles without contraction. At this stage, the disappearance of the border begins to produce a neck in the points of contact between the powder particles. Grain boundaries form between neighboring powder particles. In this phase, the shrinkage is very low. In the intermediate stage, the growth of the neck helps to reduce the pores. Also, a larger contraction in comparison with the initial stage is seen at this stage. In the final stage, the pores turn into a state of instability, and they prefer to spread evenly over the material. The density of the material reaches between $90 \%$ and $95 \%$ of the theoretical density at the end of the sintering process

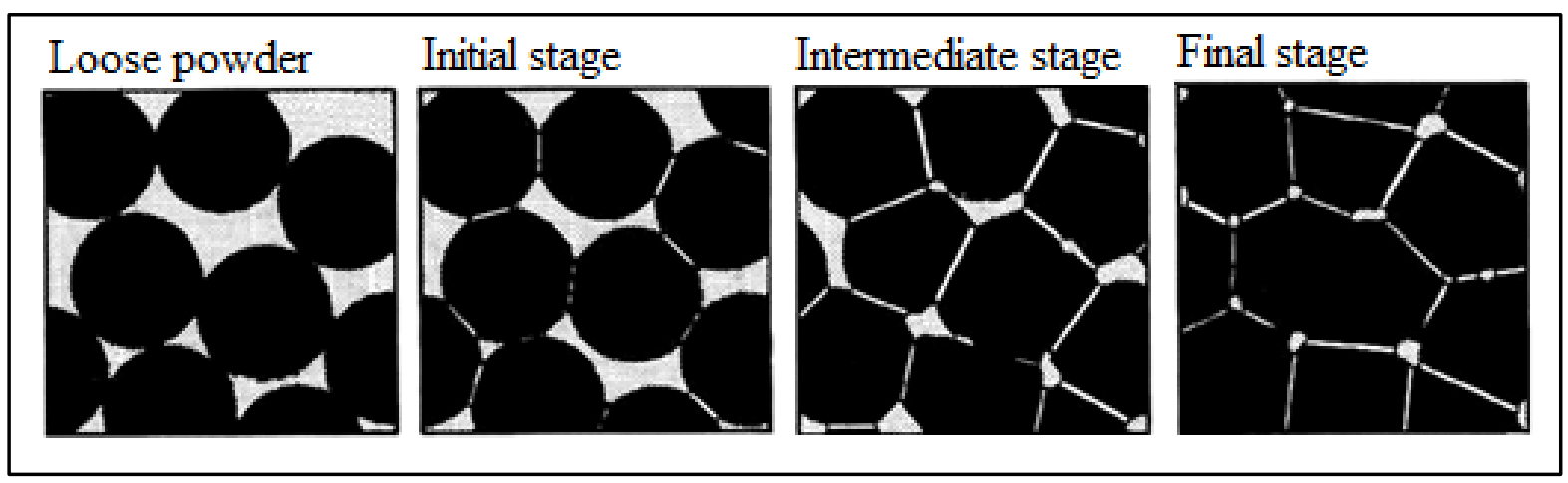

Figure 2.5 Stages of sintering process [44] 


\subsection{Precipitation Hardening}

Precipitation hardening or age hardening is one of the most effective strengthening methods, which improves the mechanical properties of metal alloys. Precipitation hardening is the process of strengthening of an alloy by precipitating fine dispersed precipitates of the solute in a supersaturated matrix [45]. Precipitation hardening mechanisms and kinetics have become areas of interest of many researchers [46]. The precipitation hardening was first explained by Meica and his coworkers [47]. In their study of an Al-Cu alloy, they observed that the alloy hardness increased after the alloy had been quenched from high temperature and then aged at low temperature. They proposed that $\mathrm{Cu}$ atoms precipitated out as particles from the supersaturated solid-solution since the solid solubility of $\mathrm{Cu}$ in $\mathrm{Al}$ decreases with a decrease in temperature. They suggested that precipitation hardening in $\mathrm{Al}-\mathrm{Cu}$ alloys resulted from the interference of $\mathrm{Cu}$ atoms with slip when grains are deformed. Precipitation hardening is achieved by the following three basic steps and as illustrates in Fig. 2.6 [46].

1. The first step is solution heat treatment or homogenization. During this step, an alloy is heated up to a temperature, between the solidus and solvus, and soaked there for an appropriate time until all solute dissolves into $(k)$ phase (Fig. 2.6). A uniform solid solution structure $(k)$ is finally produced. The second $\theta$ precipitates are completely dissolved.

2. Quenching to room temperature is the second step. During this step, the solid $(k)$ is rapidly cooled, and the solute $\theta$ is not able to diffuse out of the phase, and the alloy is said to be supersaturated. 
3. Aging is the final step in the precipitation hardening process. During this step, the alloy is heated up again to a temperature below the solvus temperature and soaked there to produce a finely dispersed precipitate. The extra atoms of the second element diffuse to nucleation sites and precipitates grow because the supersaturated phase is not stable at high temperatures.

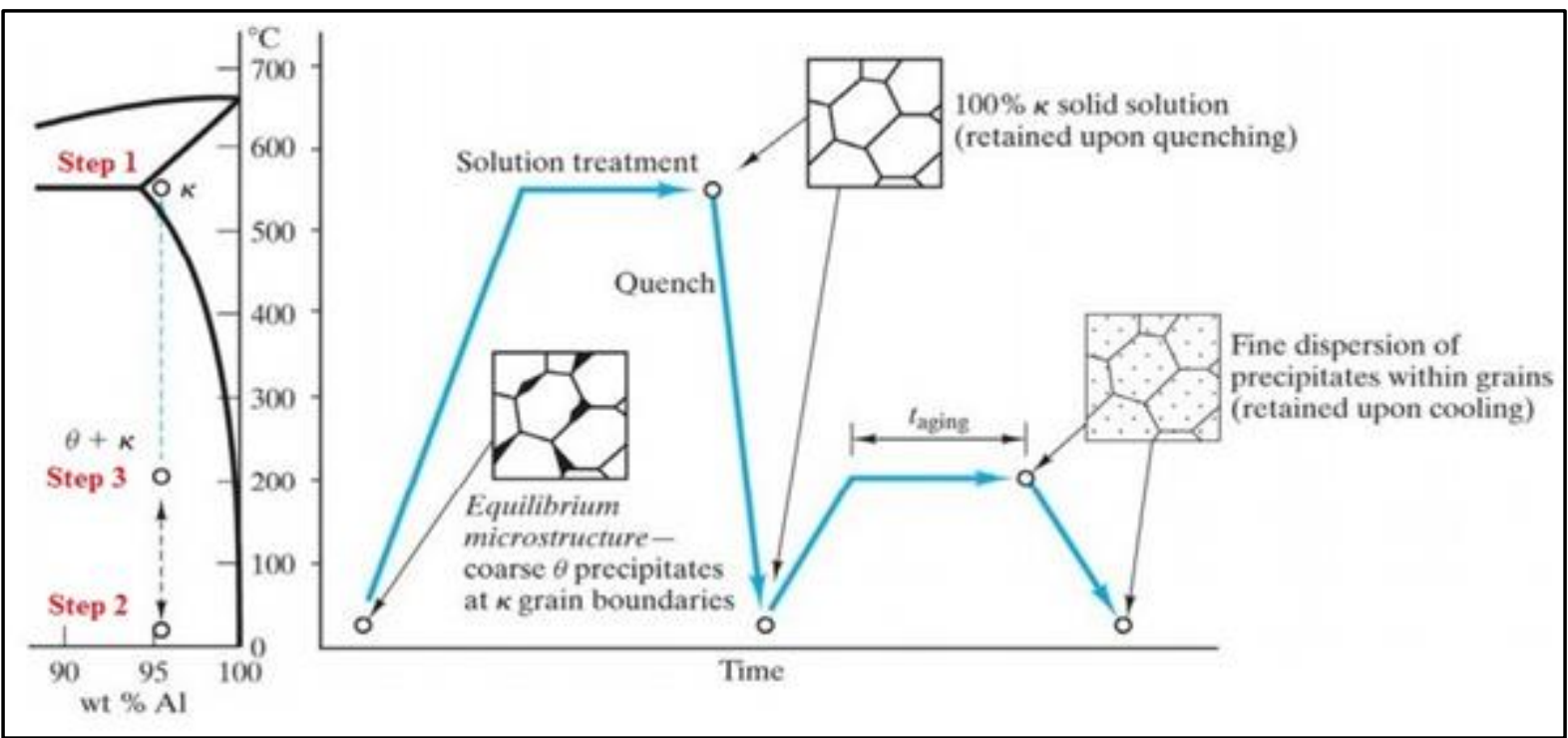

Figure 2.6 The aluminum-rich end of the $\mathrm{Al}-\mathrm{Cu}$ phase diagram showing the three steps in the age-hardening heat treatment and the microstructures that are produced [46]

The aim of the precipitation hardening process is to form finely dispersed precipitates in the alloy. These precipitates impede the movement of dislocations by either the strains around the precipitates zones, the precipitates themselves, or both. Consequently, the alloy is said to be strengthened because of the precipitation hardening. At the underaging stage, the precipitates are very small and coherent to the lattice and deformable as dislocations cut through them, which leads to an increase in the yield stress by the obstacle to dislocation motion, as presented in Fig. 2.7. The obstacles become too strong to be shared by a dislocation which that leads to increasing the yield stress. The yield stress will continue to increase as a result of the growing of the precipitates, peak strength stage as shown in Fig. 2.7. Because of the growing, the precipitates 
lose their coherence. Ultimately the precipitates size increase and become completely incoherent with its surroundings and non-deformable as the dislocations bypass them. Thereby, the misfit strains become very small, and the yield stress decrease and the alloy soften, which is the overaging stage in Fig. 2.7 [45, 48].

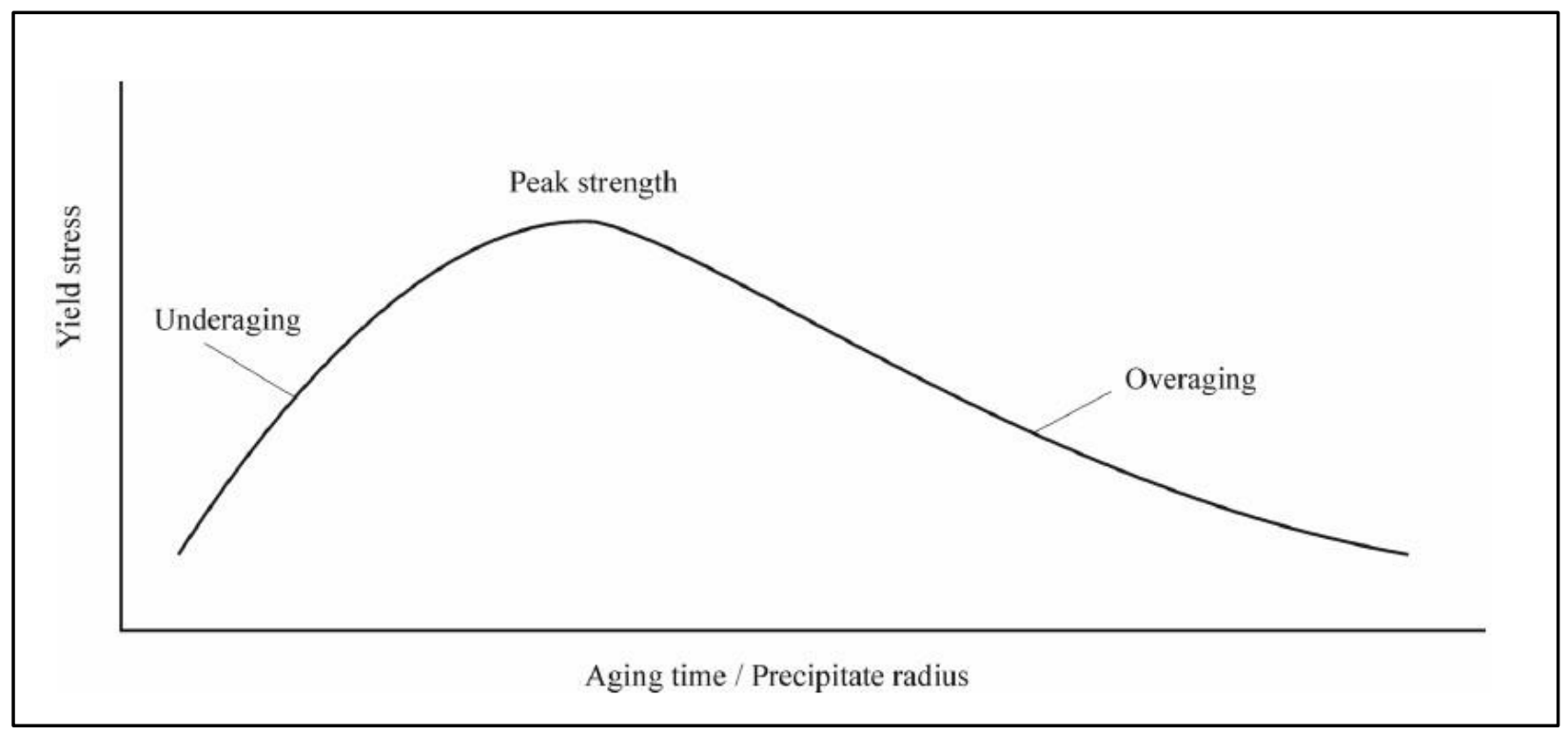

Figure 2.7 A typical one -peak precipitation hardening curve, shows the relationship between yield stress and aging time, includes three stages, underaging, peak strength, and overaging [45] 


\subsection{Literature Reviews}

The Ni-Mo system has attracted the attention of many research groups because of the unique ordering transformation of its intermetallic phases. Almost all the studies that have been done in the Ni-Mo system were carried out using transmission electron microscopy. Few works have been done in this system using microscopic techniques such as scanning electron and optical microscopy. Here are some studies of the microstructural evolution of the ordered intermetallic phases in Ni-Mo system.

Masahiko Yamamoto et al.[49] studied the structural changes during isothermal annealing of a quenched Ni-24.4 at. \% Mo alloy (nearly stoichiometric $\gamma-\mathrm{Ni}_{3} \mathrm{Mo}$ ). The samples were prepared by vacuum melting electrolytic nickel and molybdenum; followed by hot-rolling and heating at $1300^{\circ} \mathrm{C}$ and then quenching into ice-water. The samples were next annealed at $860^{\circ} \mathrm{C}$ for various periods of time and quenched. They reported that a short-range-ordered (SRO) structure was observed in the quenched sample from $1300^{\circ} \mathrm{C}$ ( $\alpha$-region) using transmission electron microscopy. Other researchers had reported that the SRO structure formed when a NiMo alloy (Ni-8 to 25at.\%Mo) was quenched from the $\alpha$-region [30, 50-56]. Yamamoto et al. [49] reported that when the quenched $\alpha$-phase of Ni-24.4at.\%Mo alloy was annealed at $860^{\circ} \mathrm{C}$ for 10 min, the $\gamma-\mathrm{Ni}_{3} \mathrm{Mo}$ was not directly formed. A meta-stable phase $\mathrm{Ni}_{2} \mathrm{Mo}$ was formed in a shortrange-ordered matrix in the annealed sample at $860^{\circ} \mathrm{C}$ for $10 \mathrm{~min}$. After one hour of annealing at $860^{\circ} \mathrm{C}$, the meta-stable phase $\mathrm{Ni}_{2} \mathrm{Mo}, \beta-\mathrm{Ni}_{4} \mathrm{Mo}$, and $\gamma-\mathrm{Ni}_{3} \mathrm{Mo}$ were formed as shown in Fig. 2.8. In Fig. 2.8, a region $\mathbf{A}$ consists of $\mathrm{Ni}_{2} \mathrm{Mo}$ and $\beta-\mathrm{Ni}_{4} \mathrm{Mo}$ in the short-range-ordered matrix, and a region $\mathbf{B}$ consists of $\gamma-\mathrm{Ni}_{3} \mathrm{Mo}$ which nucleated at grain boundaries of $\alpha$-phase. After $550 \mathrm{~h}$ of annealing at $860^{\circ} \mathrm{C}, \gamma-\mathrm{Ni}_{3} \mathrm{Mo}$ was predominated by consuming $\mathrm{Ni}_{2} \mathrm{Mo}$ and $\beta-\mathrm{Ni}_{4} \mathrm{Mo}$ phases as 
shown in Fig. 2.9. Upon prolonged annealing there are band regions as can be seen in Fig. 2.9. These band regions show the fcc lattice [49].

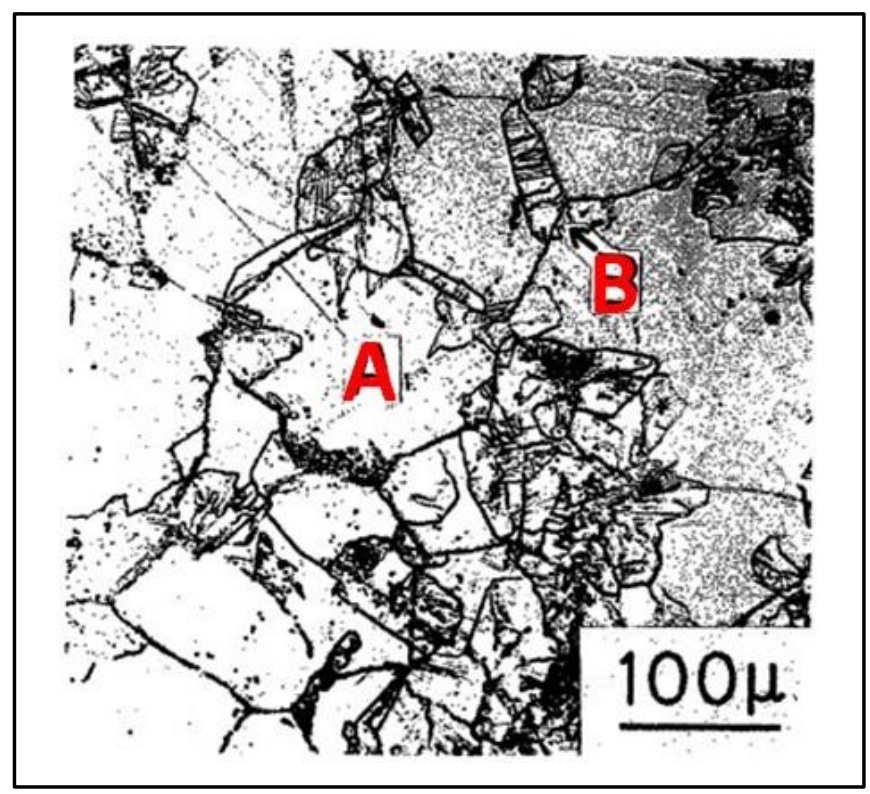

Figure 2.8 Micrograph of Ni-24.4at\%Mo alloy quenched from $\alpha$-region and then annealed at $860^{\circ} \mathrm{C}$ for $1 \mathrm{~h}$ after quenching from $\alpha$-region. A region $\mathbf{A}$ consists of $\mathrm{Ni}_{2} \mathrm{Mo}$ and $\beta-\mathrm{Ni}_{4} \mathrm{Mo}$ in the short-range-ordered matrix. A region $\mathbf{B}$ consists of $\gamma-\mathrm{Ni}_{3} \mathrm{Mo}$ which nucleated at grain boundaries of $\alpha$-phase [49]

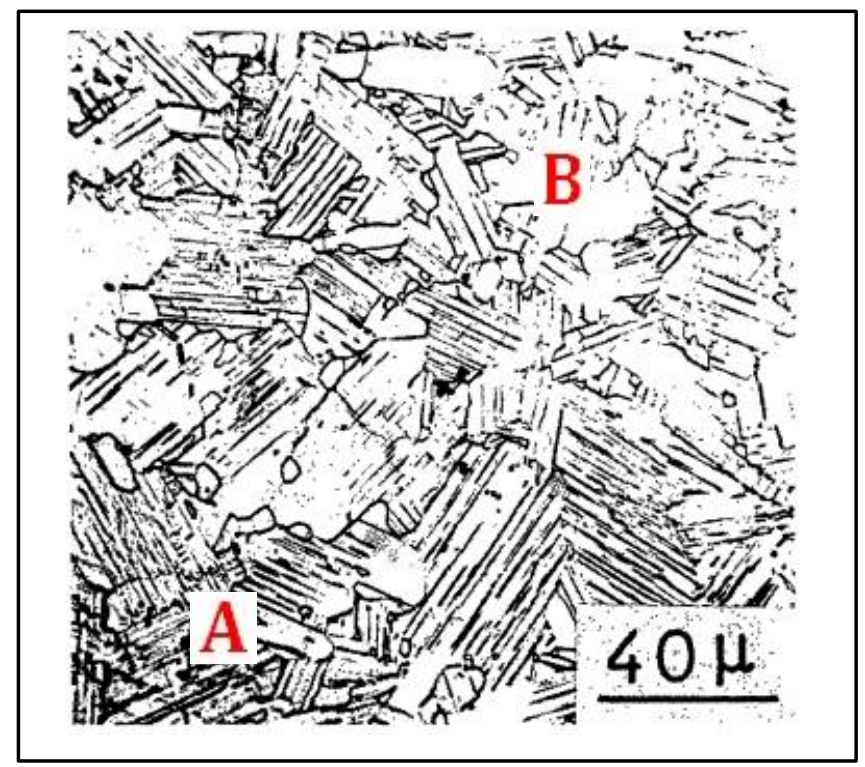

Figure 2.9 Micrograph of Ni-24.4at\%Mo alloy quenched from $\alpha$-region and then annealed at $860^{\circ} \mathrm{C}$ for 550h. A region A (bands) consists of fcc lattice. A region B consists of $\gamma-\mathrm{Ni}_{3} \mathrm{Mo}$ [49] 
N. S. Mishra et al. [56] have studied the disorder-order change in a Ni-25wt.\%Mo alloy in the temperature ranges between $680^{\circ} \mathrm{C}$ and $880^{\circ} \mathrm{C}$. Nickel and molybdenum powders were melted in an arc furnace. Samples were cut and homogenized at $1300^{\circ} \mathrm{C}$ for $1 \mathrm{~h}$ followed by quenching. Samples then were isothermally aged in steps of $50^{\circ} \mathrm{C}$ ranging from $680^{\circ} \mathrm{C}$ to $880^{\circ} \mathrm{C}$ followed by quenching. They reported that $\mathrm{Ni}_{2} \mathrm{Mo}$ was formed first and then $\beta-\mathrm{Ni}_{4} \mathrm{Mo}$, and eventually $\gamma-\mathrm{Ni}_{3} \mathrm{Mo}$ was formed when the alloy was aged at a temperature below and above $800^{\circ} \mathrm{C}$. They also concluded that the transformation from $\alpha$-phase (SRO) to $\gamma-\mathrm{Ni}_{3} \mathrm{Mo}$ phase was accomplished by nucleation and growth, which was supported by Martin et al.[53].

H. M. Tawancy [57] studied the long-range ordering (LRO) behavior and mechanical properties of Ni-Mo, Ni-Mo-Fe, and Ni-Mo-Cr alloys. Samples were cast, and homogenized/solutionized at the $\alpha$-region and then quenched. Samples were then isothermally aged between $600^{\circ} \mathrm{C}$ and $800^{\circ} \mathrm{C}$ for up to $1000 \mathrm{~h}$ followed by quenching. In all alloys, $\mathrm{Ni}_{2} \mathrm{Mo}, \beta-$ $\mathrm{Ni}_{4} \mathrm{Mo}$, and $\gamma-\mathrm{Ni}_{3} \mathrm{Mo}$ were co-existed in the microstructures. Tawancy reported that both iron and chromium stabilize the $\gamma-\mathrm{Ni}_{3} \mathrm{Mo}$ phase. Ordering to $\beta-\mathrm{Ni}_{4} \mathrm{Mo}$ and $\gamma-\mathrm{Ni}_{3} \mathrm{Mo}$ might lead to embrittlement while ordering to $\mathrm{Ni}_{2} \mathrm{Mo}$ could improve the mechanical properties.

P. L. Martin et al. [58] determined the maximum temperature for the presence of coherent (LRO) formed in Ni-(Mo, X) alloys, where $\mathrm{X}=\mathrm{Al}, \mathrm{Ta}, \mathrm{V}, \mathrm{W}$. The samples were prepared and followed by solution treatment and then aged between $700^{\circ} \mathrm{C}$ and $900^{\circ} \mathrm{C}$ for up to $10 \mathrm{~h}$. They had found that $\gamma-\mathrm{Ni}_{3} \mathrm{Mo}$ consumed the coherent metastable $\mathrm{Ni}_{x} \mathrm{Mo}$ phase when Ta substituted for Mo. Fig. 2.10 summarizes the coherent phase solvus with dissolution temperature. 


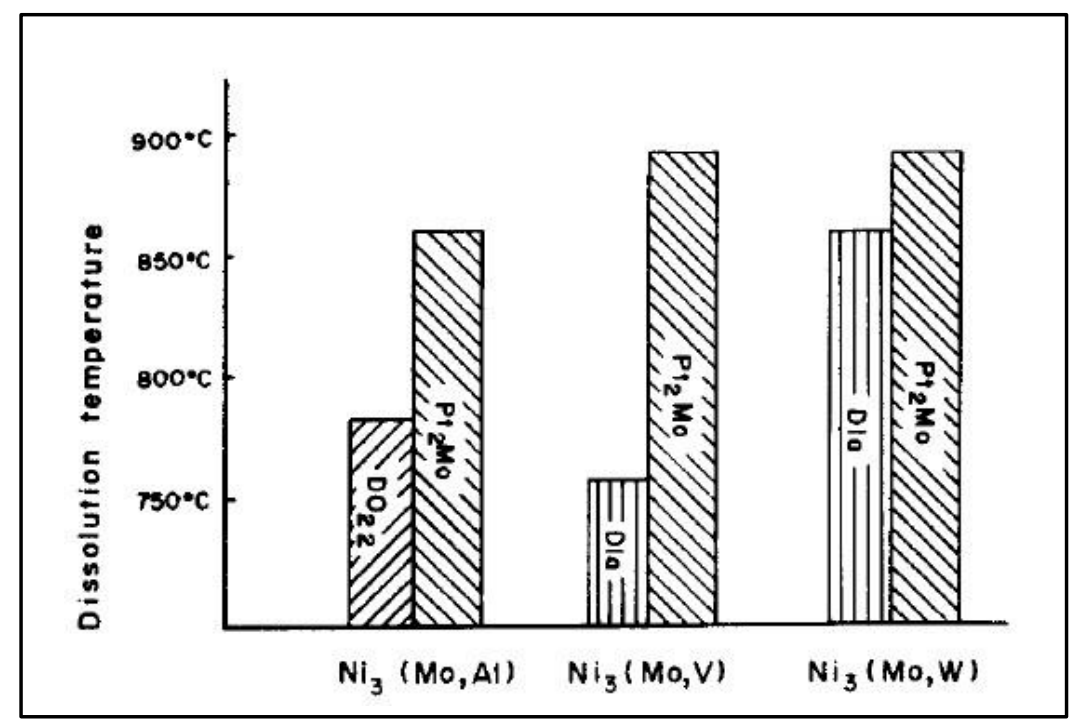

Figure 2.10 Histogram summarizing the coherent phase solvus with dissolution temperature. Do22 $(\gamma$ $\left.\mathrm{Ni}_{3} \mathrm{Mo}\right), \mathrm{Pt}_{2} \mathrm{Mo}\left(\mathrm{Ni}_{2} \mathrm{Mo}\right)$, and Dla $\left(\beta-\mathrm{Ni}_{4} \mathrm{Mo}\right)[58]$

Tawancy et al. [59] have studied the effect of a minor second phase present on the tensile and corrosion resistance in Ni-27.8wt.\% Mo and less than 0.002wt.\% C alloy (Hastelloy alloy B). Samples were cut, heat-treated (solutionized) at $1150^{\circ} \mathrm{C}$ for $2 \mathrm{~h}$ followed by quenching, and aged between $900^{\circ} \mathrm{C}$ and $1065^{\circ} \mathrm{C}$ for up to $3 \mathrm{~h}$ followed by quenching. They reported that only $\delta$-NiMo phase was identified using electron diffraction. They also found that particles of $\delta$-NiMo left behind migrated grain boundaries during aging grain. This reaction has no effect on ductility and corrosion resistance.

D. Schwam et al. [60] have investigated the microstructural evolution of Ni-47wt.\% Mo alloy. The alloy was directionally solidified by a modified Bridgman-type technique. They reported that the microstructure consisted of $50 \%$ volume fraction of $\delta$-NiMo intermetallic lamellae and solid-solution $\alpha$-Ni. A mixture of $\mathrm{Ni}_{2} \mathrm{Mo}, \beta-\mathrm{Ni}_{4} \mathrm{Mo}$, and $\gamma-\mathrm{Ni}_{3} \mathrm{Mo}$ phase was detected in the solid-solution $\alpha-\mathrm{Ni}$. They found that at an aging temperature of $890^{\circ} \mathrm{C}$, a large amount of $\gamma-\mathrm{Ni}_{3} \mathrm{Mo}$ phase was detected in the $\alpha-\mathrm{Ni}$ matrix. 
A number of investigations have been reported on the microstructural evolution of $\mathrm{Ni}_{3} \mathrm{Mo}$ alloy, only below the peritectoid temperature $\left(910^{\circ} \mathrm{C}\right)$ and mostly provided by transmission electron microscopy. In this work, designing the microstructure of $\mathrm{Ni}_{3} \mathrm{Mo}$ alloy below and above the peritectoid temperature will be reported using optical microscopy, scanning electron microscopy, and X-ray diffraction. Yet, no published data were found of the reverse peritectoid phase transformation of $\mathrm{Ni}_{3} \mathrm{Mo}$ alloy. Our study will provide better understanding of the structural evolution of $\mathrm{Ni}_{3} \mathrm{Mo}$ alloy below and above the peritectoid temperature. 


\section{Experimental Procedures}

Mechanical alloying and powder metallurgy methods were used in this work to prepare bulk Ni-25at.\%Mo alloy (stoichiometric $\mathrm{Ni}_{3} \mathrm{Mo}$ ) samples. The goals of the experiments were first, to prepared the bulk Ni-25at.\%Mo samples and then do heat-treatment in various ways, in order to investigate the microstructural evolution and their related hardness of $\mathrm{Ni}_{3} \mathrm{Mo}$ alloy. This study was expected to lead to a better understanding of the effect of the microstructural evolution on the hardness of $\mathrm{Ni}_{3} \mathrm{Mo}$ alloy to enhance its performance and broaden its applications.

Bulk samples preparation started by milling a mixture of reduced $\mathrm{Ni}$ and $25 \mathrm{at} \% \mathrm{Mo}$ powders in a high-energy ball mill. The milled powders then were cold-compacted and sintered followed by quenching. The bulk samples then were cut, heat-treated, and prepared for characterization using standard metallographic techniques. Characterization started with density measurements, X-ray diffraction (XRD) before and after heat treatments, optical microscopy and scanning electron microscopy (SEM), and microhardness testing for bulk samples before and after heat treatments.

\subsection{Sample Preparation}

Elemental powder of nickel was acquired from Alfa Aesar at $149 \mu \mathrm{m}$ size and $99.8 \%$ purity, and molybdenum was also purchased from Alfa Aesar at $149 \mu \mathrm{m}$ size and $99.9 \%$ purity. All powders were reduced in a Lindberg Blue M (Model\#54233) tube furnace (Fig. 3.1) under hydrogen gas flows at $500^{\circ} \mathrm{C}$ for $1 \mathrm{~h}$ and furnace cooled. The amount of the reduced elemental powders of $\mathrm{Ni}$ and $\mathrm{Mo}$ were measured to form a mixture of $75 \mathrm{at} . \% \mathrm{Ni}$ and $25 \mathrm{at} . \% \mathrm{Mo}$ (stoichiometric $\gamma-\mathrm{Ni}_{3} \mathrm{Mo}$ ). All handling and mixing of the powder were carried out in a glove box under an argon atmosphere to minimize oxidation. 
The Ni-25at.\%Mo mixture was milled in a SPEX 8000 high energy shaker (Fig 2.2a) using a tungsten carbide milling vial (Fig 2.2b) with 7/16" tungsten carbide (WC) balls. The charge ratio (milling ball weight to powder weight) was $2: 1$. The charge weight was $20 \mathrm{~g}$, and four WC balls were added and their weight was around $40.30 \mathrm{~g}$. The loading and sealing were performed in a glove box under an argon atmosphere to minimize oxidation during MA. The whole charge was milled for $10 \mathrm{~h}$. The vial was flipped and rotated every $30 \mathrm{~min}$ at the first $2 \mathrm{~h}$ to minimize welding to the walls. After milling, the vail and the milled powder were transferred back to the glove box.

The milled powder was cold-compacted using a steel mold (3/4" diameter) and a uniaxial press as shown in Fig. 3.2. The milled powder was compacted at $550 \mathrm{MPa}$ stress and held for 5 $\min$ (Fig. 3-3). The cold-compacted samples were sintered, pressure-less sintering, at $1300^{\circ} \mathrm{C}$ for $100 \mathrm{~h}$ in total.

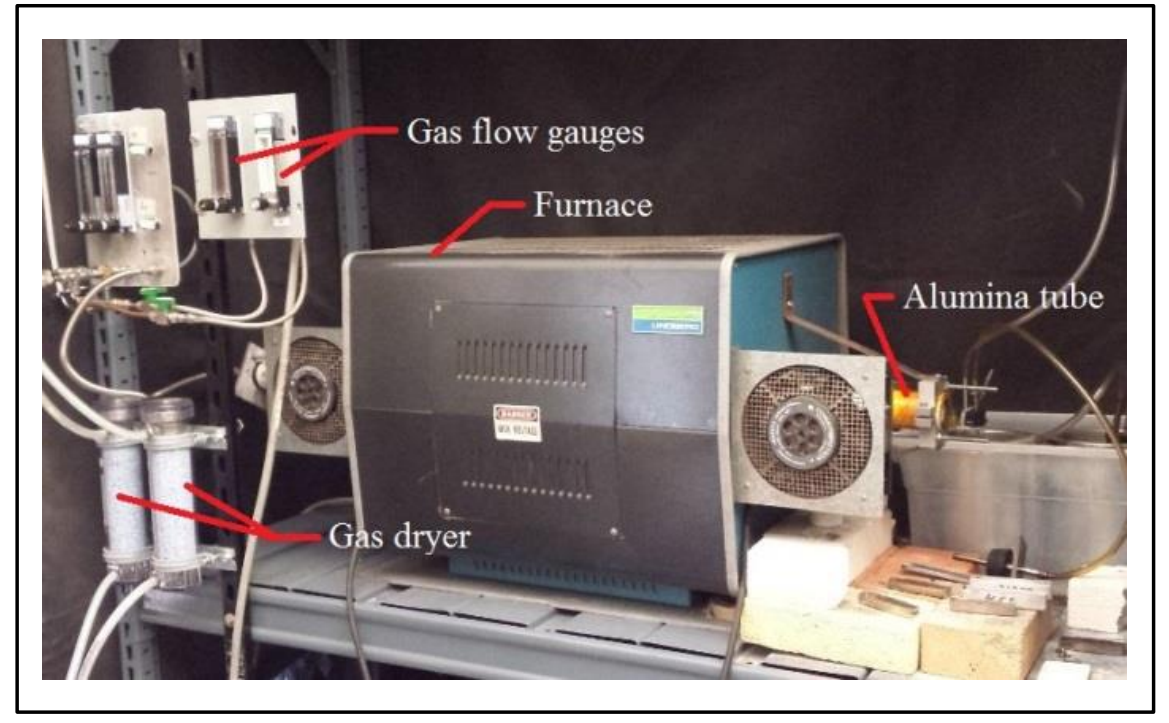

Figure 3.1 Tube furnace ( Lindberg Blue M (Model\# 54233))

After $25 \mathrm{~h}$ at $1300^{\circ} \mathrm{C}$ the sample was quenched, cold-compacted, and then sintered again at $1300^{\circ} \mathrm{C}$ for $25 \mathrm{~h}$ followed by quenching. This step was repeated for a total of $100 \mathrm{~h}$ sintering, to 
improve the density of the bulk samples. The sintering was carried out in a Lindberg Blue M (Model\# 54233) tube furnace under hydrogen and argon gases flow to minimize oxidation.

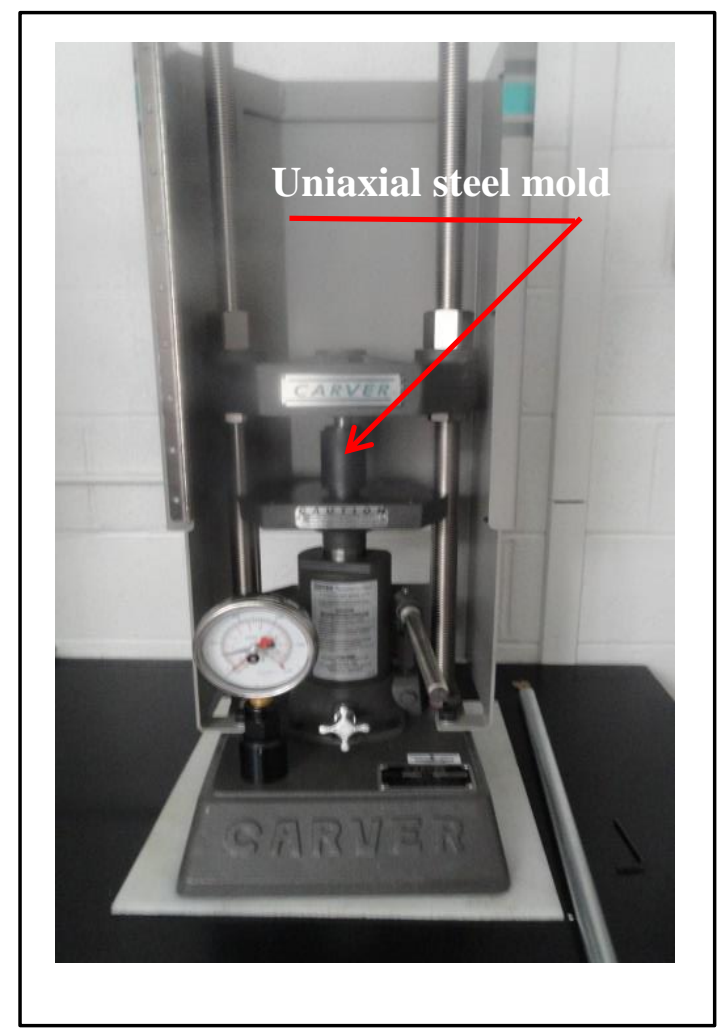

Figure 3.2 Uniaxial press (CARVER)

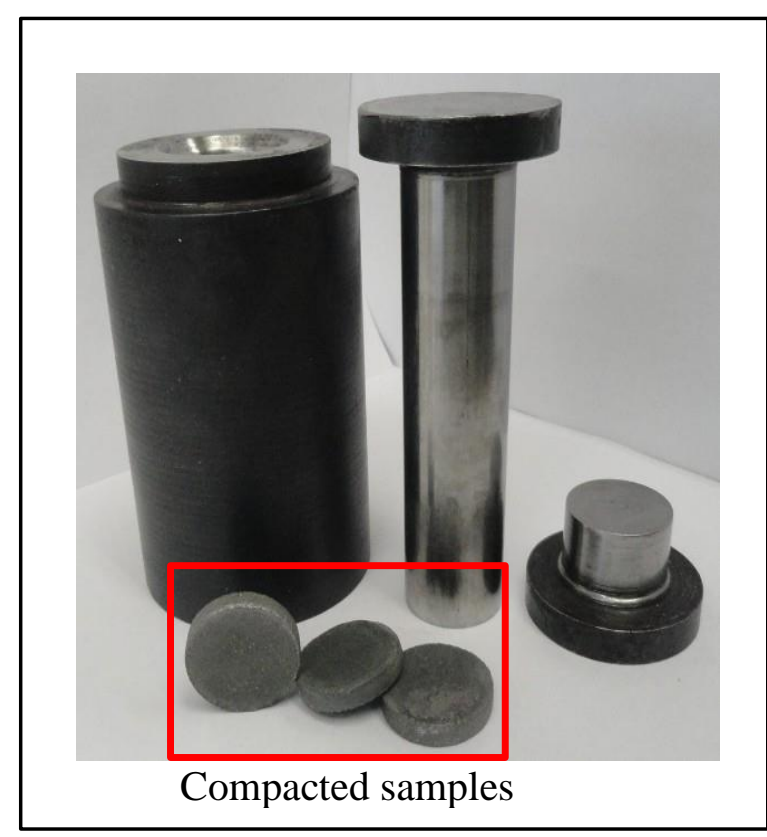

Figure 3.3 Uniaxial steel mold set and compacted samples

\subsection{Heat-treatment Steps}

After sintering, the bulk samples were cut into slices with around $1 \mathrm{~mm}$ thick and semicircle with diameter around $9 \mathrm{~mm}$. The heat treatments were performed in a front load Deletch furnace at temperature ranges from $600^{\circ} \mathrm{C}$ up to $1050^{\circ} \mathrm{C}$ in salt baths. Two different salt mixtures were used to carry out the heat-treatments. For the heat-treatments between $600^{\circ} \mathrm{C}$ and $900^{\circ} \mathrm{C}$, the salt mixture composition was $\mathrm{NaCl} 10-15 \%, \mathrm{KCl} 20-30 \%, \mathrm{BaCl}_{2} 40-50 \%$, and $\mathrm{CaCl}_{2}$ $15-20 \%$, and their melting point was around $400^{\circ} \mathrm{C}$. Whereas, the salt mixture composition was 
$\mathrm{BaCl}_{2} 70-96 \%$ and $\mathrm{NaCl} 30-4 \%$ and their melting point was about $800^{\circ} \mathrm{C}$, for heat-treatments between $900^{\circ} \mathrm{C}$ and $1050^{\circ} \mathrm{C}$. The heat-treatment steps are summarized as following:

1. Solution treatment/sintering: heating up the cold-compacted samples at $1300^{\circ} \mathrm{C}$ for 100 hours in total, to obtain the solid solution $\alpha(\mathrm{Ni})$ phase.

2. Quenching: the solutionized samples were quenched into water to form supersaturated solid solution $\alpha$-Ni.

3. Aging: by heating up the samples at temperatures between $600^{\circ} \mathrm{C}$ and $1050^{\circ} \mathrm{C}$ and soaking for the designed length of time and followed by quenching into water.

The purpose and the conditions of each heat treatment are summarized in Table 3.1. The full heat treatment matrixes of the heat treatment below and above the peritectoid temperature are summarized in Tables 3.2 and 3.3.

Table 3.1 Summary of the heat-treatment conditions and purposes

\begin{tabular}{|c|c|l|}
\hline \multicolumn{2}{|c|}{ Heat-treatment conditions } & \multirow{2}{*}{ Heat-treatment purposes } \\
\hline Temperature $\left({ }^{\circ} \mathrm{C}\right)$ & Time (hour) & \\
\hline $600-900$ & $0.25-100$ & Structural evolution of $\gamma$-Ni 3 Mo phase \\
\hline \begin{tabular}{c} 
Quenched \\
\hline $910-1050$
\end{tabular} & 100 & Forming the $\gamma$-Ni $\mathrm{Ni}_{3}$ Mo phase \\
\hline $910-1050$ & $0.05-10$ & $\begin{array}{l}\text { Structural evolution of } \alpha \text {-Ni and } \delta \text {-NiMo from } \\
\text { the } \gamma \text {-Ni } i_{3} \text { Mo phase }\end{array}$ \\
\hline & $0.05-10$ & $\begin{array}{l}\text { Structural evolution of } \alpha \text {-Ni and } \delta \text {-NiMo from } \\
\text { the supersaturated solid solution } \alpha \text {-Ni phase }\end{array}$ \\
\hline
\end{tabular}


Table 3.2 Summary of the full heat-treatment matrix between $600^{\circ} \mathrm{C}$ and $900^{\circ} \mathrm{C}$.

\begin{tabular}{|c|c|c|c|c|c|c|c|c|}
\hline \multirow{3}{*}{$\begin{array}{c}\text { Aging } \\
\text { Temperature } \\
\left({ }^{\circ} \mathrm{C}\right)\end{array}$} & \multicolumn{8}{|c|}{ Aging time } \\
\hline & \multicolumn{2}{|c|}{ Minute } & \multicolumn{6}{|c|}{ Hour } \\
\hline & 15 & 30 & 1 & 2 & 5 & 10 & 25 & 100 \\
\hline 600 & (C) & (C) & (C) & (C) & (C) & (C) & (C) & (C) \\
\hline 650 & (C) & (C) & (C) & (C) & - & - & (C) & - \\
\hline 700 & (C) & (C) & (C) & (C) & - & - & (C) & - \\
\hline 750 & (C) & (C) & (C) & (C) & - & - & (C) & - \\
\hline 800 & (C) & (C) & (C) & (C) & (C) & (C) & (C) & - \\
\hline 850 & (C) & (C) & (C) & (C) & - & - & (C) & - \\
\hline 900 & (C) & (C) & (C) & (C) & - & - & (C) & - \\
\hline
\end{tabular}

Table 3.3 Summary of the full heat-treatment matrix between $910^{\circ} \mathrm{C}$ and $1050^{\circ} \mathrm{C}$.

\begin{tabular}{|c|c|c|c|c|c|c|c|}
\hline \multirow{3}{*}{$\begin{array}{c}\text { Aging } \\
\text { Temperature } \\
\left({ }^{\circ} \mathrm{C}\right)\end{array}$} & \multicolumn{7}{|c|}{ Aging Time } \\
\hline & \multicolumn{3}{|c|}{ Minute } & \multicolumn{4}{|c|}{ Hour } \\
\hline & 5 & 15 & 30 & 1 & 2 & 5 & 10 \\
\hline 910 & (P) & (P) & (P) & (P) & (P) & - & (P) \\
\hline 930 & (P) & (P) & (P) & (P) & (P) & - & (P) \\
\hline 970 & (P) & (P) & (P) & (P) & (P) & - & (P) \\
\hline 1050 & (P) & (P) & (P) & (P) & (P) & (P) & - \\
\hline
\end{tabular}

\subsection{Characterization Techniques}

To investigate the effect of the heat-treatments on the microstructural evolution of the Ni25at.\%Mo alloy bulk samples were characterized. The density of the bulk samples was determined by Archimedes' principle. The XRD was used to define the presented phases before and after heat treatments. Hardness testing was performed on bulk samples before and after heat 
treatments. Also, SEM was used to provide an assessment of the microstructure of the present phases and the densification.

\subsubsection{Density Measurements}

The densities were measured for both green compacts and bulk samples. The density measurement was taken after each sintering step by Archimedes' principle. Fig. 3.4 illustrates Archimedes density determination apparatus. Archimedes' density approach was utilized by taking the weight of a sample in air $\left(\mathrm{W}_{\text {air }}\right)$ and then in ethanol $\left(\mathrm{W}_{\text {ethanol }}\right)$ at room temperature, the density of air $\rho_{\text {air }}=0.0012 \mathrm{~g} / \mathrm{cc}$ and ethanol $\rho_{\text {ethanol }}=0.79 \mathrm{~g} / \mathrm{cc}$. Then the density of the green compact and bulk samples can be determined using Equation 3.1 [61].

$$
\rho_{\text {measurement }}=\frac{W_{\text {air }}}{\left(W_{\text {air }}+W_{\text {ethanol }}\right)} *\left(\rho_{\text {ethanol }-} \rho_{\text {air }}+\rho_{\text {air }}\right.
$$

For comparison, theoretical density was calculated using Equation 3.2 [62]. The densities of $\mathrm{Ni}(8.91 \mathrm{~g} / \mathrm{cc})$ and $\mathrm{Mo}(10.22 \mathrm{~g} / \mathrm{cc})$ were used to calculate the theoretical density using Equation 3.2.

$$
\rho_{t h}=\frac{100}{\frac{C_{N i}}{\rho_{N i}}+\frac{C_{M o}}{\rho_{M o}}}=\frac{100 \mathrm{~g}}{\frac{64.73}{8.91}+\frac{35.27}{10.22}}=9.33 \mathrm{~g} / \mathrm{cm}^{3}
$$

where $\mathrm{C}$ is the concentration of alloy element (wt.\%), and $\rho$ is the density of alloy element. The density measurements of green and sintered samples as a percentage of the theoretical value were plotted against sintering time, as presented in Fig. 3.5. The close pores density was not counted here. The density of the bulk samples increased with sintering time. The bulk samples were compacted again after being sintered, to improve their densities. 


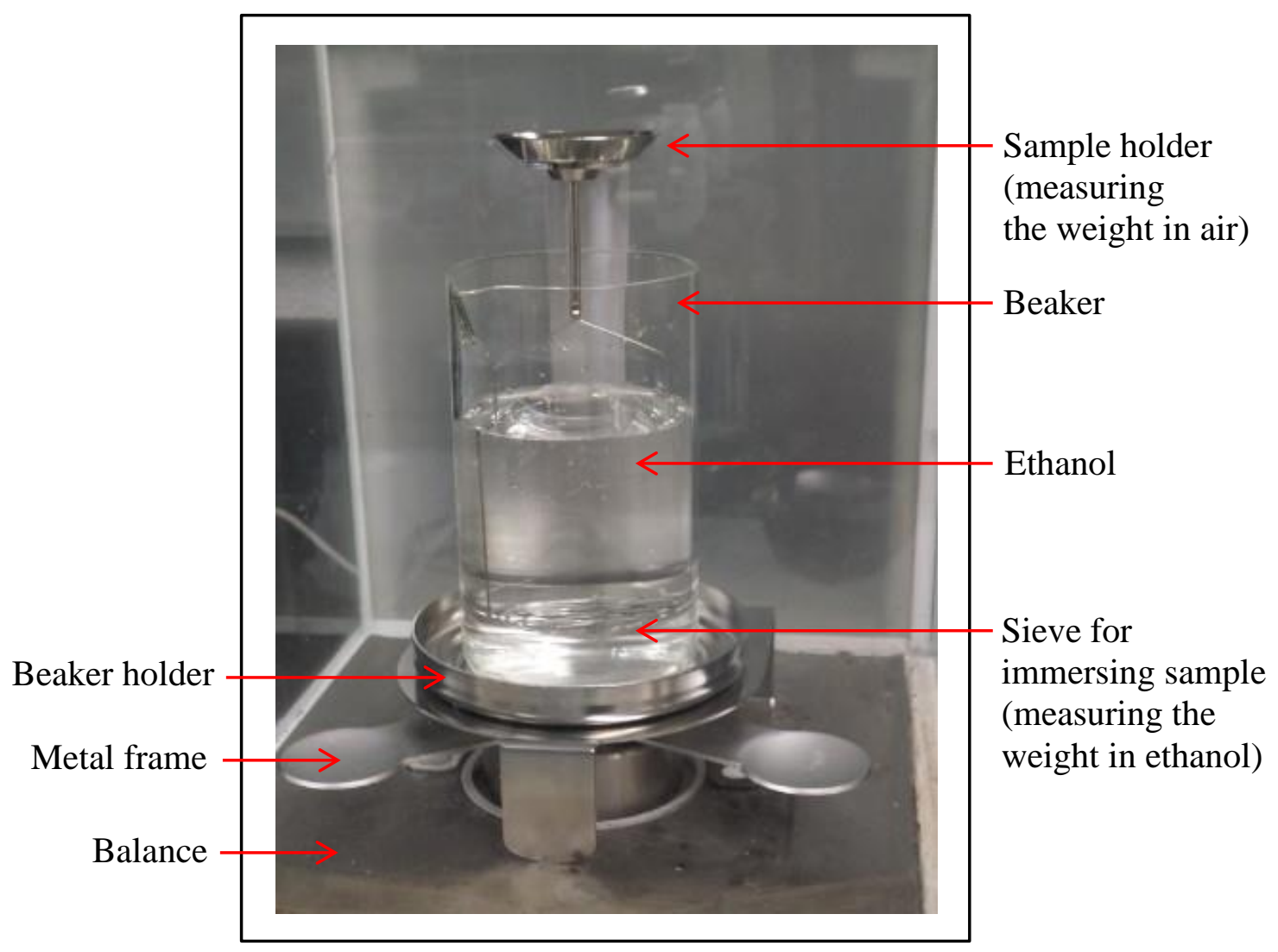

Figure 3.4 Archimedes density determination apparatus

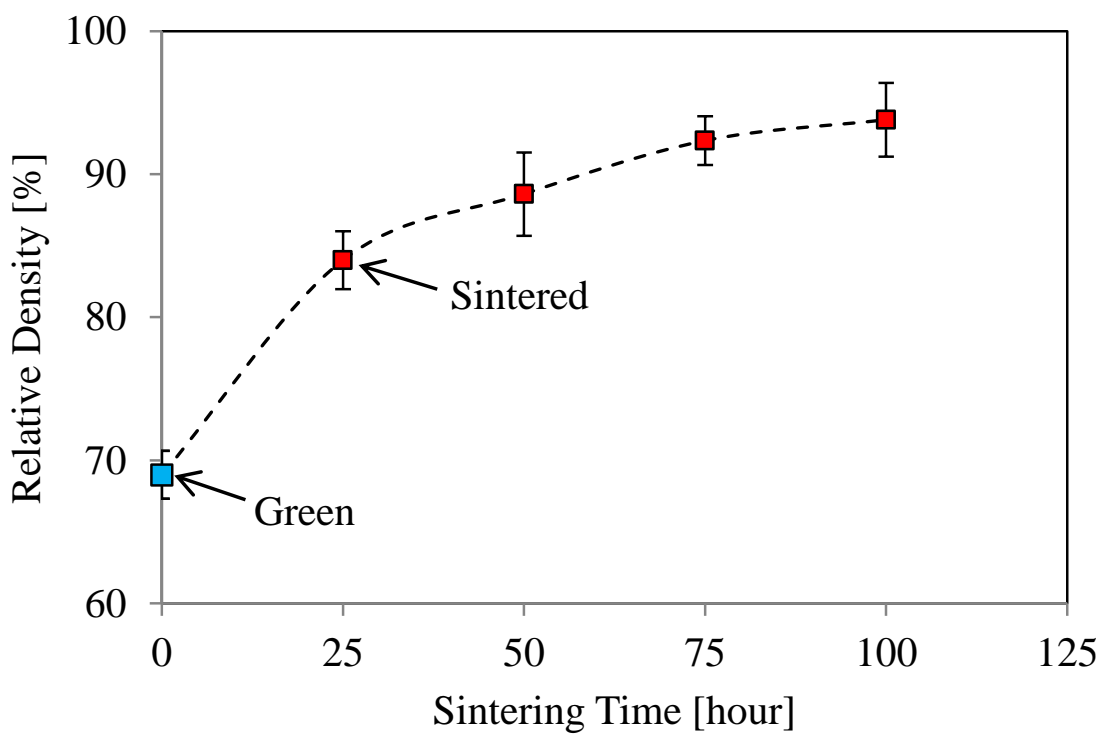

Figure 3.5 Density measurements of green compacted and sintered samples as a percentage of the theoretical value plotted with respect to sintering time. After $25 \mathrm{~h}$ the samples were quenched, recompacted, and sintered. This step was repeated for a total of $100 \mathrm{~h}$ sintering followed by quenching. 


\subsubsection{X-ray Diffraction}

X-ray diffraction (XRD) was used to examine the milled powders and bulk samples before and after heat treatments. XRD was done using a PANalytical X'Pert Pro PW 3040

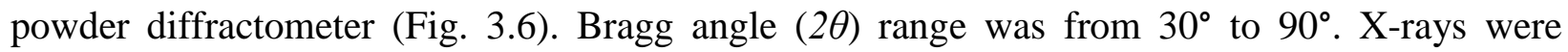
generated by $\mathrm{Cu}$ source by using $45 \mathrm{Kw}$ and $40 \mathrm{~mA}$. For statistical reasons, each sample was run twice in the diffractometer. The XRD data focused on peak broadening and shifting. XRD data were profile fitted using X'Pert High Score Plus software before calculation.

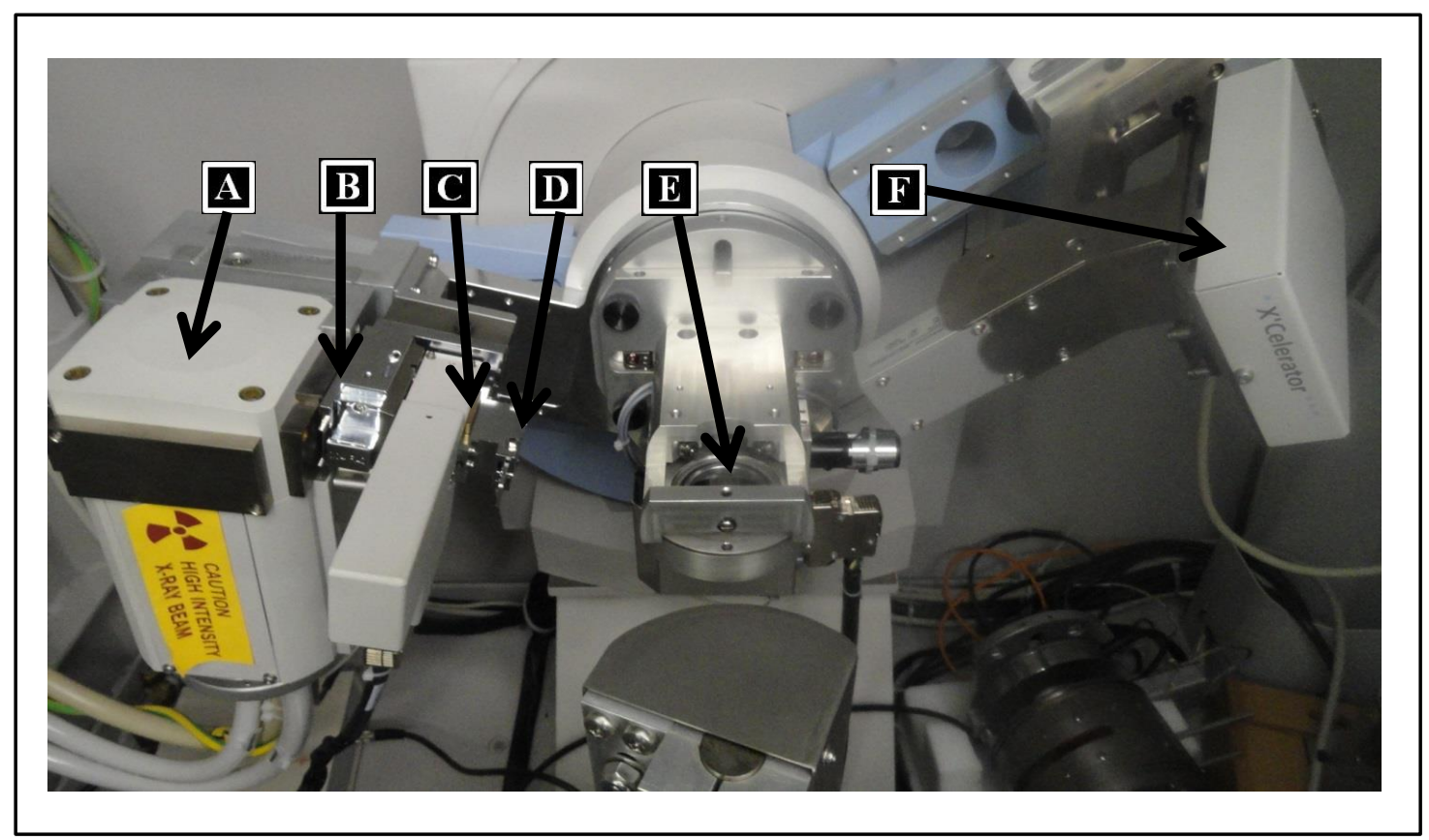

Figure 3.6 XRD (PANalytical X'Pro PW 3040 diffractometer) (A) an X-ray source, (B) nickel filter, (C) $10 \mathrm{~mm}$ mask, (D) $1^{\circ}$ anti-scatter slit, (E) sample holder, (F) $\mathrm{X}^{\prime}$ accelerator X-ray detector. 
Lattice parameters were calculated for sintered samples using Equation 3.3 [63]. The diffraction angle associates with a $\mathrm{d}$-spacing $\mathrm{d}_{\mathrm{hkl}}$. Lattice parameter can be calculated when $\mathrm{d}_{\mathrm{hkl}}$ is multiplied by the square root of the sum of the squares of the values $h, k$, and 1 for each set of planes.

$$
a_{\text {lattice parameter }}=d_{h k l} * \sqrt{h^{2}+k^{2}+l^{2}}
$$

where $a$ is the lattice parameter, $d_{h k l}$ is d-spacing, $h k l$ are planes generating the peak. The lattice parameter of solid solution $\alpha$-Ni phase was calculated based on (111) and (200) planes. The lattice parameter was used to determine the composition of the solid solution $\alpha-\mathrm{Ni}$ using the existing solubility data (Fig. 3.7) [64]. A plot was generated for the composition of solid solution $\alpha-\mathrm{Ni}$ as a function of aging time for aged samples between $600^{\circ} \mathrm{C}$ and $900^{\circ} \mathrm{C}$.

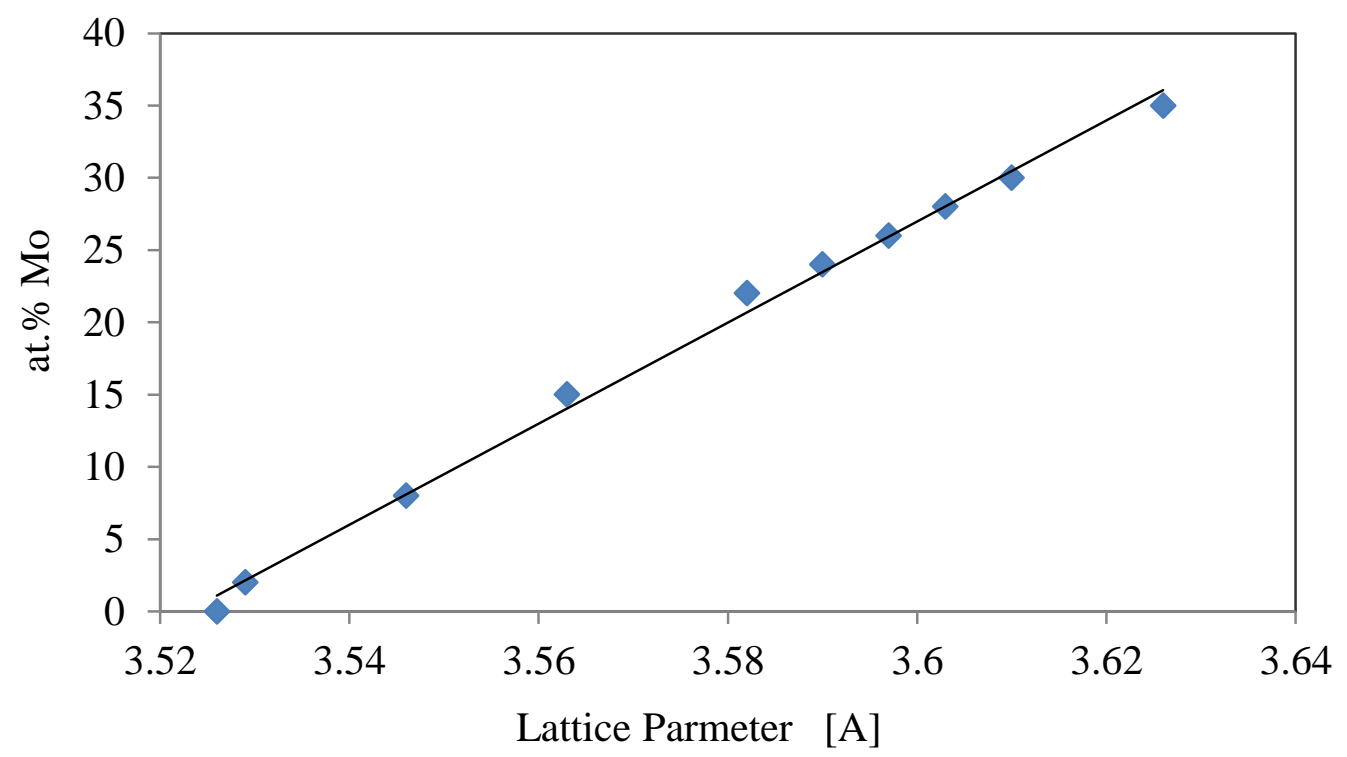

Figure 3.7 Atomic \% of molybdenum in nickel as a function of lattice parameter [64] 


\subsubsection{Hardness Testing}

Bulk samples (before and after heat-treatment) were cut, mounted, ground, and polished. Hardness testing was performed on bulk samples before and after heat-treatment to assess the effect of the heat-treatment. Vickers microhardness testing was carried out using a LECO DM400 as shown in Fig. 3.8 at 100 gf for 5 seconds. At least six measurements were taken per sample for statistical reliability. Plots of microhardness values of heat-treated samples against heat-treatment time were generated.

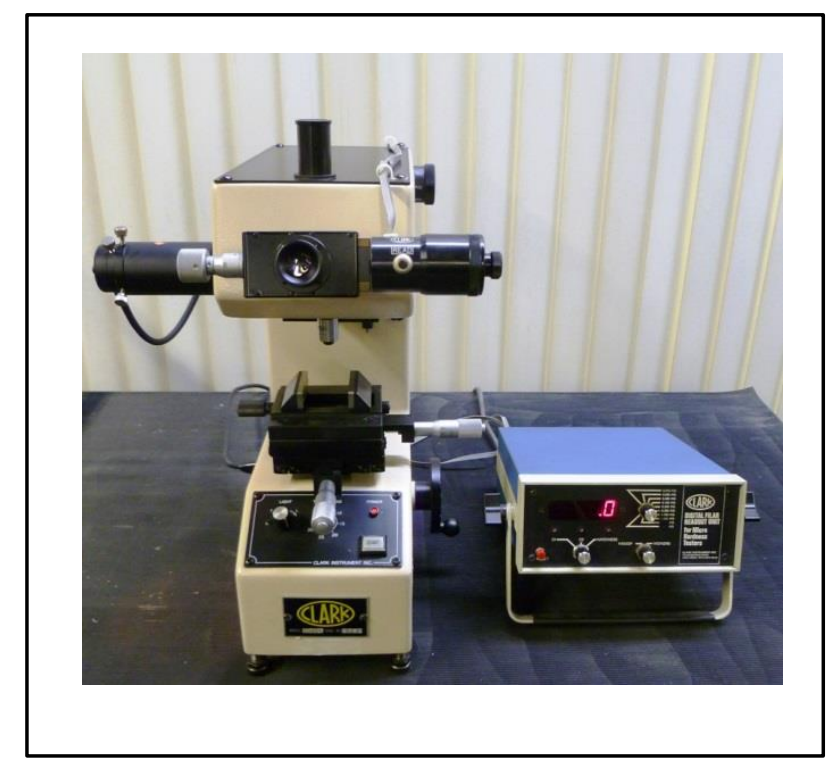

Figure 3.8 Vickers microhardness tester (LECO DM-400)

Vickers hardness is micro-indentation hardness test. In this test, a diamond indent, in the shape of a right pyramid with a square base (Fig. 3.9), uses for indenting the test material. During measurement, a load of 1 to $100 \mathrm{kgf}$ is applied smoothly which forces the indenter into the test material. The full load is applied for 5 or 15 seconds. After that, the load is removed, and the two impression diagonals are measured. Knoop test is similar to Vickers test, except that Vickers is more sensitive to measurement errors than Knoop. Also, Vickers test is less sensitive 
to the surface condition than Knoop test. The Vickers hardness is calculated by dividing the load by the square area of indentation using the following equation [63].

$$
H V=\frac{1.854 * F}{d^{2}} \quad \frac{K g f}{m^{2}}
$$

where $H V$ is Vickers hardness, $F$ is the load in Kgf, and $d$ is the average diagonal of $d_{1}$ and $d_{2}$ in $\mu \mathrm{m}$.

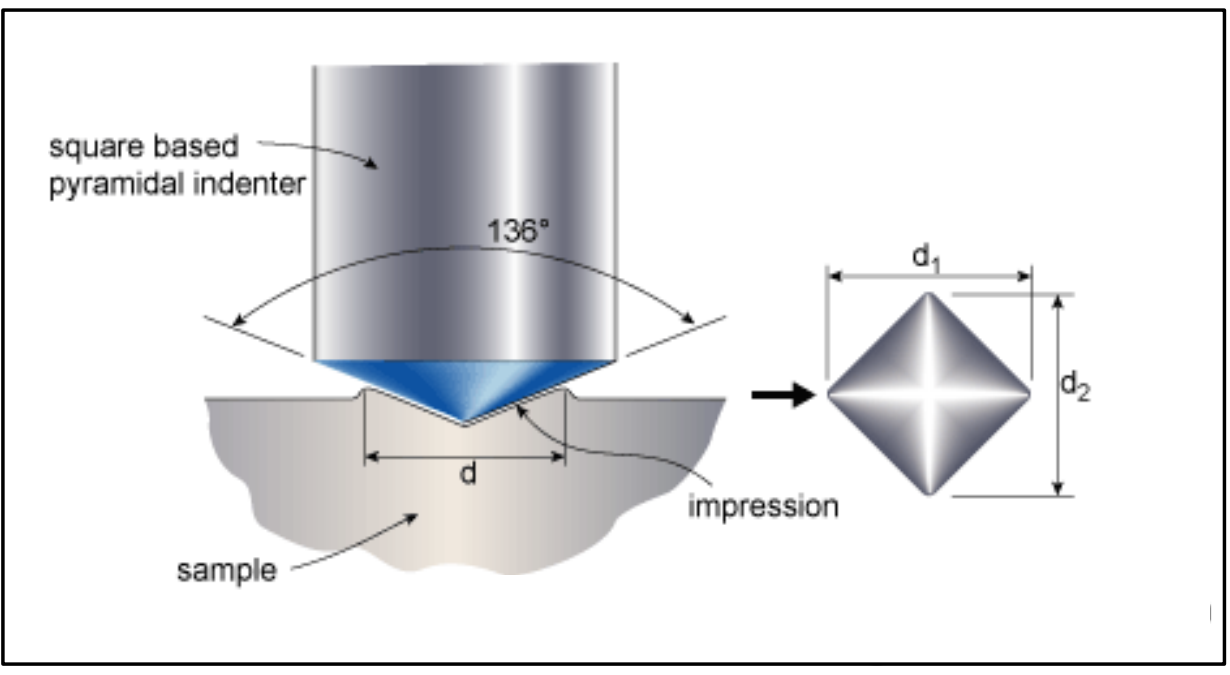

Figure 3.9 Vickers indentation and measurement of impression diagonal (www.twi-global.com)

\subsubsection{Scanning Electron Microscopy (SEM)}

A FEI Quanta 600 FEG Environmental Scanning Electron Microscope (Fig. 3.10) was used to image selected samples, to investigate the development of the new phases. The acceleration voltage was $20 \mathrm{kV}$, and working distances were between $8 \mathrm{~mm}-15 \mathrm{~mm}$ with different magnifications. The samples were prepared for SEM using standard metallographic techniques (mounting, grinding, polishing, etching using a solution of $\mathrm{FeCl}_{3} 5 \mathrm{~g}, \mathrm{HCl} 100 \mathrm{ml}$, and $10 \mathrm{ml} \mathrm{H}_{2} \mathrm{O}$, and conductive coating). 


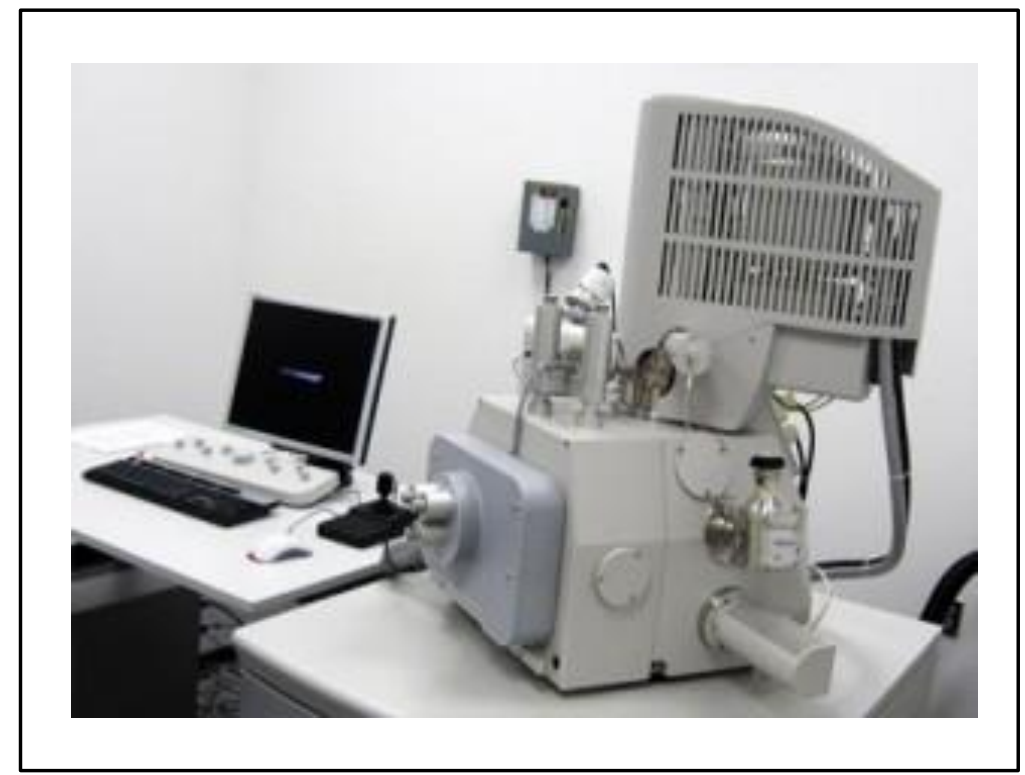

Figure 3.10 Environmental Scanning Electron Microscope (FEI Quanta 600 FEG)

In the following chapters (four through six) the results of this work are presented and discussed. These chapters are written as journal articles. These chapters are the enhanced versions of already published manuscripts at MS\&T and TMS proceedings [65-67]. Each chapter includes abstract, introduction, experimental procedures, results, discussion, and summary. Chapter seven comprises the summary of this work. 


\section{Bulk Processing and Microstructural Evolution of $\gamma-\mathrm{Ni}_{3} \mathrm{Mo}$}

\subsection{Abstract}

High-energy ball milling was used to produce a homogeneously blended and partially alloyed elemental nickel and molybdenum of $\mathrm{Ni}_{3} \mathrm{Mo}$ composition. Alloy samples were coldcompacted, sintered/solutionized at $1300^{\circ} \mathrm{C}$ for $25 \mathrm{~h}$ and quenched to retain the solid solution $\alpha$ Ni. The cold compaction and subsequent sintering were repeated for a total of $100 \mathrm{~h}$ of sintering/solutionization time to achieve near full density. Aging was performed between $600^{\circ} \mathrm{C}$ and $900^{\circ} \mathrm{C}$ for up to $100 \mathrm{~h}$, to investigate the microstructural evolution of $\gamma-\mathrm{Ni}_{3} \mathrm{Mo}$ phase. Scanning electron microscopy, x-ray diffraction, and hardness testing were used to analyze the aged samples to study the microstructural evolution and their related hardness. The phases observed in the aged samples were $\gamma-\mathrm{Ni}_{3} \mathrm{Mo}, \delta$-NiMo, solid solution $\alpha$-Ni or their mixtures. Cellular precipitation was observed in some samples. Hardness values were as high as $880 \mathrm{Kg} / \mathrm{mm}^{2}$ in the samples aged at $800^{\circ} \mathrm{C}$.

\subsection{Introduction}

The Ni-Mo system phase diagram (Fig. 2.1) shows three ordered intermetallic $\beta-\mathrm{Ni}_{4} \mathrm{Mo}$, $\gamma-\mathrm{Ni}_{3} \mathrm{Mo}$, and $\delta$-NiMo. The metastable $\mathrm{Ni}_{2} \mathrm{Mo}$ phase was observed in the 1970 s by Saburi et al., and it is not shown in the $\mathrm{Ni}-\mathrm{Mo}$ phase diagram [30]. $\mathrm{Ni}_{2} \mathrm{Mo}, \gamma-\mathrm{Ni}_{3} \mathrm{Mo}$, and $\beta-\mathrm{Ni}_{4} \mathrm{Mo}$ are superstructures of the fcc high-temperature phase. There have been a number of studies on the ordering systems in $\gamma-\mathrm{Ni}_{3} \mathrm{Mo}[50,52-55,57], \beta-\mathrm{Ni}_{4} \mathrm{Mo}[68,69]$, and $\delta$-NiMo [60]. Das et al. [70], in their investigation, quenched the disordered $\gamma-\mathrm{Ni}_{3} \mathrm{Mo}$ from high temperature and then aged below the peritectoid temperature. They reported that $\mathrm{Ni}_{2} \mathrm{Mo}$ formed first and then $\beta-\mathrm{Ni}_{4} \mathrm{Mo}$ precipitated next; they both coexisted for some time. 
Upon prolonged aging, these precipitates are subsequently replaced by the equilibrium $\gamma-\mathrm{Ni}_{3} \mathrm{Mo}$ phase. Similar results were observed in studies by Mishera et al. [56, 71] of Ni-20 to 25at.\%Mo alloys. Both of the above studies were primarily TEM studies performed on very small processed samples.

The present work deals with the processing of bulk Ni-25at.\%Mo alloy utilizing powder processing methods and studying the microstructural evolution during aging of the supersaturated solid-solution $\alpha-\mathrm{Ni}$ and the associated hardness behavior.

\subsection{Experimental Procedures}

Ni-25at.\%Mo alloy was prepared by mechanical alloying elemental powders of nickel of 99+ \% purity and molybdenum of $99.9 \%$ purity, both purchased from Alfa Aesar. The mixture was mechanically alloyed in a tungsten carbide medium in a SPEX mill for 10h. The milled powder was cold compacted in a uniaxial steel mold at $550 \mathrm{MPa}$ stress. The compacted specimens were homogenized/sintered in a tube furnace at $1300^{\circ} \mathrm{C}$ under hydrogen and argon gases flow for $25 \mathrm{~h}$ (Step 1 in Fig. 4.1). The cold compaction and the sintering routines were repeated for a total of $100 \mathrm{~h}$ sintering followed by quenching (Step 2 in Fig. 4.1), yielding a density of $8.754 \mathrm{~g} / \mathrm{cc}(\sim 93.8 \%)$. The sintered samples sectioned into $1 \mathrm{~mm}$ thick slices using a diamond saw. Isothermal aging was done in salt baths at temperatures ranging from $600^{\circ} \mathrm{C}$ to $900^{\circ} \mathrm{C}$ (Step 3 in Fig. 4.1) followed by quenching. X-ray diffraction was performed on all powders (blended and mechanically alloyed) and aged samples; optical and scanning electron microscopes (SEM) were performed on sintered and aged samples. Vickers microhardness values were obtained for all samples using LECO DM-400 at $100 \mathrm{gf}$ for 5 seconds. 


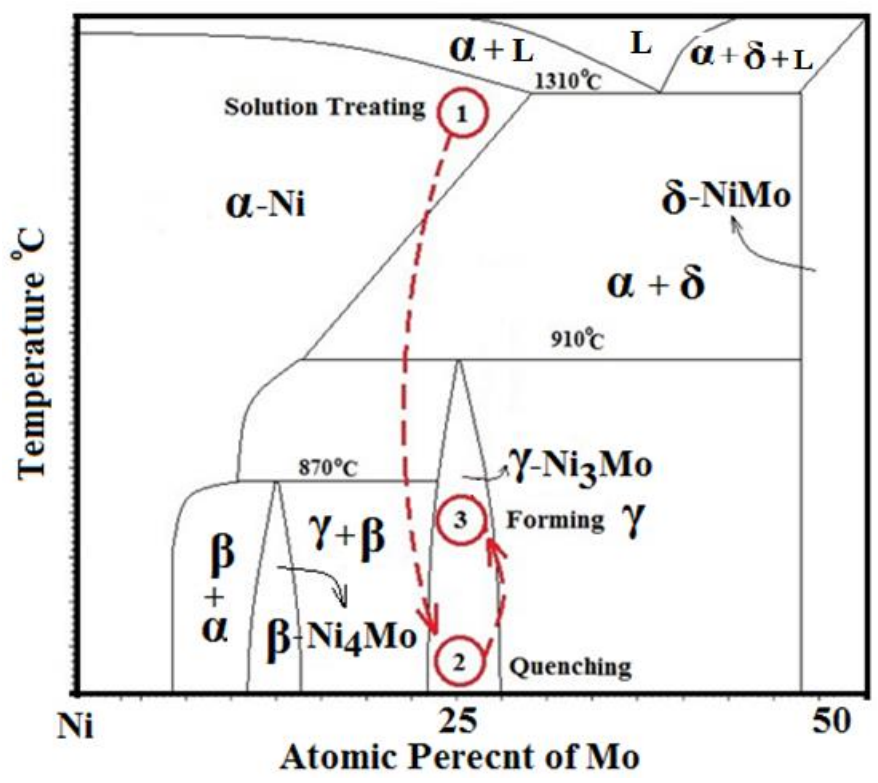

Figure 4.1 Partial phase diagram of Ni-Mo system with the heat-treatment steps: (1) sintering/solutionized at $1300^{\circ} \mathrm{C}$ for total $100 \mathrm{~h}$; (2) quenching; (3) aging at temperatures between $600^{\circ} \mathrm{C}-900^{\circ} \mathrm{C}$ for up to $100 \mathrm{~h}$ followed by quenching.

\subsection{Results}

XRD profiles are shown in Figs. 4.2 through 4.5. The blended Ni-Mo powder is shown in Fig. 4.2a. Partially mechanically alloyed Ni-Mo powder (Fig. 4.2b) formed a complete solid solution (Fig. 4.2c) after compaction and then sintering at $1300^{\circ} \mathrm{C}$ for a total of $100 \mathrm{~h}$. The (111) and (200) peaks of fcc Ni shifted to the lower angles and became broader as the solution formed by mechanical alloying as well as sintering, Figs 4.2b-c. Fig. 4.3 shows the XRD patterns of samples aged at $600^{\circ} \mathrm{C}$ and different aging times. At an aging temperature of $600^{\circ} \mathrm{C}$, the solid solution initially transformed to a mixture of $\mathrm{Ni}_{2} \mathrm{Mo}, \beta-\mathrm{Ni}_{4} \mathrm{Mo}$, and $\gamma-\mathrm{Ni}_{3} \mathrm{Mo}$, and eventually to $100 \% \gamma-\mathrm{Ni}_{3} \mathrm{Mo}$ after $100 \mathrm{~h}$ of aging as shown in Figs. 4.3a-d. The stable phase, $\gamma-\mathrm{Ni}{ }_{3} \mathrm{Mo}$, progressively formed at $600^{\circ} \mathrm{C}$ to completion after $100 \mathrm{~h}$, and that was also true for aging at $650^{\circ} \mathrm{C}$. 


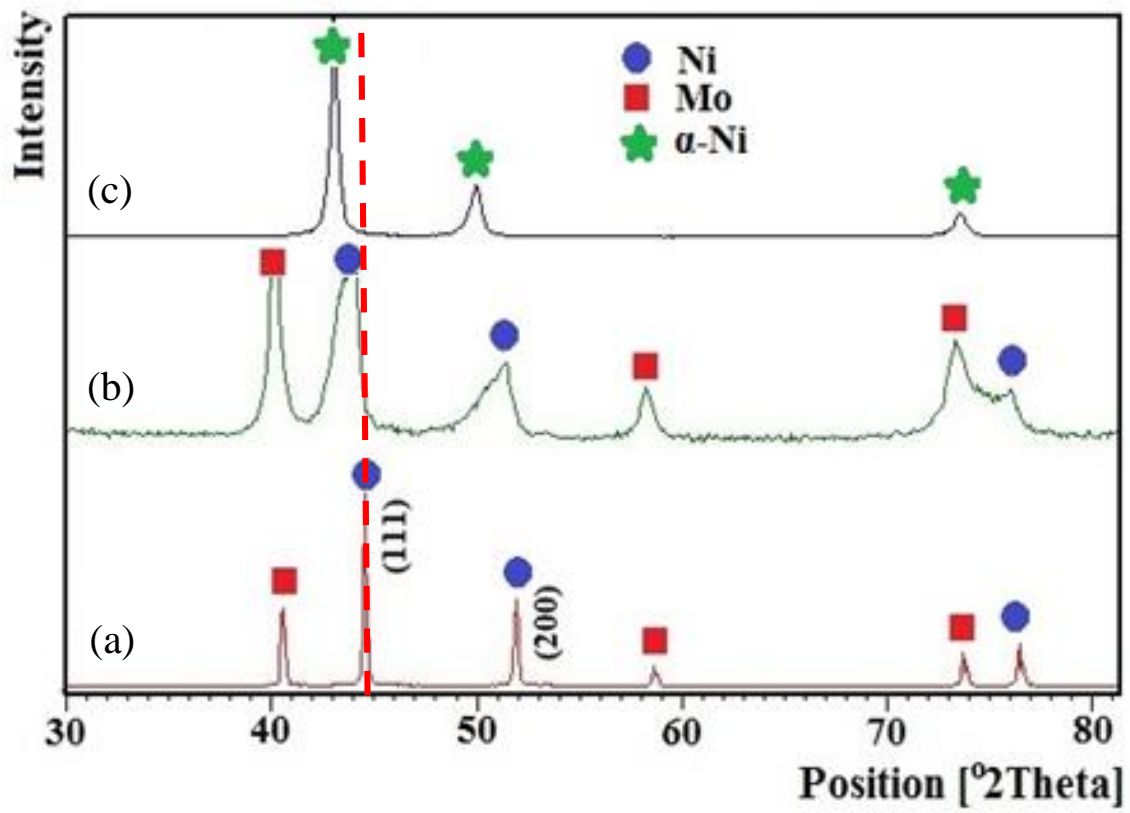

Figure 4.2 XRD profiles of (a) Ni and Mo blended powder. (b) Mechanically Alloyed for 10h by using SPEX mill. (c) Sintered/Solutionized sample at $1300^{\circ} \mathrm{C}$ for a total of $100 \mathrm{~h}$ followed by quenching

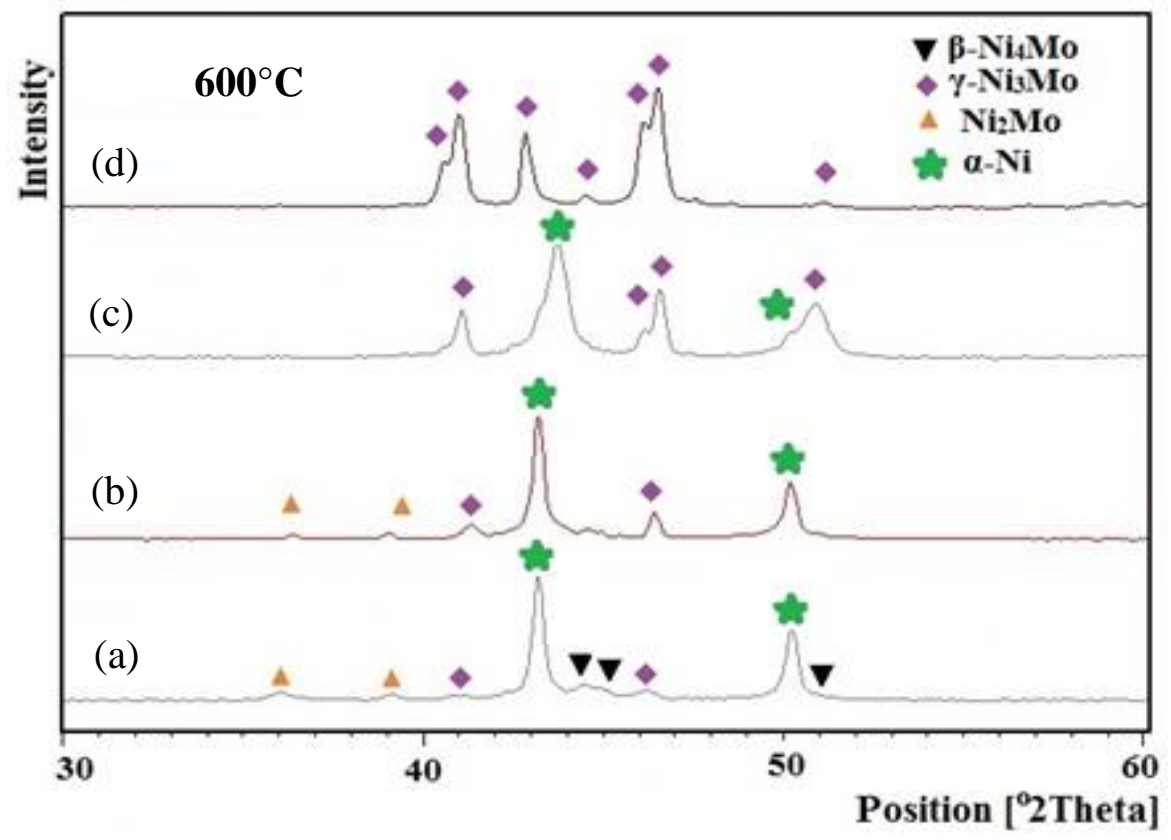

Figure 4.3 XRD patterns of Ni-25at.\%Mo alloy isothermally aged at $600^{\circ} \mathrm{C}$ for: (a) $15 \mathrm{~min}$; (b) $5 \mathrm{~h}$; (c) $25 \mathrm{~h}$; (d) $100 \mathrm{~h}$.

Aging at other temperatures $\left(700^{\circ} \mathrm{C}, 750^{\circ} \mathrm{C}, 800^{\circ} \mathrm{C}\right.$, and $850^{\circ} \mathrm{C}$ for $\left.25 \mathrm{~h}\right)$ always ended up with a solid solution and $\gamma-\mathrm{Ni}_{3}$ Mo phases. The XRD profiles for specimens aged at $850^{\circ} \mathrm{C}$ and 
$900^{\circ} \mathrm{C}$ are shown in Figs. 3-4 and 3-5. At an aging temperature of $850^{\circ} \mathrm{C}$ (Figs. $4.4 \mathrm{a}-\mathrm{c}$ ), the $\gamma$ $\mathrm{Ni}_{3}$ Mo phase developed with reduced Mo concentration from the supersaturated 25at.\%Mo. XRD profiles in Figs. 4.5 a-c show aging at $900^{\circ} \mathrm{C}$ and different aging times, where the solid solution phase was dominant in the end, after $\mathrm{Ni}_{2} \mathrm{Mo}, \beta-\mathrm{Ni}_{4} \mathrm{Mo}$, and $\gamma-\mathrm{Ni}_{3} \mathrm{Mo}$ precipitations followed by $\delta$-NiMo transformation.

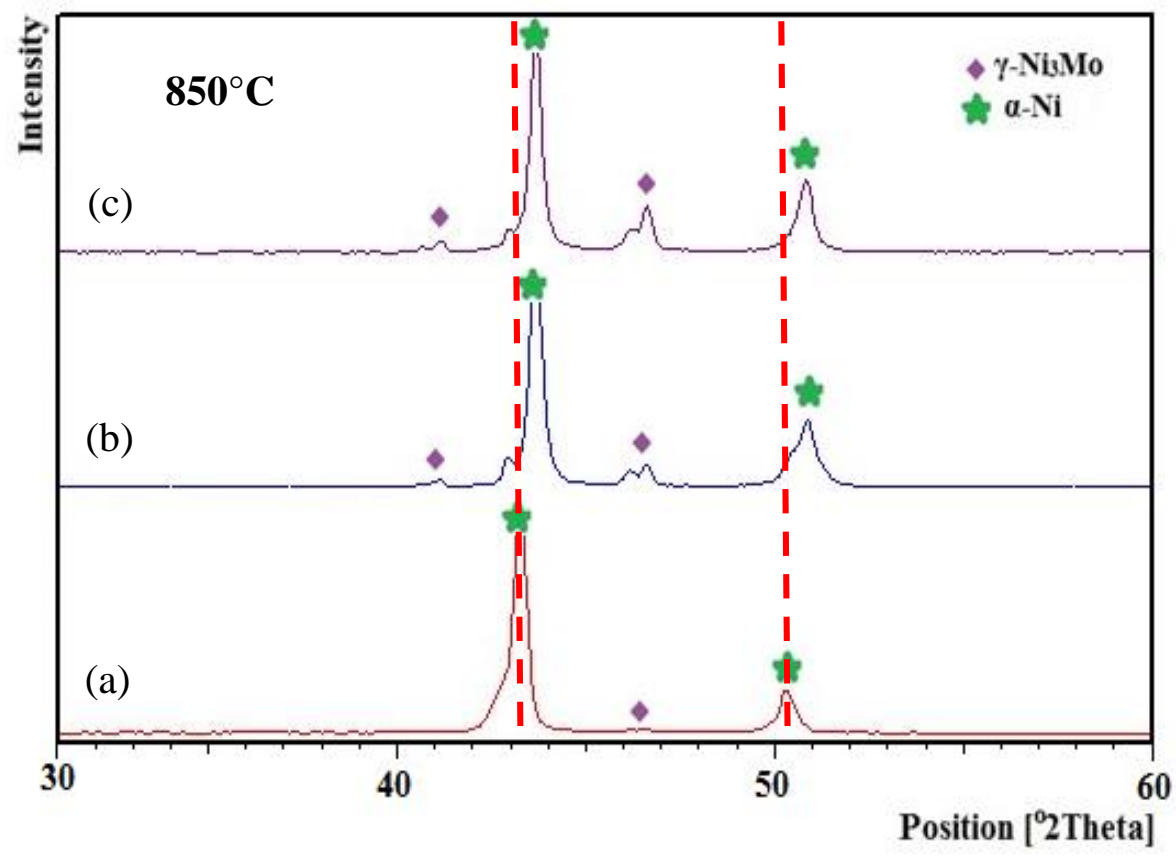

Figure 4.4 XRD profiles of Ni-25at.\%Mo alloy isothermally aged at $850^{\circ} \mathrm{C}$ for: (a) $30 \mathrm{~min}$; (b) $2 \mathrm{~h}$; (c) $25 \mathrm{~h}$.

The lattice parameter was calculated based on (111) and (200) planes using the following equation [63]:

$$
a_{\text {lattice parameter }}=d_{h k l} * \sqrt{h^{2}+k^{2}+l^{2}}
$$

where $d_{h k l}$ is d-spacing, $h k l$ are planes generating the peak. Using the existing solubility data on the Ni-Mo alloy system [64] and the lattice parameter of $\alpha$-Ni phase, plots were developed for the composition of $\alpha-\mathrm{Ni}$ phase as a function of aging time at $600^{\circ} \mathrm{C}-900^{\circ} \mathrm{C}$; they are presented in 
Fig. 4.6. The Mo composition dropped with aging time, dropping slowly for lower aging temperatures $600^{\circ} \mathrm{C}$ and $650^{\circ} \mathrm{C}$, and much sharper for higher aging temperatures.

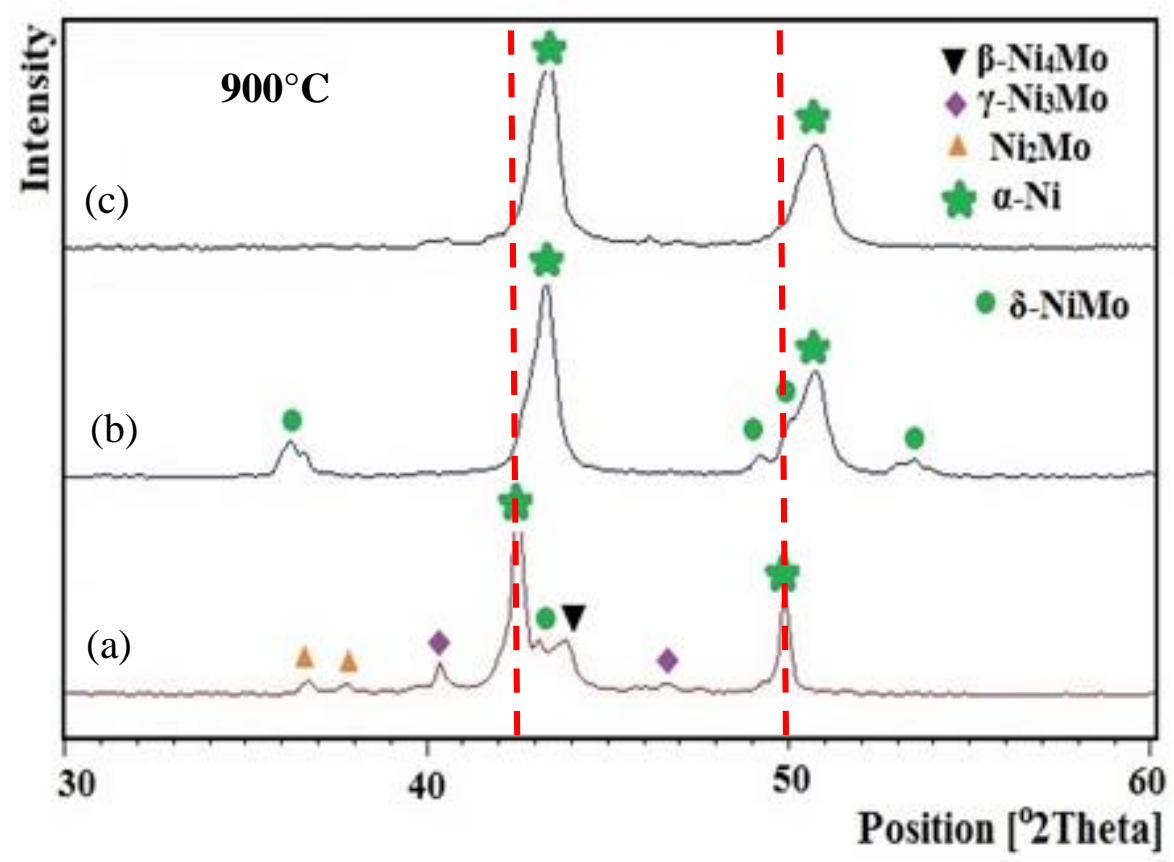

Figure 4.5 XRD profiles of Ni-25at.\%Mo alloy isothermally aged at $900^{\circ} \mathrm{C}$ for (a) $30 \mathrm{~min}$, (b) $2 \mathrm{~h}$, and (c) $25 \mathrm{~h}$.

SEM and optical microscopy were used to examine sintered and isothermally aged samples, and selected micrographs are shown in Figs. 4.7 to 4.10 . Fig. 4.7 shows the microstructure of the sample compacted and sintered at $1300^{\circ} \mathrm{C}$ for $100 \mathrm{~h}$ and quenched to room temperature. The microstructure contained equiaxed $\alpha$-Ni grains, approximately $110 \mu \mathrm{m}$ in diameter, and included annealing twins. 


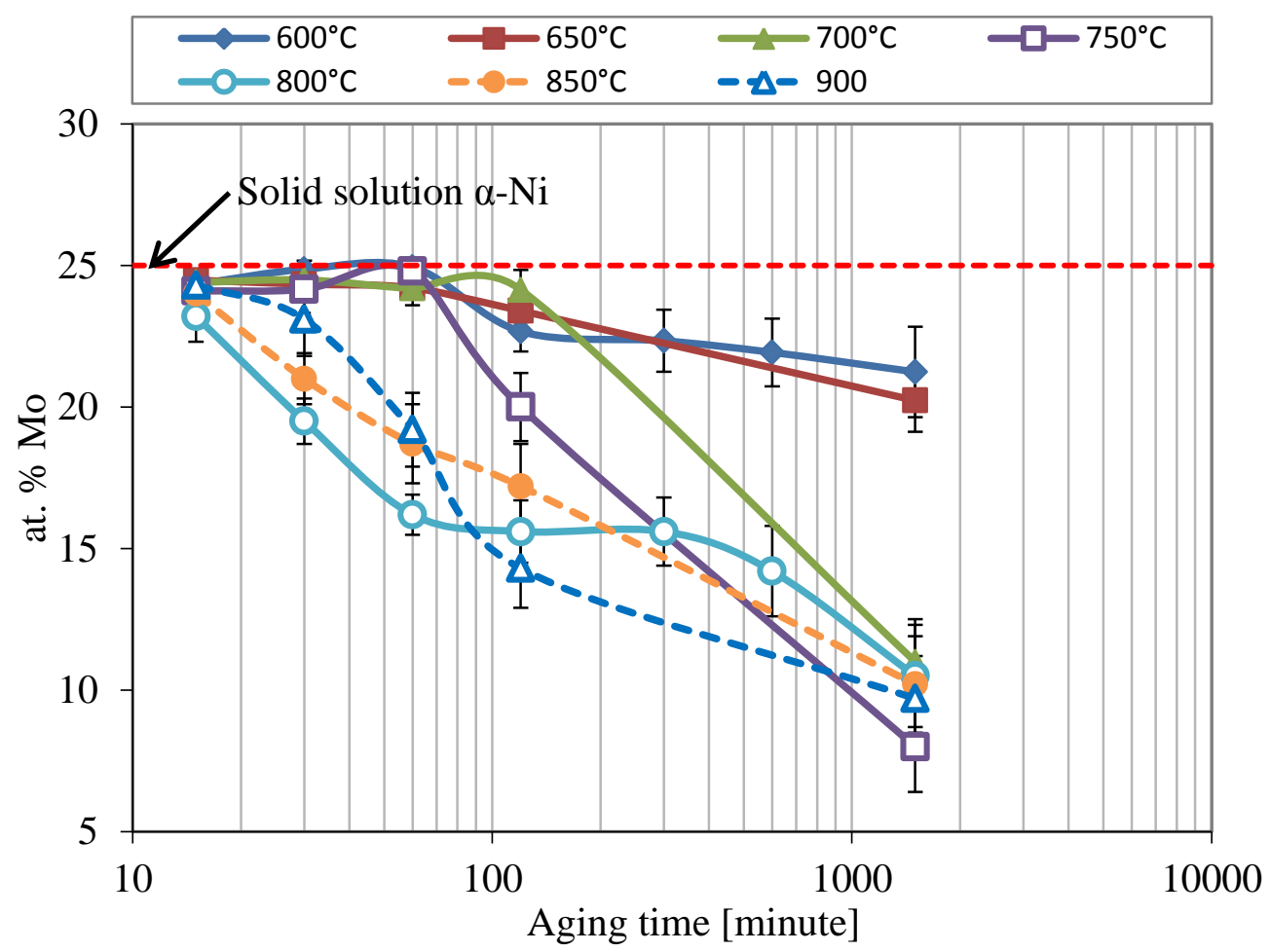

Figure 4.6 Composition of solid solution $\alpha$-Ni determined from the existing solubility data [64] and X-ray data.

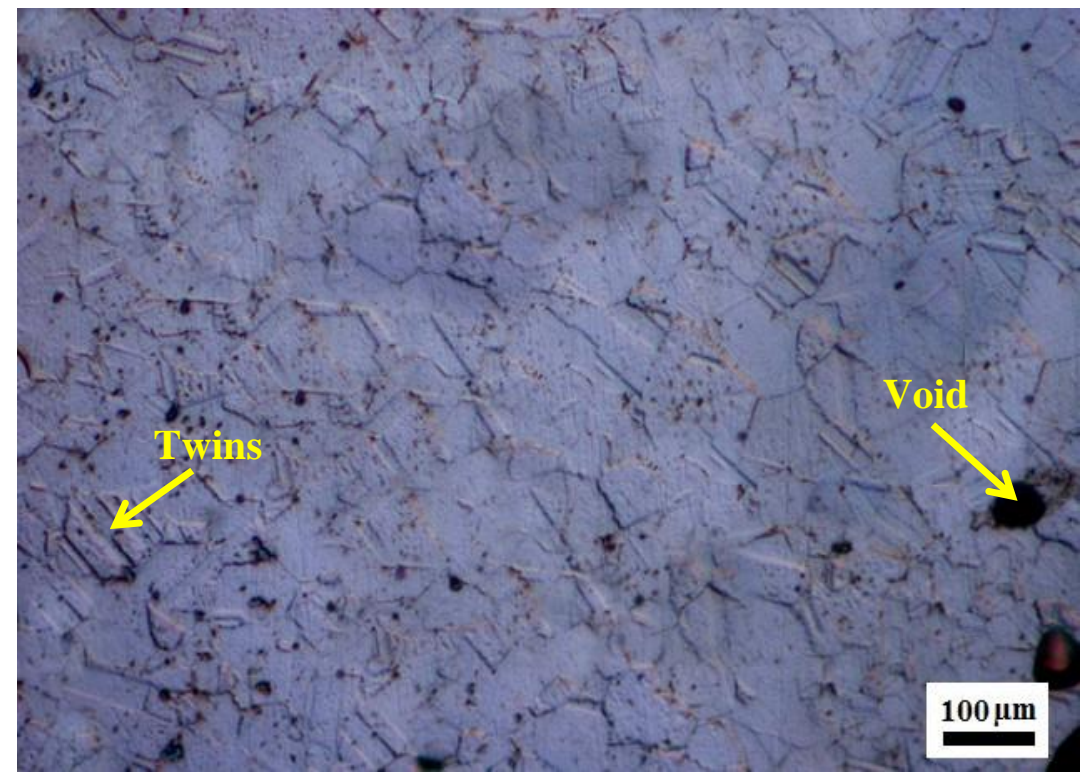

Figure 4.7 Optical micrograph of Ni-25at.\%Mo alloy sintered/solutionized at $1300^{\circ} \mathrm{C}$ for $100 \mathrm{~h}$ followed by rapid quenching the microstructure showed equiaxed and twined grains of solid solution $\alpha$-Ni phase (the black regions are spherical voids). Etchant: $\mathrm{FeCl}_{3} 5 \mathrm{~g}, \mathrm{HCl} 100 \mathrm{ml}$, and $10 \mathrm{ml} \mathrm{H}_{2} \mathrm{O}$. 
Aging at $600^{\circ} \mathrm{C}$ (Figs. 4-8a-c) produced $\gamma-\mathrm{Ni}_{3}$ Mo precipitates, mostly at grain boundaries which grew to eventually consume the $\alpha-\mathrm{Ni}$ phase. At $850^{\circ} \mathrm{C}$ (Fig. $4.9-\mathrm{a}$ ), $\gamma-\mathrm{Ni}_{3} \mathrm{Mo}$ particles inside $\alpha$-Ni grains or near the grain boundaries were much larger than those at the grain boundaries. The amount of the $\gamma-\mathrm{Ni}_{3} \mathrm{Mo}$ phase increased with aging time, according to $\mathrm{X}$-ray data (Fig. 4.4). Fig. $4.9 \mathrm{~b}$ shows the microstructure of the sample aged for $25 \mathrm{~h}$ at $850^{\circ} \mathrm{C}$. Based on the XRD data, the microstructure of the aged sample at $850^{\circ} \mathrm{C}$ for $25 \mathrm{~h}$ is a mixture of $\alpha-\mathrm{Ni}$ and $\gamma$ $\mathrm{Ni}_{3} \mathrm{Mo}$ phases. Aging at $850^{\circ} \mathrm{C}$ for $25 \mathrm{~h}$ was not sufficient to form $100 \% \gamma-\mathrm{Ni}_{3} \mathrm{Mo}$ phase.

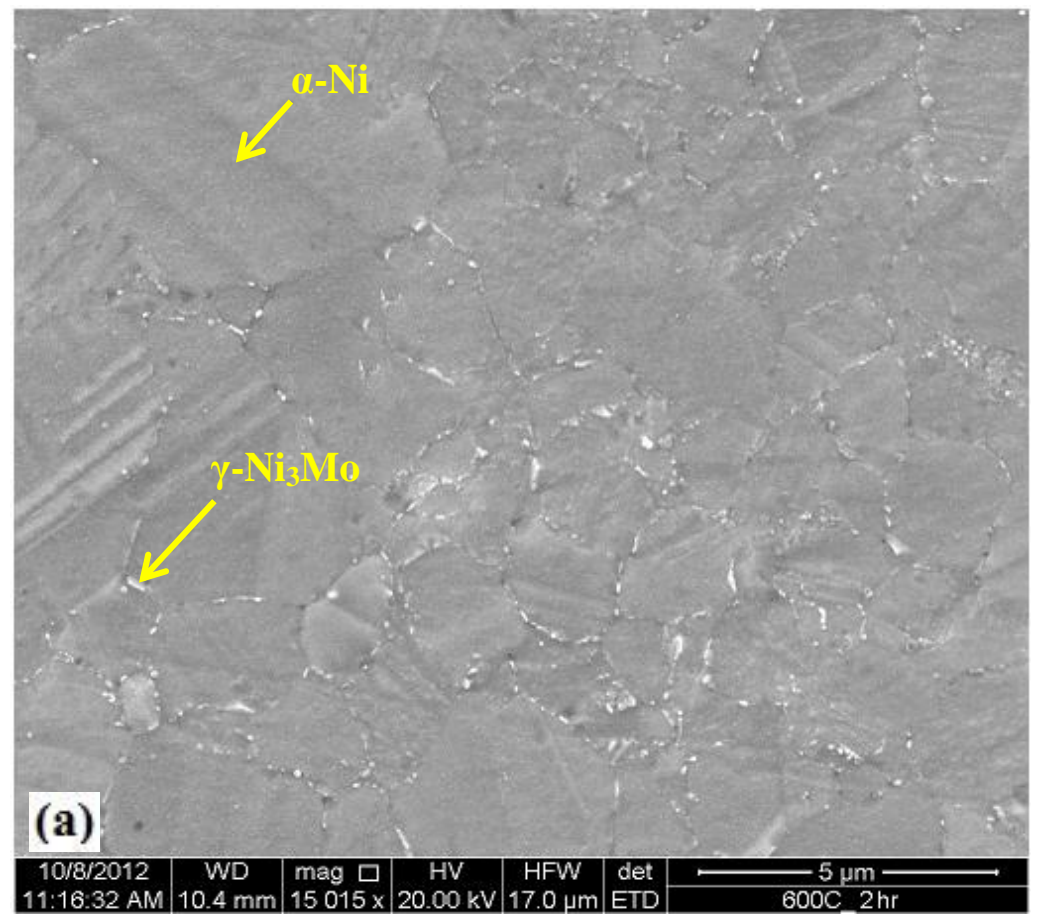



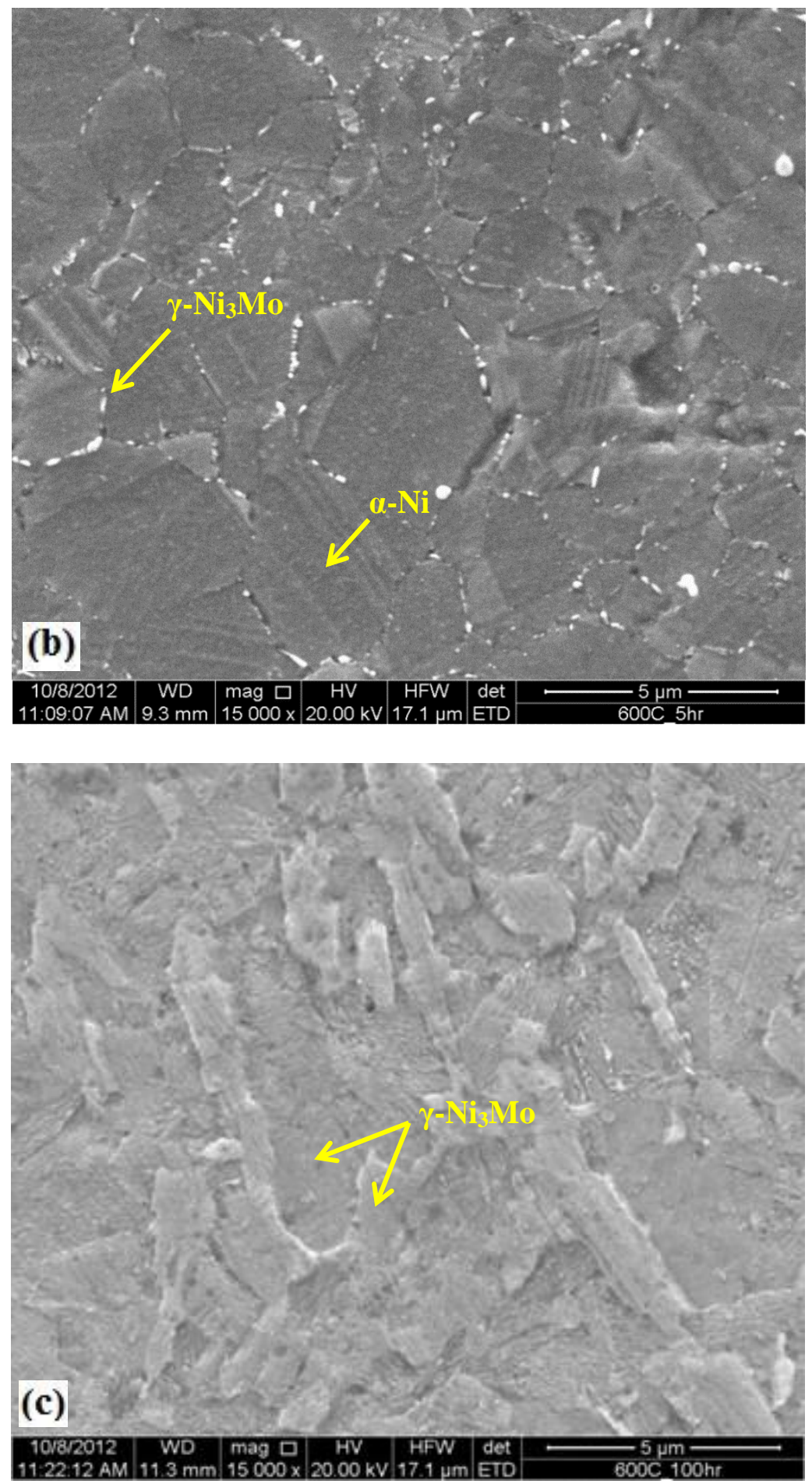

Figure 4.8 SEM micrographs of Ni-25at.\%Mo alloy isothermally aged at $600^{\circ} \mathrm{C}$ for: (a) $2 \mathrm{~h}$ showing a microstructure of twinned grains of $\alpha-\mathrm{Ni}$ phase and the precipitates of $\gamma-\mathrm{Ni}_{3} \mathrm{Mo}$ along the grain boundaries; (b) $5 \mathrm{~h}$ consisting of $\alpha-\mathrm{Ni}$ grains and $\gamma-\mathrm{Ni}_{3}$ Mo precipitates along the grain boundaries; (c) $100 \mathrm{~h}$ consisting of the equilibrium $\gamma-\mathrm{Ni}_{3} \mathrm{Mo}$ phase. The voids are not included in these smaller fields of views. Etchant: $\mathrm{FeCl}_{3} 5 \mathrm{~g}, \mathrm{HCl} 100 \mathrm{ml}$, and $10 \mathrm{ml} \mathrm{H}_{2} \mathrm{O}$. 

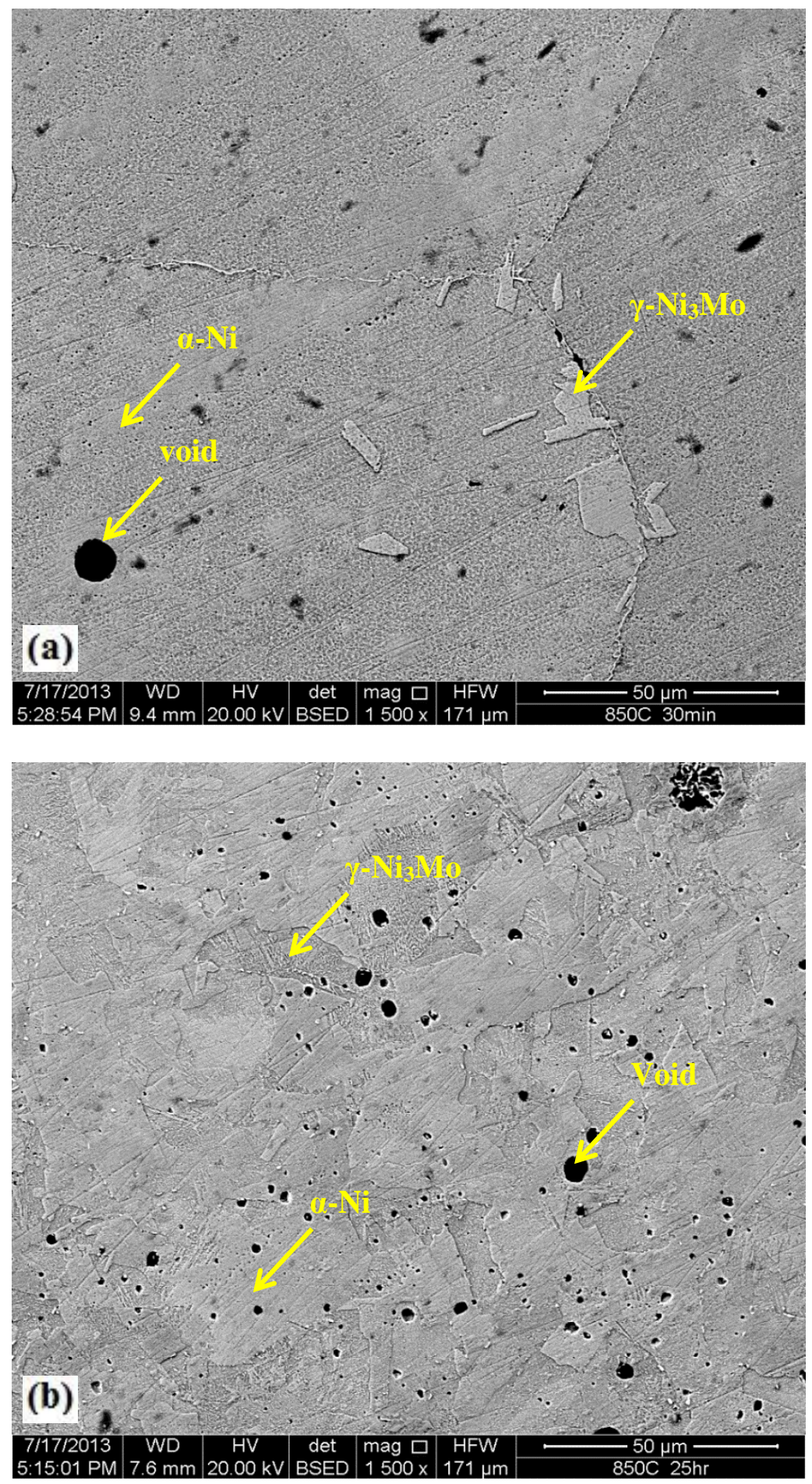

Figure 4.9 SEM micrographs of $\mathrm{Ni}-25 \mathrm{at} \% \mathrm{Mo}$ alloy isothermally aged at $850^{\circ} \mathrm{C}$ for: (a) $30 \mathrm{~min}$ showing a microstructure of $\alpha-\mathrm{Ni}$ phase and precipitates of $\gamma-\mathrm{Ni}_{3} \mathrm{Mo}$ along and within the grain boundaries; (b) $25 \mathrm{~h}$ consisting of $\alpha-\mathrm{Ni}$ and $\gamma-\mathrm{Ni}_{3} \mathrm{Mo}$ phase according to the XRD data. The black regions are voids. Etchant: $\mathrm{FeCl}_{3} 5 \mathrm{~g}, \mathrm{HCl} 100 \mathrm{ml}$, and $10 \mathrm{ml} \mathrm{H}_{2} \mathrm{O}$. 
SEM micrographs of specimens aged at $900^{\circ} \mathrm{C}$ for $30 \mathrm{~min}, 2 \mathrm{~h}$ and $25 \mathrm{~h}$ are shown in Fig. 4.10. Precipitates were found both along and within the grain boundaries. From XRD data in Fig. 4.5a-c, the precipitates were $\gamma-\mathrm{Ni}_{3} \mathrm{Mo}$ up to $1 \mathrm{~h}$ of aging (Figs $4.9 \mathrm{a}$ and b), and $\delta$-NiMo after $2 \mathrm{~h}$ of aging (Fig. 4.10c). Cellular structures at some grain boundaries were also observed in Fig.4.10c. It is unclear from the XRD results, at this time, what the fine line-up particles (basket weave like strands) were, but it was highly expected that the fine line particles were $\delta$-NiMo in the $\alpha$-Ni matrix.

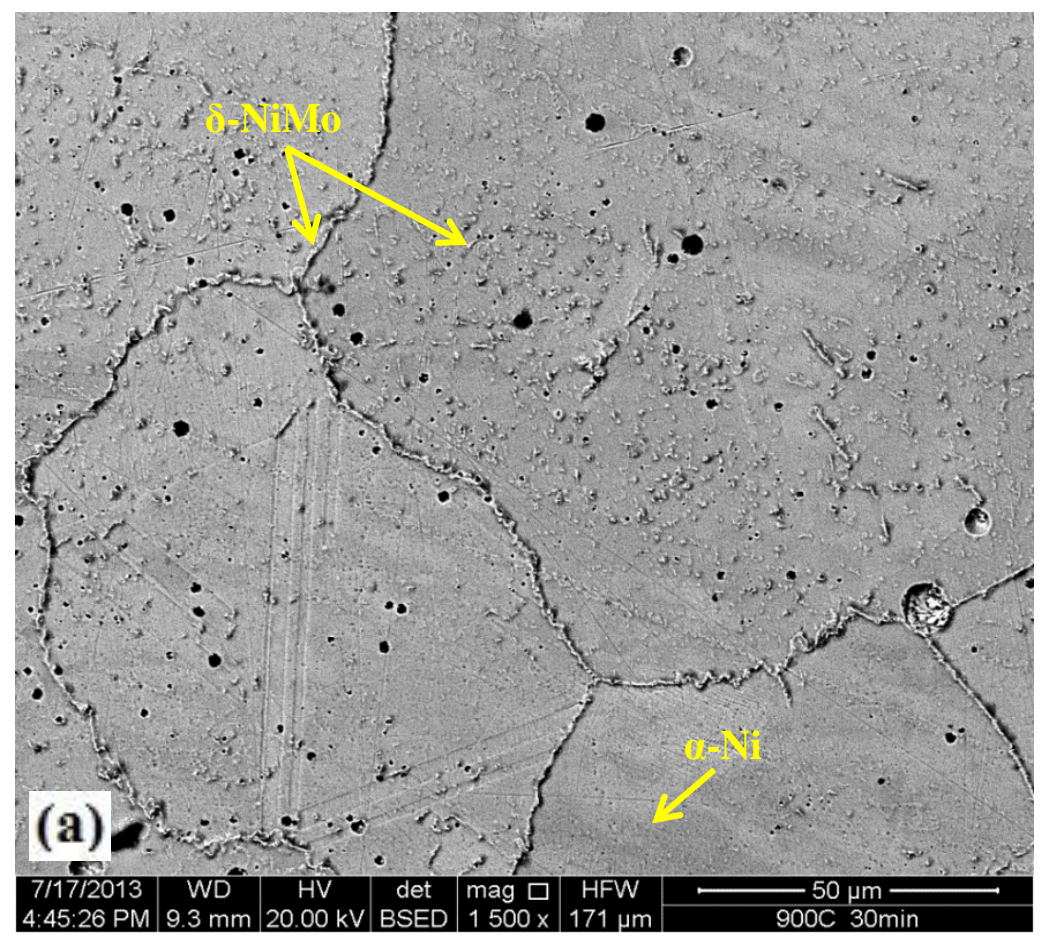



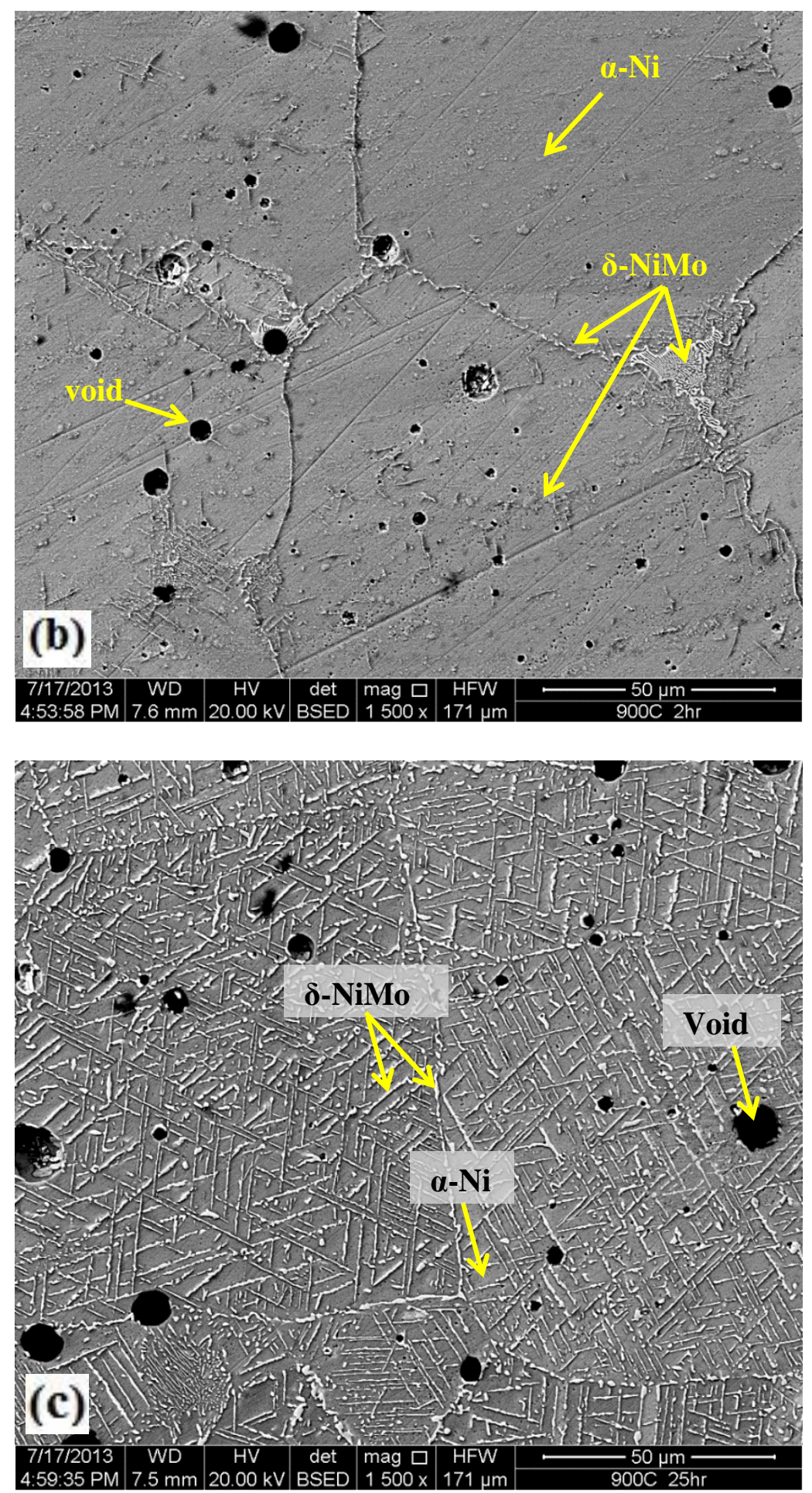

Figure 4.10 SEM micrographs of Ni-25at.\%Mo alloy aged at $900^{\circ} \mathrm{C}$ for :(a) 30 min consisting of mixture of $\gamma-\mathrm{Ni}_{3} \mathrm{Mo}$ and $\delta$-NiMo precipitates along and within the grain boundaries of $\alpha$-Ni phase; (b) $2 \mathrm{~h}$ consisting of $\delta$-NiMo precipitates along and within the grain boundaries of $\alpha-\mathrm{Ni}$ phase; (c) $25 \mathrm{~h}$ consisting of a basket weave strands of $\delta$-NiMo within the grain boundaries of $\alpha$-Ni phase. The black regions are voids. Etchant: $\mathrm{FeCl}_{3} 5 \mathrm{~g}, \mathrm{HCl} 100 \mathrm{ml}$, and $10 \mathrm{ml} \mathrm{H}_{2} \mathrm{O}$. 
Vickers microhardness measurements were performed to investigate the effect of the microstructural evolution on the mechanical properties of the alloy. As seen in Fig. 4.11, the hardness increased with aging time in all cases; a maximum of $880 \mathrm{Kg} / \mathrm{mm}^{2}$ was reached for the sample aged at $800^{\circ} \mathrm{C}$, except for samples aged at $900^{\circ} \mathrm{C}$. The rate of hardness increase was much smaller for samples aged at low temperatures $\left(600^{\circ} \mathrm{C}-700^{\circ} \mathrm{C}\right)$, and steeper for those aged at higher temperatures $\left(750^{\circ} \mathrm{C}-850^{\circ} \mathrm{C}\right)$. Like, traditional age-hardening behavior, overaging came sooner for the high temperature aged samples, and later for low temperature aged samples, the difference here was that high temperature aged samples are harder.

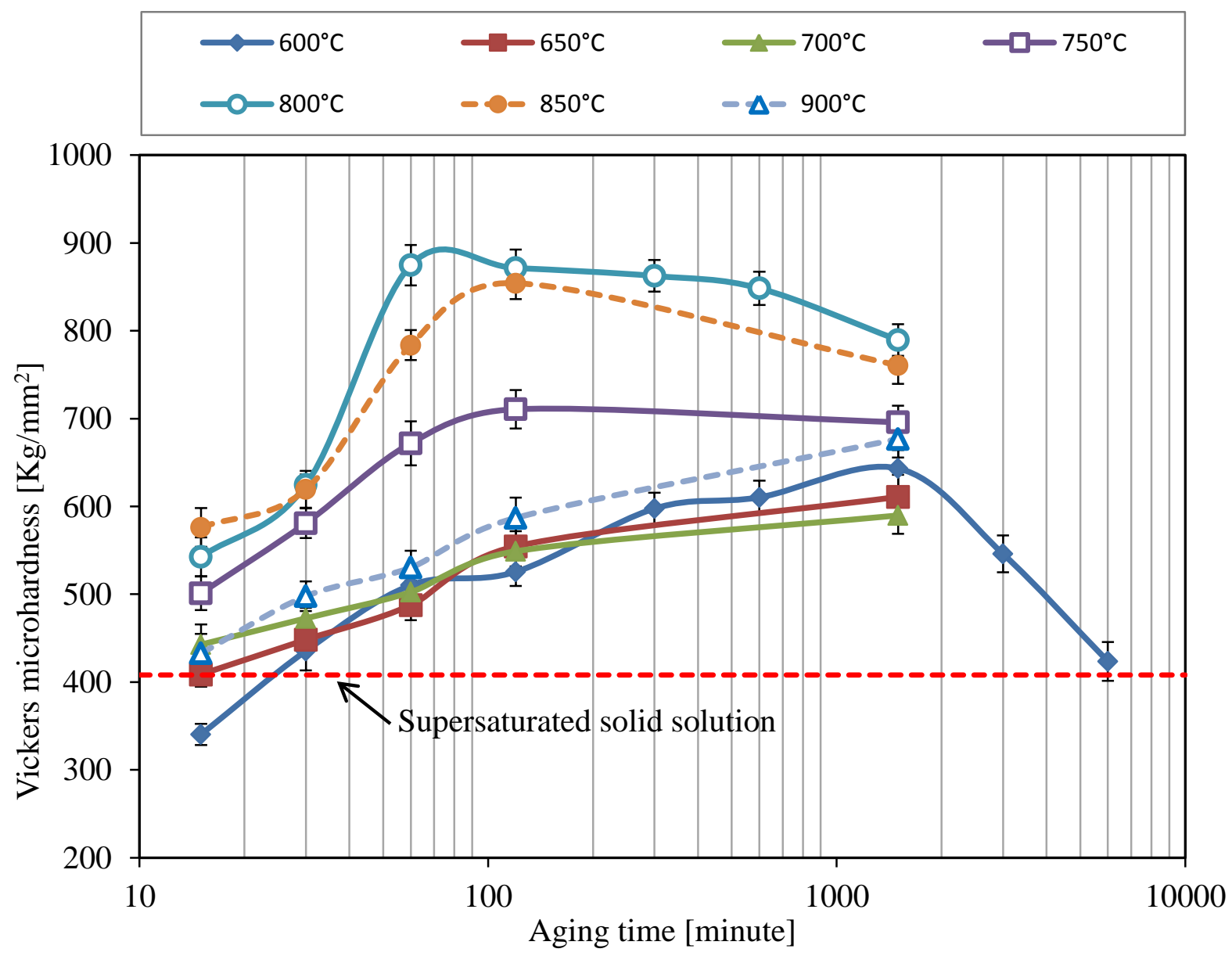

Figure 4.11 Microhardness of Ni-25at.\%Mo alloy aged plotted against aging time. 


\subsection{Discussion}

After milling, Ni peaks became broader and shifted to the lower angles as shown in Fig. 4.2b. This was related to the increase of lattice parameter of $\mathrm{Ni}$ due to the dissolution of Mo atom in $\alpha$-Ni phase. After sintering at $1300^{\circ} \mathrm{C}$ for $100 \mathrm{~h}$, the (111) and (200) peaks of Ni shifted more to the lower angles and were due to the formation of a complete solid-solution $\alpha$-Ni as seen in Fig. 4.2c. At an aging temperature of $600^{\circ} \mathrm{C}, \mathrm{Ni}_{2} \mathrm{Mo}$ and $\beta-\mathrm{Ni}_{4} \mathrm{Mo}$ formed and then eventually $100 \% \gamma-\mathrm{Ni}_{3} \mathrm{Mo}$ formed after $100 \mathrm{~h}$. It was reported that $\mathrm{Ni}_{2} \mathrm{Mo}$ formed first and then $\beta-\mathrm{Ni}_{4} \mathrm{Mo}$, and eventually $\gamma-\mathrm{Ni}_{3} \mathrm{Mo}$ formed when the alloy was aged at a temperature below and above $800^{\circ} \mathrm{C}$ [56]. Yamamoto et al.[49] reported that when the Ni-24.4at.\%Mo alloy quenched from $\alpha-$ phase and then annealed at $860^{\circ} \mathrm{C}$ for 10 min a meta-stable phase $\mathrm{Ni}_{2} \mathrm{Mo}$ formed in a short-rangeordered $\alpha$-Ni matrix. The meta-stable phases $\mathrm{Ni}_{2} \mathrm{Mo}, \beta-\mathrm{Ni}_{4} \mathrm{Mo}$, and the stable $\gamma-\mathrm{Ni}_{3} \mathrm{Mo}$ formed at $860^{\circ} \mathrm{C}$ for $1 \mathrm{~h}$, and to $100 \% \gamma-\mathrm{Ni}_{3} \mathrm{Mo}$ after $550 \mathrm{~h}$. In this work, the $100 \%$ stable $\gamma-\mathrm{Ni}_{3} \mathrm{Mo}$ formed at $600^{\circ} \mathrm{C}$ after $100 \mathrm{~h}$. Figs. $4.3 \mathrm{~d}$ and 4.8 show the XRD profile and SEM micrograph of $\gamma-\mathrm{Ni}_{3} \mathrm{Mo}$ phase, respectively. It has been suggested that the formation of the stable $\gamma-\mathrm{Ni}_{3} \mathrm{Mo}$ from the supersaturated solid solution $\alpha-\mathrm{Ni}$ was accomplished by nucleation and growth mechanism [49, $56]$.

After aging at a temperature of $850^{\circ} \mathrm{C}$, the precipitated particles look different than other precipitated aging temperatures. Small and large precipitated particles of $\gamma-\mathrm{Ni}_{3} \mathrm{Mo}$ along and within the grain boundaries of $\alpha-\mathrm{Ni}$ phase were observed at $850^{\circ} \mathrm{C}$ for $30 \mathrm{~min}$ as seen in Fig. 39a. These precipitated particles grew after $25 \mathrm{~h}$ as shown in Fig. 4.9b. Based on the XRD data, a mixture of the $\alpha-\mathrm{Ni}$ and $\gamma-\mathrm{Ni}_{3} \mathrm{Mo}$ phases were detected at a short time again at $850^{\circ} \mathrm{C}$, and the amount of the $\gamma-\mathrm{Ni}_{3} \mathrm{Mo}$ phase increased with aging time, as shown in Fig. 4.4. Also, at other aging temperatures $\left(700^{\circ} \mathrm{C}, 750^{\circ} \mathrm{C}, 800^{\circ} \mathrm{C}\right.$, and $\left.850^{\circ} \mathrm{C}\right) \alpha-\mathrm{Ni}$ and $\gamma-\mathrm{Ni}_{3} \mathrm{Mo}$ phases were observed, 
it was noted that the amount of the $\gamma-\mathrm{Ni}_{3} \mathrm{Mo}$ phase increased with aging time. Aging at these temperatures for $25 \mathrm{~h}$ was not sufficient to form $100 \% \gamma-\mathrm{Ni}_{3} \mathrm{Mo}$ phase. It was reported that $\gamma$ $\mathrm{Ni}_{3} \mathrm{Mo}$ phase was formed at $860^{\circ} \mathrm{C}$ after $550 \mathrm{~h}[49]$. The $\gamma-\mathrm{Ni}_{3} \mathrm{Mo}$ phase possibly was more stable and formed early at a low temperature, e. g. $600^{\circ} \mathrm{C}$.

At $900^{\circ} \mathrm{C}$, besides the solid-solution phase, the intermetallic $\delta$-NiMo was detected up to $2 \mathrm{~h}$, and the solid-solution $\alpha-\mathrm{Ni}$ was detected as the dominant phase after $25 \mathrm{~h}$ (Fig. 4.5). Small precipitated particles within and along the grain boundaries were observed as seen in Figs 4.10a and $\mathrm{b}$. A cellular structure at some grain boundaries connections was also observed after $2 \mathrm{~h}$ as seen in Fig. 4.10c. After 25h, a basket weave like structure and continuously precipitated particles along the grain boundaries were observed (Fig. 4.10d). XRD data showed that solidsolution $\alpha-\mathrm{Ni}$ was the dominant phase after $25 \mathrm{~h}$. The solid-solution peaks (111) and (200) shifted to the higher angles with aging time. That was due to the depletion of Mo from the solid-solution $\alpha-\mathrm{Ni}$, which indicated that phase transformations were happing. This was also happened at other aging temperatures as seen in Fig. 4.6. Not all the observed phase can be detected by XRD because sometimes the detector did not pick up all the diffracted rays. Also, the samples were not homogeneous that could be due to the samples preparation method. The samples were coldcompacted using an uniaxial press that sometimes led to non-uniform densities, where the sample's surfaces were denser than the core [72]. That somehow affected the homogeneity of the phase transformation in the samples. This was noticed even at the other aging temperatures. However, the formation of $\delta$-NiMo at $900^{\circ} \mathrm{C}$ below the peritectoid temperature $\left(910^{\circ} \mathrm{C}\right)$ could be due to the impurities in the alloy, which led to lower the formation temperature of $\delta$-NiMo phase.

The hardness increased with aging time and overaging occured as seen in Fig. 4.11. It was reported that the ordering to $\mathrm{Ni}_{2} \mathrm{Mo}$ could increase the mechanical strength of Ni-Mo alloys 
[57]. This may explain the increase in hardness at the early stage of aging while ordering to $\gamma$ $\mathrm{Ni}_{3} \mathrm{Mo}$ led to decreasing the hardness. This was seen at samples aged at $600^{\circ} \mathrm{C}$ when the hardness increased and peaked with the complete formation of $\gamma-\mathrm{Ni}_{3} \mathrm{Mo}$ after $100 \mathrm{~h}$. Samples aged at $900^{\circ} \mathrm{C}$ were expected to be harder than others due to the formation of $\delta$-NiMo phase, but that did not happen. This could be because of the grain growth and particles coarsening.

\subsection{Summary}

Microstructural evolution in bulk supersaturated $\mathrm{Ni}-25 \mathrm{at} . \%$ Mo during aging between $600^{\circ} \mathrm{C}-900^{\circ} \mathrm{C}$ and the related hardness were studied. Transforming to the equilibrium $\gamma-\mathrm{Ni}_{3} \mathrm{Mo}$ phase usually began with the formation of the metastable phase $\mathrm{Ni}_{2} \mathrm{Mo}$ and $\beta-\mathrm{Ni}_{4} \mathrm{Mo}$. The equilibrium $\gamma-\mathrm{Ni}_{3} \mathrm{Mo}$ formed at $600^{\circ} \mathrm{C}$ after $100 \mathrm{~h}$, which nucleated at the grain boundaries of $\alpha$ $\mathrm{Ni}$ and then grew with aging time. The results were in agreement with Mishra et al. [56] and Martin et al. [73]. At aging temperatures up to $850^{\circ} \mathrm{C}$ for up to $25 \mathrm{~h}$ the phase transformation was a mixture of $\gamma-\mathrm{Ni}_{3} \mathrm{Mo}$ and $\alpha-\mathrm{Ni}$. Aging for $25 \mathrm{~h}$ was not sufficient to be completely transformed into $100 \% \gamma-\mathrm{Ni}_{3} \mathrm{Mo}$ phase. The formation of the intermetallic $\delta$-NiMo phase was observed only at $900^{\circ} \mathrm{C}$ as cellular and basket-like structures. Schematic diagram of phase transformation of Ni25at.\% Mo alloy during aging between $600^{\circ} \mathrm{C}-900^{\circ} \mathrm{C}$ and different aging times is shown in Fig. 4.12. The nature of the aging resulted in similar properties to the traditional aging, in the sense that hardness increased with time, and overaging was observed to take place. At an aging temperature of $600^{\circ} \mathrm{C}$ hardness increased and peaked with the complete formation of $\gamma-\mathrm{Ni}_{3} \mathrm{Mo}$ phase. A Vickers' hardness of $880 \mathrm{Kg} / \mathrm{mm}^{2}$ was reached for the samples aged at $800^{\circ} \mathrm{C}$ for $1 \mathrm{~h}$ and then decreases to $800 \mathrm{Kg} / \mathrm{mm}^{2}$ with aging time. Forming $\delta$-NiMo phase at $900^{\circ} \mathrm{C}$ did not 
increase the hardness as expected which could have been due to the grain growth and particle coarsening. 


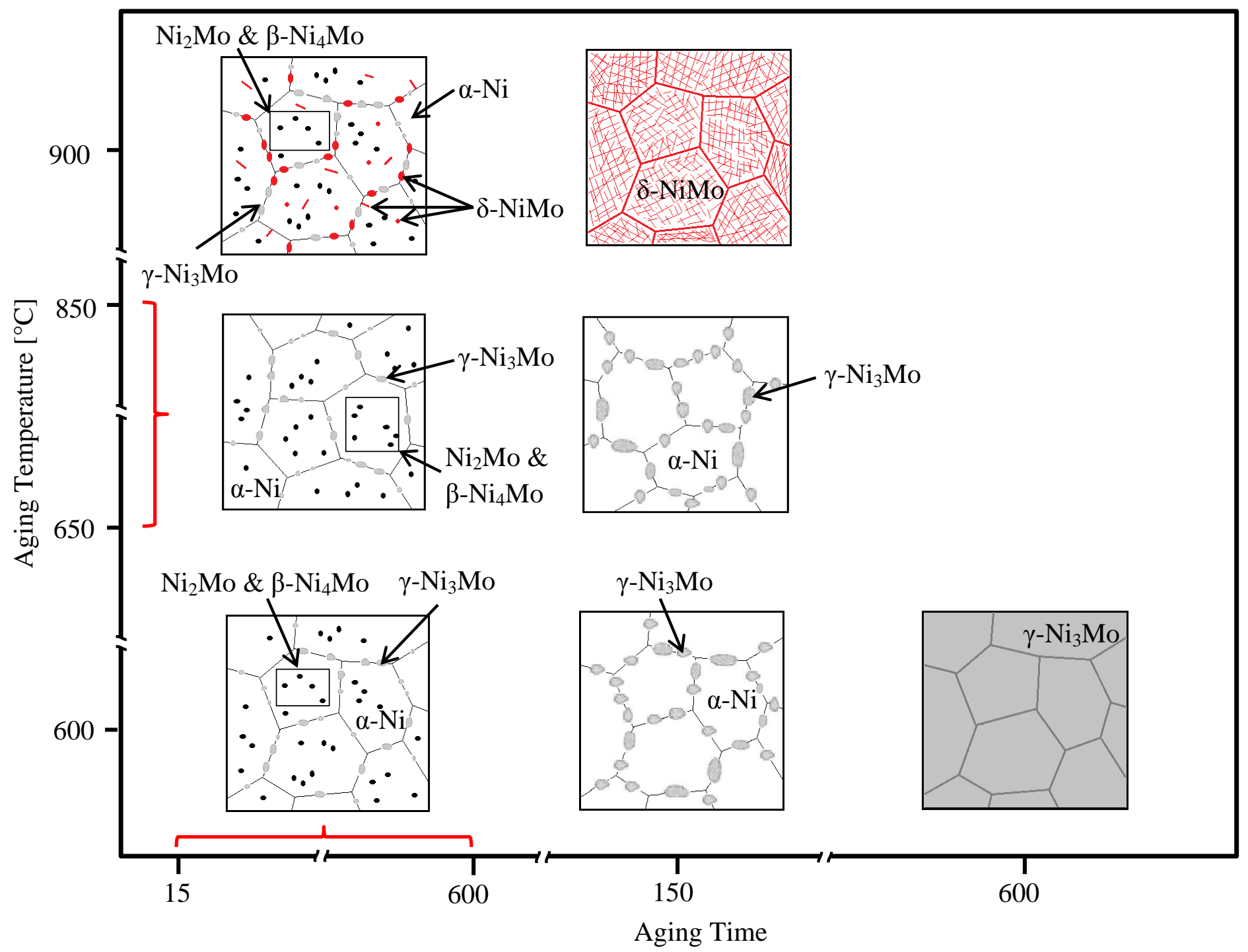

Figure 4.12 Schematic diagram summarizing the phase transformation of Ni-25at.\%Mo alloy during aging between $600^{\circ} \mathrm{C}-900^{\circ} \mathrm{C}(\mathrm{y}-\mathrm{axis})$ and different aging times (x-axis). 
Chapter Five

\section{Reverse Peritectoid Phase Transformation in $\mathrm{Ni}_{3} \mathrm{Mo}$ Alloy}

\subsection{Abstract}

The microstructural evolution and microhardness of the product of the reverse peritectoid reaction in $\mathrm{Ni}_{3} \mathrm{Mo}$ alloy were studied. High-energy ball milling was used to produce a partially alloyed elemental nickel and molybdenum of $\mathrm{Ni}_{3} \mathrm{Mo}$ composition, cold-compacted and then sintered/solutionized at $1300^{\circ} \mathrm{C}$ for $100 \mathrm{~h}$ and quenched. The equilibrium $\gamma-\mathrm{Ni}_{3} \mathrm{Mo}$ was formed isothermally at $600^{\circ} \mathrm{C}$. The reverse peritectoid transformation was performed between $910^{\circ} \mathrm{C}$ and $1050^{\circ} \mathrm{C}$ for up to $10 \mathrm{~h}$. Structural and morphological characterization of the milled powder, sintered and heat-treated samples were performed using XRD, optical and scanning microscopes. Hardness values increased quickly initially to as high as twice that of the transforming $\gamma-\mathrm{Ni}_{3} \mathrm{Mo}$ intermetallic at $910^{\circ} \mathrm{C}$ but then decreased gradually with both transformation temperatures and times.

\subsection{Introduction}

Microstructural design in alloys usually involves cooling the alloy from a single phase region to a multiple phase region, a typical example being the heat treatment of steel. It is not common to heat up an alloy from a single phase region to a multiple phase region at a higher temperature to design its microstructure. This work reports on microstructural evolution during reverse peritectoid transformation in the Ni-Mo alloy system and their corresponding mechanical properties. Here, the reaction is given by $\gamma-\mathrm{Ni}_{3} \mathrm{Mo} \rightarrow \alpha-\mathrm{Ni}+\delta$-NiMo. The mechanical alloying

process, cold compaction, and sintering were used to prepare bulk samples of the intermetallic, $\gamma-\mathrm{Ni}_{3} \mathrm{Mo}$, and this has already been reported [67]. In that work supersaturated Ni-25at.\%Mo alloy transformed to $\gamma-\mathrm{Ni}_{3} \mathrm{Mo}$ below the peritectoid temperature. XRD profiles showed that the 
solid solution $\alpha-\mathrm{Ni}$ sequentially transformed to $\mathrm{Ni}_{2} \mathrm{Mo}, \beta-\mathrm{Ni}_{4} \mathrm{Mo}$ and then $\gamma-\mathrm{Ni}_{3} \mathrm{Mo}$ upon prolonged aging. While there have been some studies on the structural development of $\gamma-\mathrm{Ni}_{3} \mathrm{Mo}$ $[50,54,55,67]$ and $\beta-\mathrm{Ni}_{4} \mathrm{Mo}[30,74,75]$ from $\alpha-\mathrm{Ni}$ solid solution and $\delta$-NiMo [76-78], the development of $\alpha-\mathrm{Ni}+\delta$-NiMo structure is not well known. This study, thereby, reports the study of the microstructural evolution and the related properties resulting from the transformation of $\gamma-\mathrm{Ni}_{3} \mathrm{Mo}$ to $\alpha-\mathrm{Ni}+\delta-\mathrm{NiMo}$.

\subsection{Experimental Procedures}

An elemental blend of Ni-25at.\%Mo was mechanically alloyed by milling in a tungsten carbide medium in a SPEX 8000M Mixer/Mill® for 10h, pressed at $550 \mathrm{MPa}$ into discs of 19 $\mathrm{mm}$ in diameter and $4 \mathrm{~mm}$ thick using an uniaxial steel mold. The pressed samples were sintered/homogenized in a tube furnace at $1300^{\circ} \mathrm{C}$ for $25 \mathrm{~h}$. The cold compaction and the sintering routines were repeated for a total of $100 \mathrm{~h}$ sintering followed by quenching. One $\mathrm{mm}$ thick sample slices were heat-treated in a salt bath at $600^{\circ} \mathrm{C}$ for $100 \mathrm{~h}$ and then quenched, to form the equilibrium $\gamma-\mathrm{Ni}_{3}$ Mo phase. The reverse peritectoid transformations were performed with the $\gamma-\mathrm{Ni}_{3} \mathrm{Mo}$ samples in salt baths between $910^{\circ} \mathrm{C}$ and $1050^{\circ} \mathrm{C}$ for up to $10 \mathrm{~h}$ followed by quenching. Fig. 5.1 illustrates the sample preparation steps (1,2, and 3) and heat-treatment step (4). Heattreated samples were characterized using X-ray diffraction, optical and scanning electron microscopes (SEM). Vickers microhardness values were obtained for all samples using LECO DM-400 at $100 \mathrm{gf}$ for 5 seconds. 


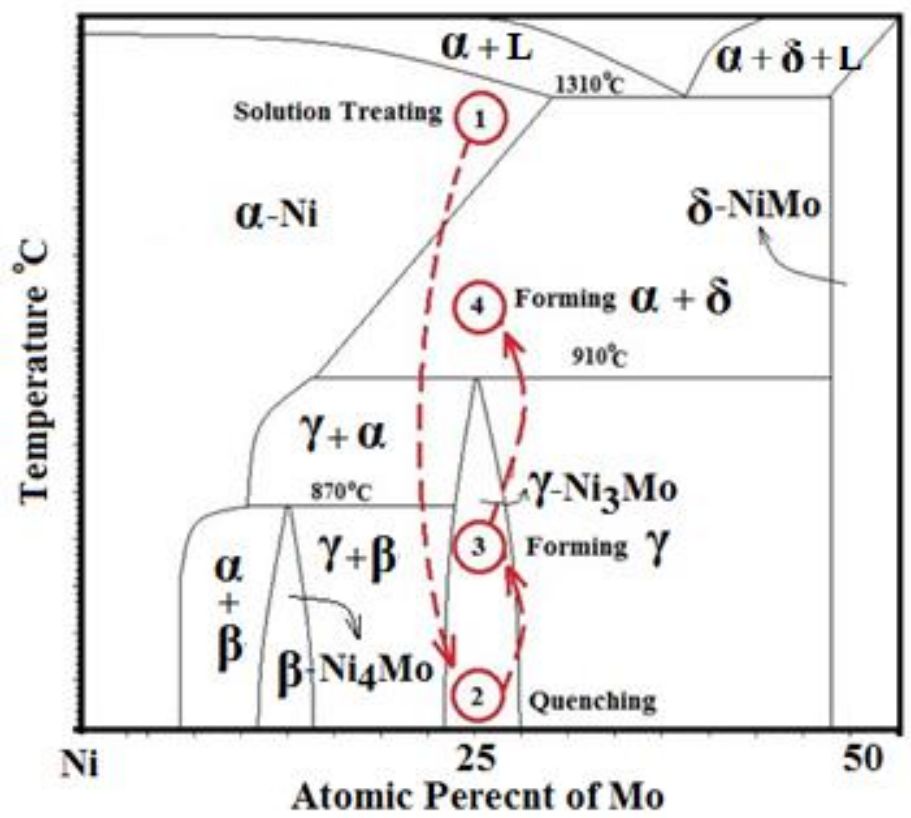

Figure 5.1 Partial phase diagram of Ni-Mo system with the heat-treatment steps: (1) sintering/solutionized at $1300^{\circ} \mathrm{C}$ for total $100 \mathrm{~h}$; (2) quenching; (3) aging at $600^{\circ} \mathrm{C}$ for $100 \mathrm{~h}$ followed by quenching; (4) heattreatment to $\alpha-\mathrm{Ni}-\delta$-NiMo followed by quenching.

\subsection{Results}

The XRD profiles of sample preparation (milling, cold-compaction, and sintering) and heat-treatment (the formation of the equilibrium $\gamma-\mathrm{Ni}_{3} \mathrm{Mo}$ ) are shown in Figs. 4.2 and 4.3, respectively. Fig. 5.2 shows the XRD profiles of heat-treated samples at $910^{\circ} \mathrm{C}$ from 5 min up to 10h. The complete transformation from $\gamma-\mathrm{Ni}_{3} \mathrm{Mo}$ to $\alpha-\mathrm{Ni}$ was observed; the small amount of $\delta$ NiMo present was not picked up in the XRD. The $\gamma-\mathrm{Ni}_{3} \mathrm{Mo}$ peaks were detected in heat-treated samples up to $2 \mathrm{~h}$. XRD for reverse peritectoid transformations at $970^{\circ} \mathrm{C}$ and $1050^{\circ} \mathrm{C}$ are shown in Figs. 5.3 and 5.4, respectively. The transformation sequence was similar to the one at $910^{\circ} \mathrm{C}$ except that this time the $\delta$-NiMo peaks were observed. 


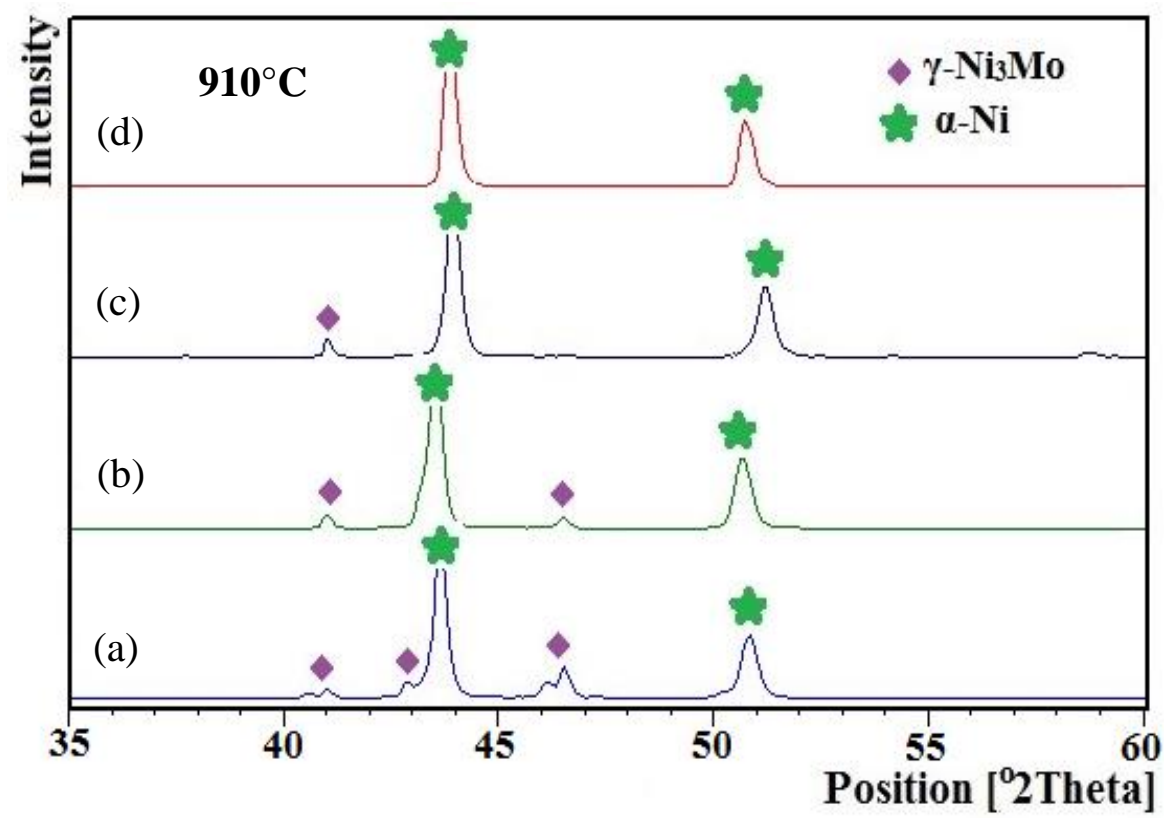

Figure 5.2 XRD patterns of the heat-treated sample at $910^{\circ} \mathrm{C}$ for (a) $5 \mathrm{~min}$, (b) $30 \mathrm{~min}$, (c) $2 \mathrm{~h}$, and (d) $10 \mathrm{~h}$.

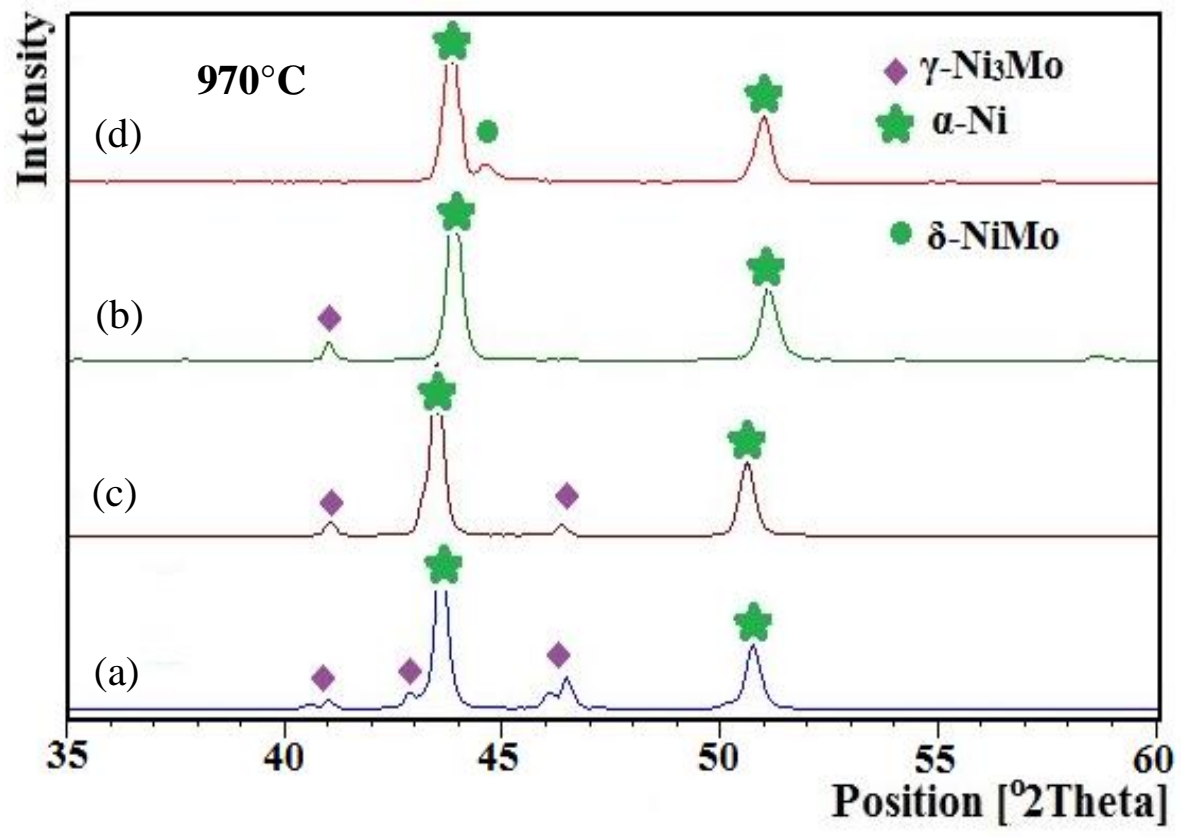

Figure 5.3 XRD patterns of the heat-treated sample at $970^{\circ} \mathrm{C}$ for (a) $5 \mathrm{~min}$, (b) $30 \mathrm{~min}$, (c) $1 \mathrm{~h}$, and (d) $10 \mathrm{~h}$. 


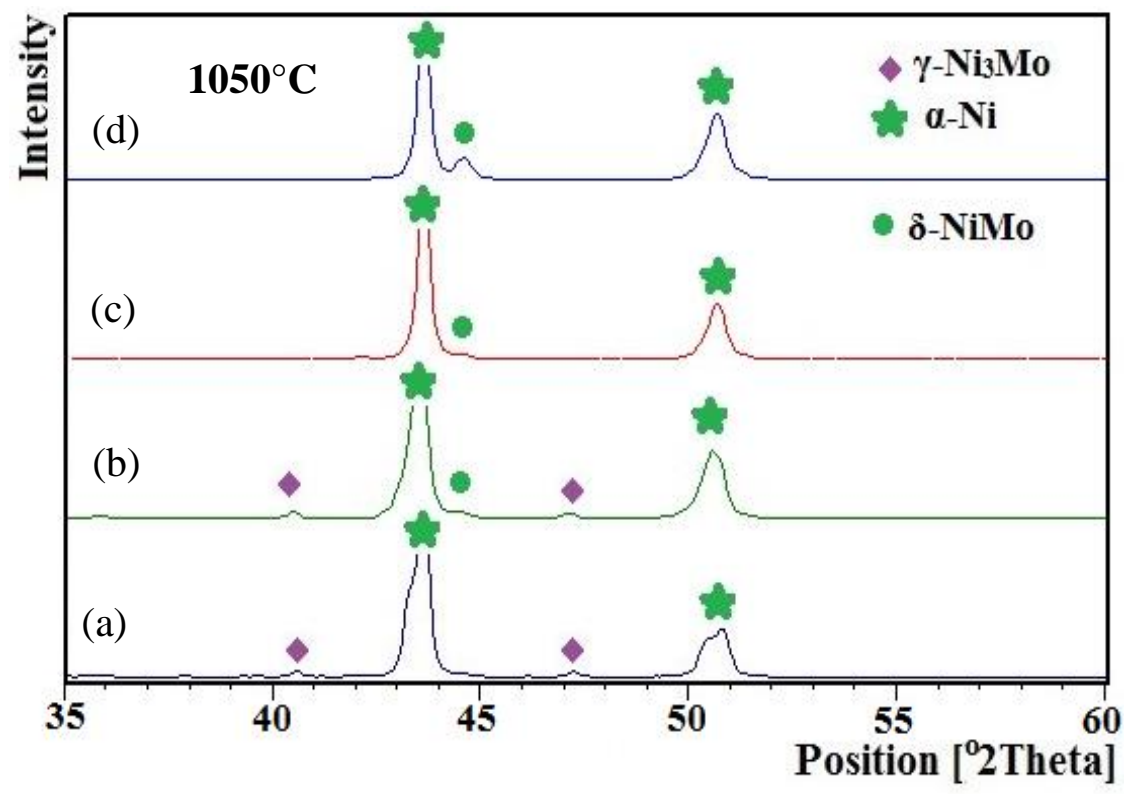

Figure 5.4 XRD patterns of the heat-treated sample at $1050^{\circ} \mathrm{C}$ for (a) $5 \mathrm{~min}$, (b) $30 \mathrm{~min}$, (c) $2 \mathrm{~h}$, and (d) $5 \mathrm{~h}$.

The microstructure of the cold-compacted and sintered sample at $1300^{\circ} \mathrm{C}$ for $100 \mathrm{~h}$ and followed by quenching, i.e., supersaturated solid solution is shown in Fig. 4.7. The microstructure of the equilibrium $\gamma-\mathrm{Ni}_{3} \mathrm{Mo}$, as a result of aging at $600^{\circ} \mathrm{C}$ for $100 \mathrm{~h}$, is shown in Fig. 5.5. The development of $\gamma-\mathrm{Ni}_{3} \mathrm{Mo}$ formed from solid solution $\alpha-\mathrm{Ni}$ was reported on previously [67]. Small precipitated particles of $\delta$-NiMo along and within the grain boundaries of a mixture of $\alpha$-Ni and $\gamma-\mathrm{Ni}_{3} \mathrm{Mo}$ were observed (Fig. 5.6a and b). After 10h, $\delta$-NiMo particles developed into small colonies of a pearlite-like structure in the $\alpha$-Ni matrix as seen in Fig. 5.6c. 


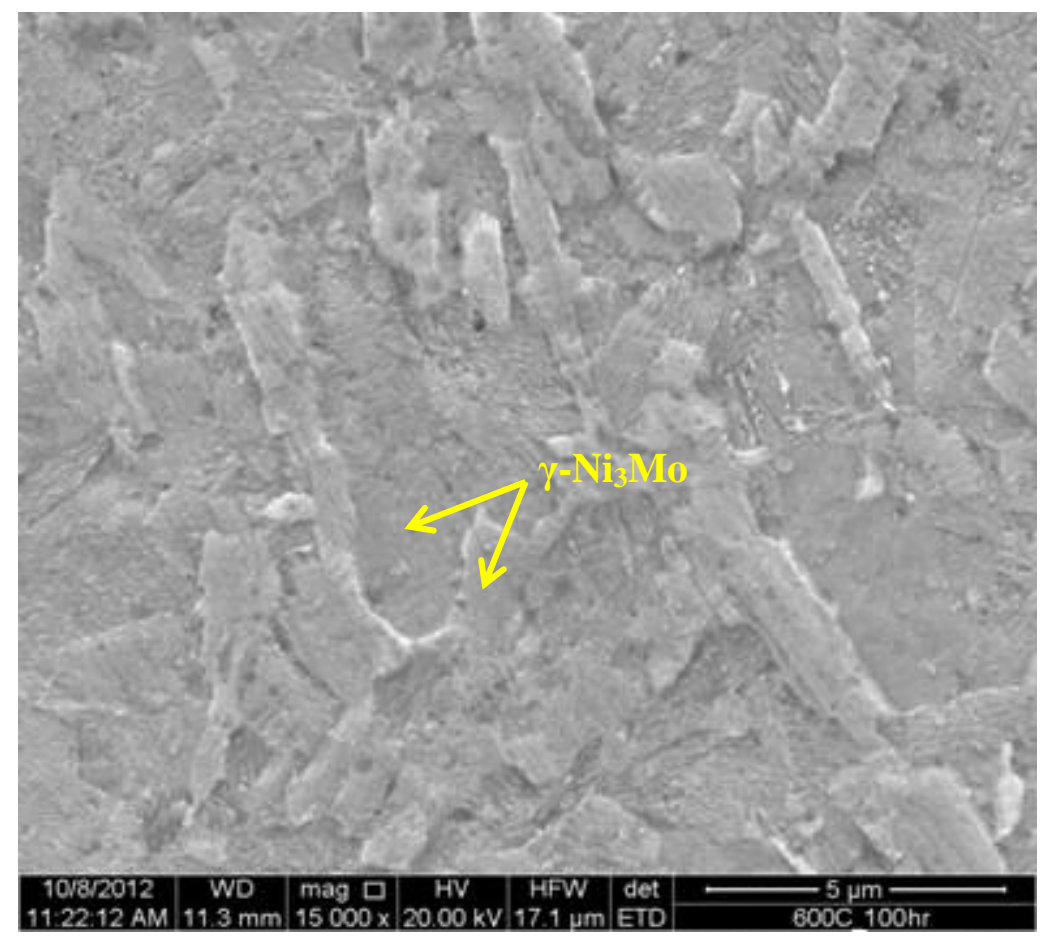

Figure 5.5 SEM micrographs of Ni-25at.\%Mo alloy isothermally aged at $600^{\circ} \mathrm{C}$ for $100 \mathrm{~h}$ consisting of grains of $\gamma-\mathrm{Ni}_{3} \mathrm{Mo}$. The voids are not included in these smaller fields of views. Etchant: $\mathrm{FeCl}_{3} 5 \mathrm{~g}, \mathrm{HCl}$ $100 \mathrm{ml}$, and $10 \mathrm{ml} \mathrm{H}_{2} \mathrm{O}$.

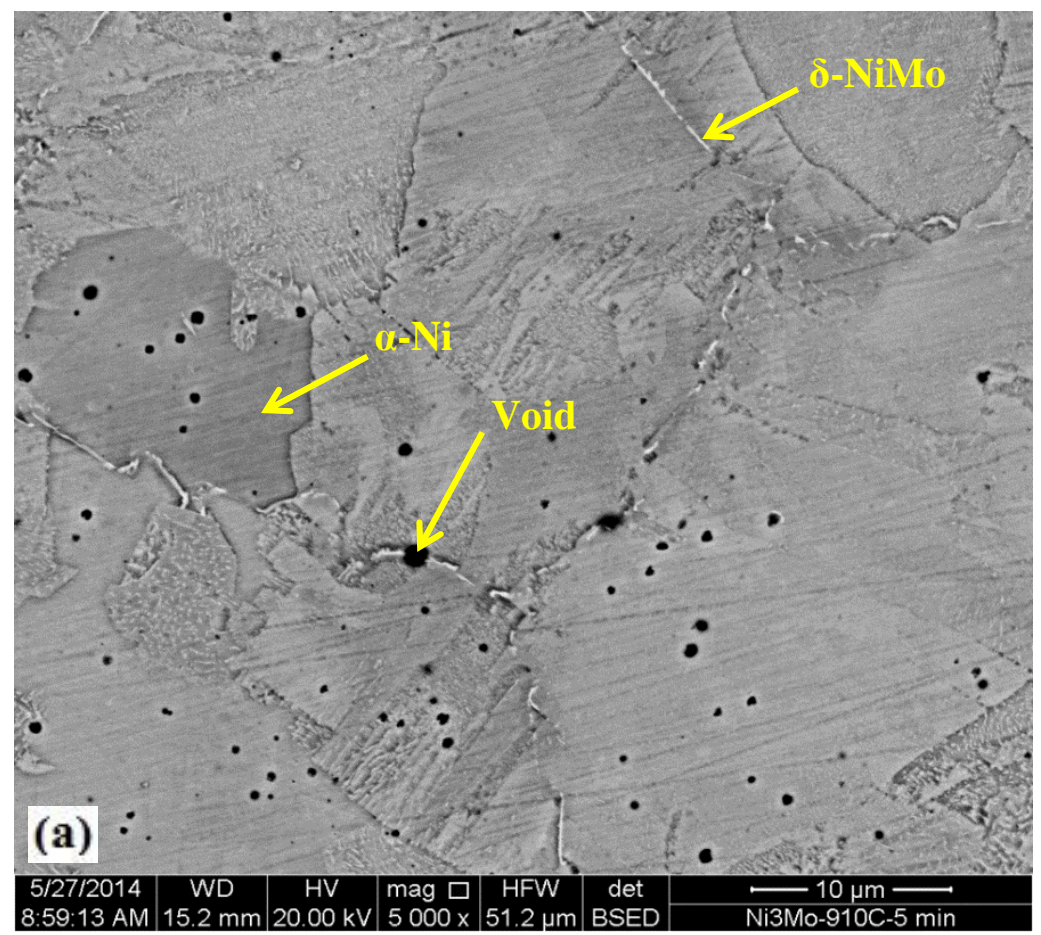



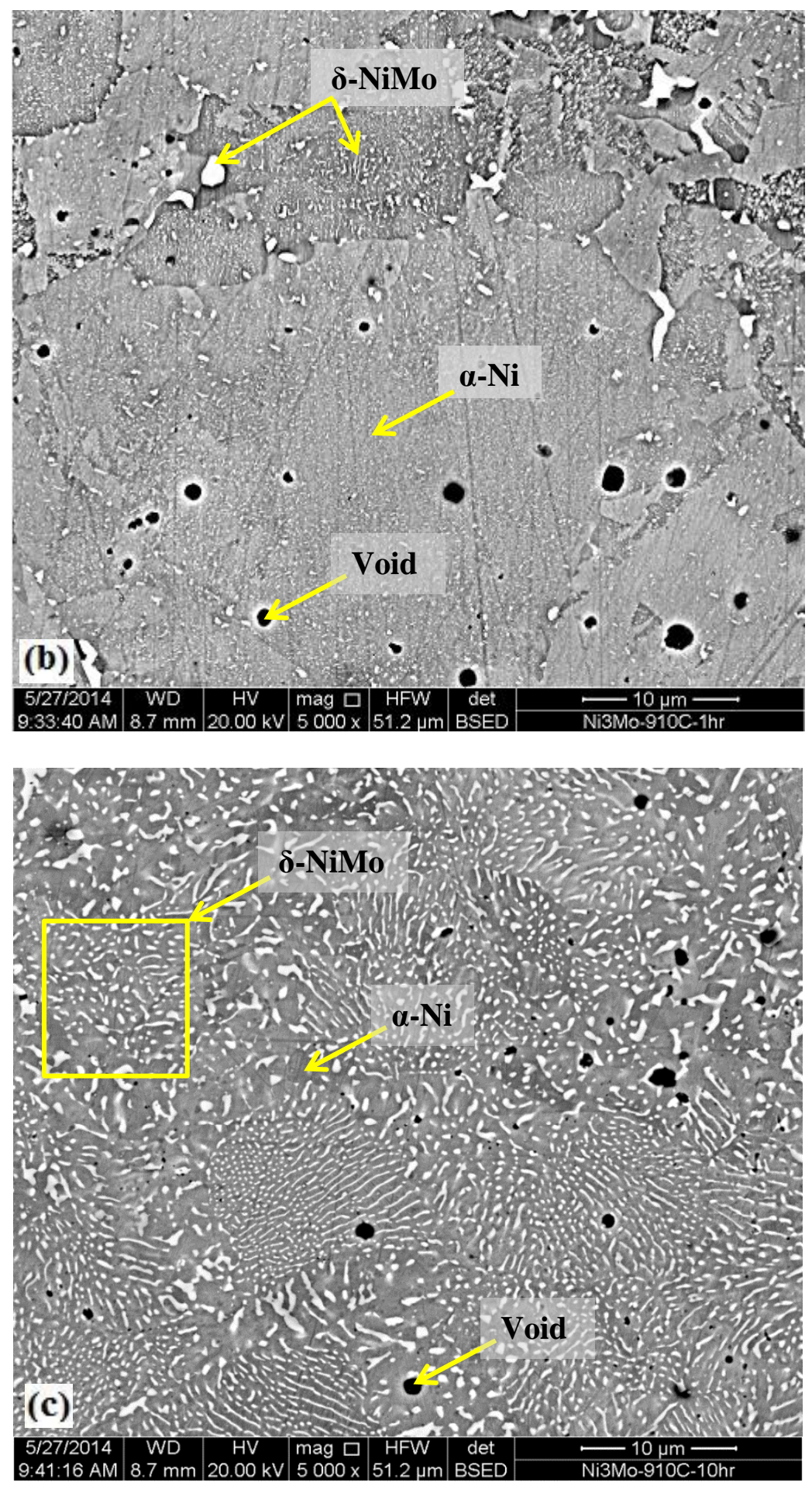

Figure 5.6 SEM micrographs Ni-25at.\%Mo alloy heat-treated at $910^{\circ} \mathrm{C}$ for: (a) $5 \mathrm{~min}$, (b) $1 \mathrm{~h}$, and (c) $10 \mathrm{~h}$. These micrographs are consisting of precipitated particles of $\delta$-NiMo (white) in the $\alpha$-Ni matrix (gray). Black reigns are voids. Etchant: $\mathrm{FeCl}_{3} 5 \mathrm{~g}, \mathrm{HCl} 100 \mathrm{ml}$, and $10 \mathrm{ml} \mathrm{H}_{2} \mathrm{O}$. 
Selected SEM micrographs of samples heat-treated at $970^{\circ} \mathrm{C}$ for $5 \mathrm{~min}, 30 \mathrm{~min}, 2 \mathrm{~h}$ and 10h are shown in Fig. 5.7. The microstructures in Fig. 5.7 show that the precipitation took place at both the grain boundaries and inside the grains and they did coarsen with time. As demonstrated in the XRD profiles, the $\alpha$-Ni phase formed first followed by the precipitation of $\delta$ NiMo. Some regions showed a network of interconnected high aspect ratio particles of $\delta$-NiMo (Fig. 5.7c), but the connectivity disappeared with coarsening as seen in Fig. 5.7d.

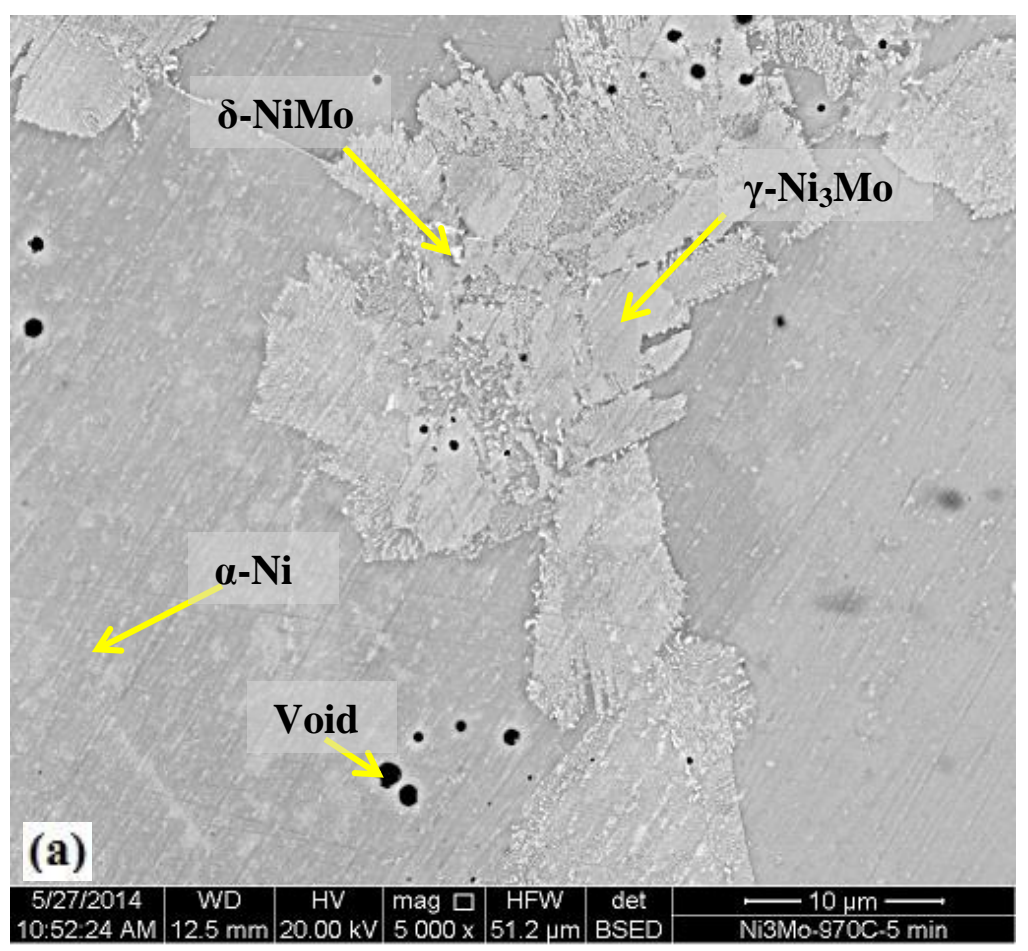



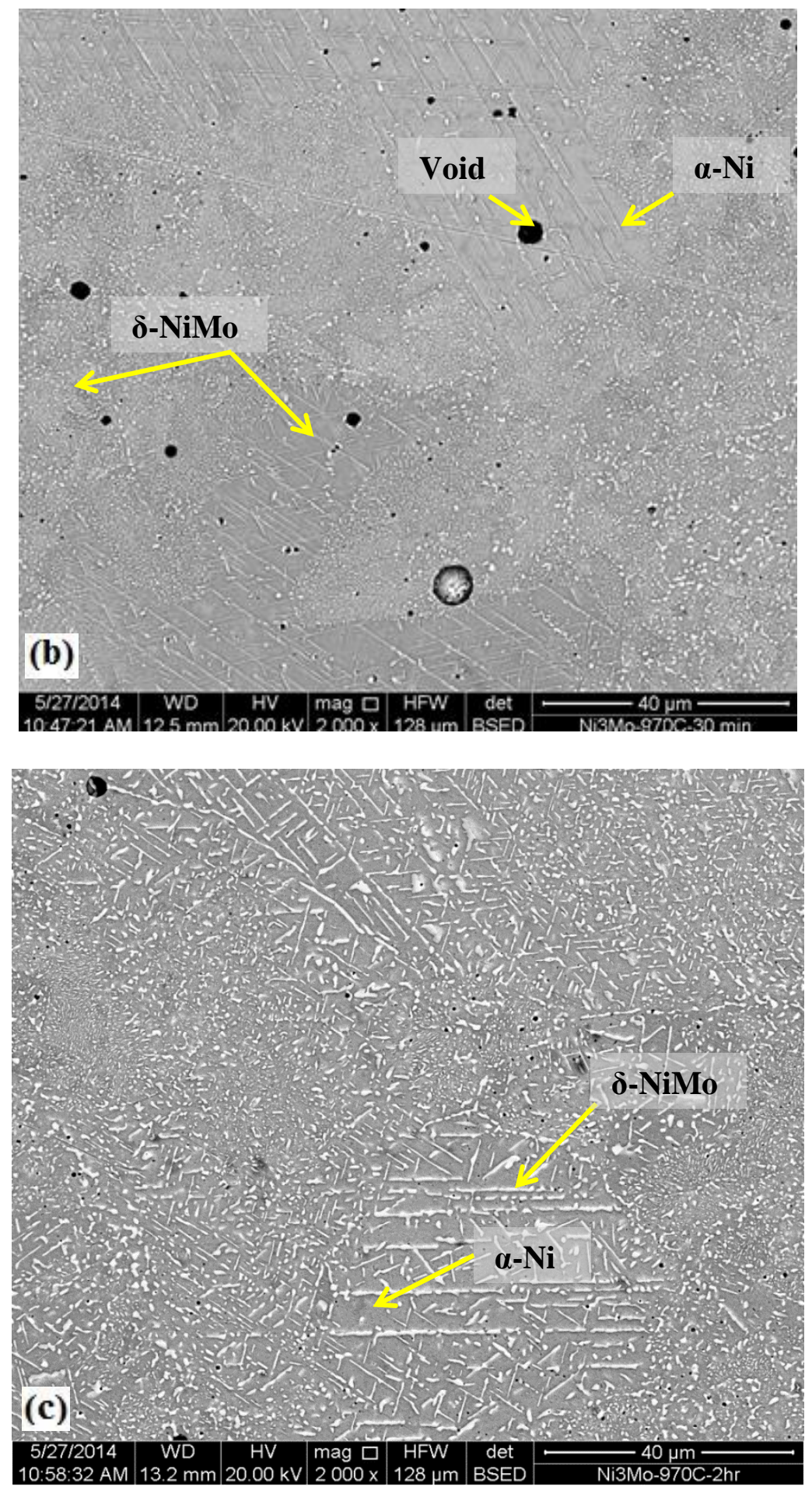


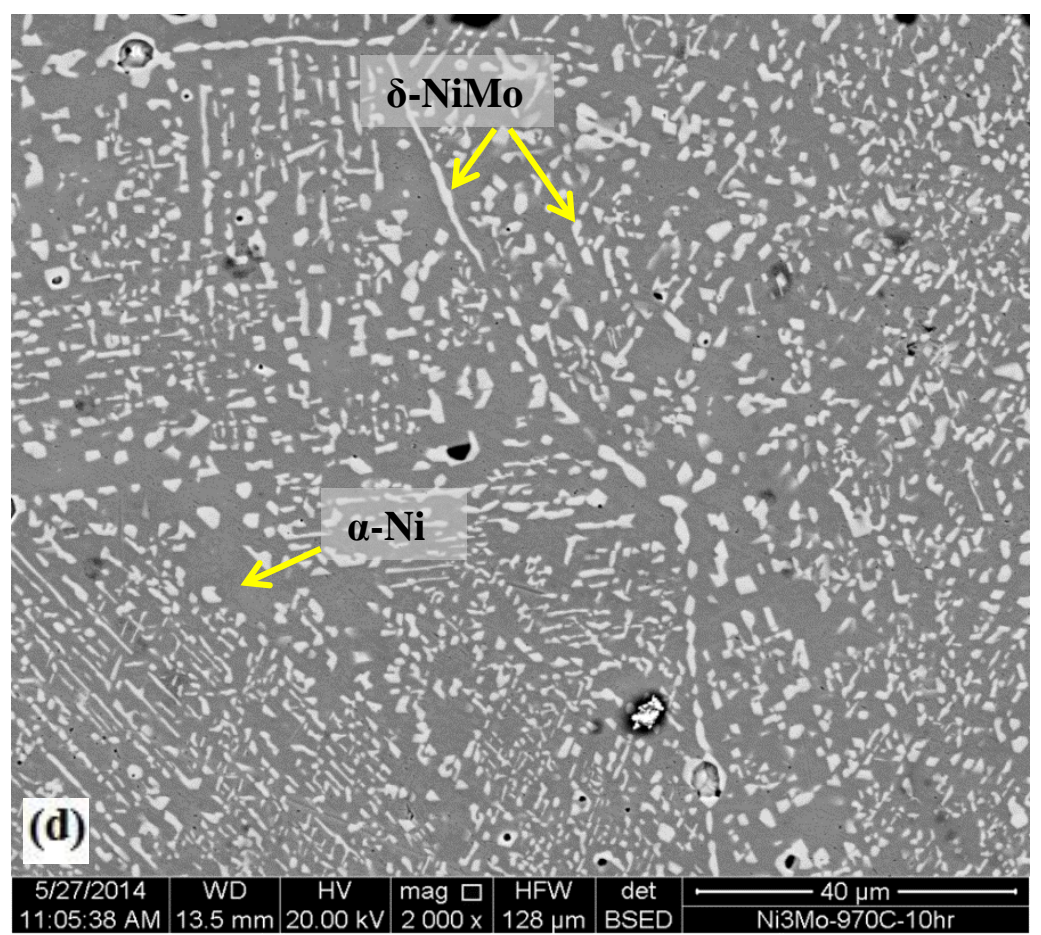

Figure 5.7 SEM micrographs of Ni-25at.\%Mo alloy heat-treated at $970^{\circ} \mathrm{C}$ for (a) $5 \mathrm{~min}$, (b) $30 \mathrm{~min}$, (c) $2 \mathrm{~h}$, and (d) $10 \mathrm{~h}$. These micrographs are showing the development of the precipitation of $\delta$-NiMo (white) along and within the grain boundaries of $\alpha-\mathrm{Ni}$ (gray). All black regions are voids. Etchant: $\mathrm{FeCl}_{3} 5 \mathrm{~g}, \mathrm{HCl}$ $100 \mathrm{ml}$, and $10 \mathrm{ml} \mathrm{H}_{2} \mathrm{O}$.

Fig. 5.8 shows microstructures at a transformation temperature of $1050^{\circ} \mathrm{C}$. In this case, the precipitate formed has a peanut-like shape and also coarsened with time. These evolutions affected the mechanical properties of the alloy as revealed in Fig. 5.9. The Vickers microhardness value for all heat-treated samples raised very quickly from $468 \mathrm{Kg} / \mathrm{mm}^{2}$ for the transforming $\gamma-\mathrm{Ni}_{3} \mathrm{Mo}$ intermetallic in five minutes to as high as about $907 \mathrm{Kg} / \mathrm{mm}^{2}$ for the sample which transformed at the lowest temperature of $910^{\circ} \mathrm{C}$. Overall, the hardness decreased with heat-treatment temperature as well as time. 

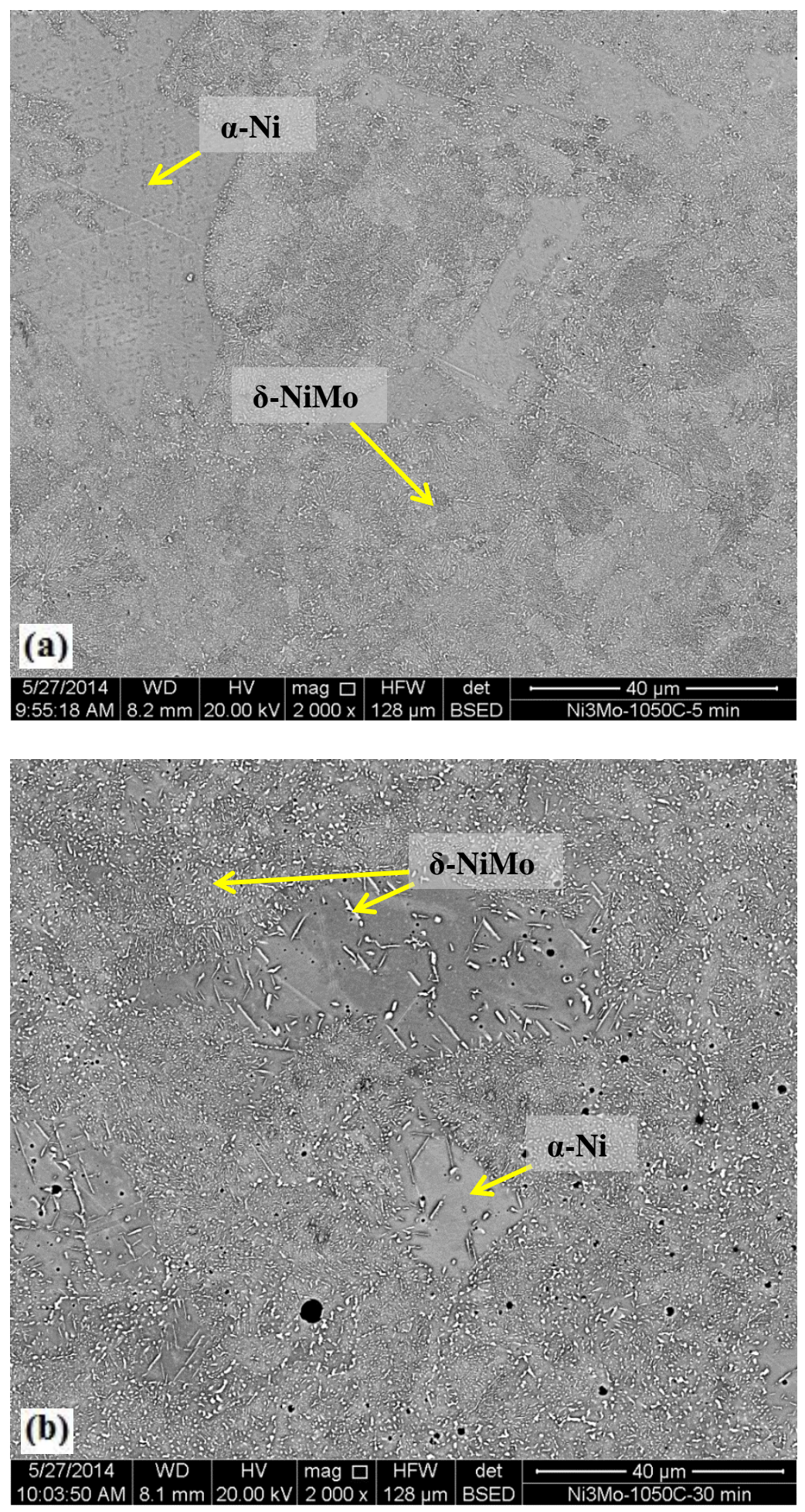

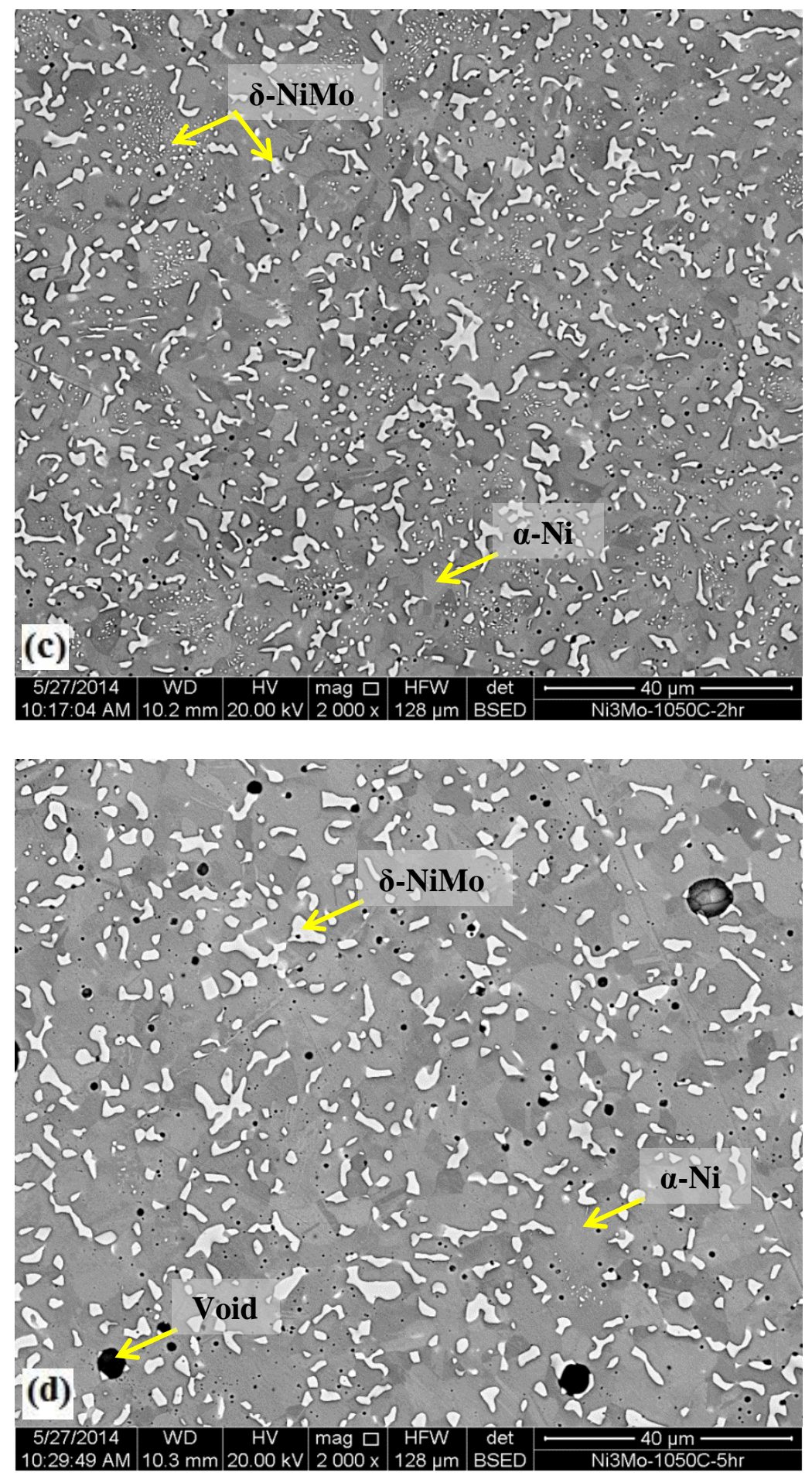

Figure 5.8 SEM micrographs of heat-treated specimens at $1050^{\circ} \mathrm{C}$ for (a) $5 \mathrm{~min}$, (b) $30 \mathrm{~min}$, (c) $2 \mathrm{~h}$, and (d) $5 \mathrm{~h}$. These micrographs are showing precipitated particles of $\delta$-NiMo (white) in an $\alpha$ $\mathrm{Ni}$ matrix (gray). Black regions are voids. Etchant: $\mathrm{FeCl}_{3} 5 \mathrm{~g}, \mathrm{HCl} 100 \mathrm{ml}$, and $10 \mathrm{ml} \mathrm{H}_{2} \mathrm{O}$. 


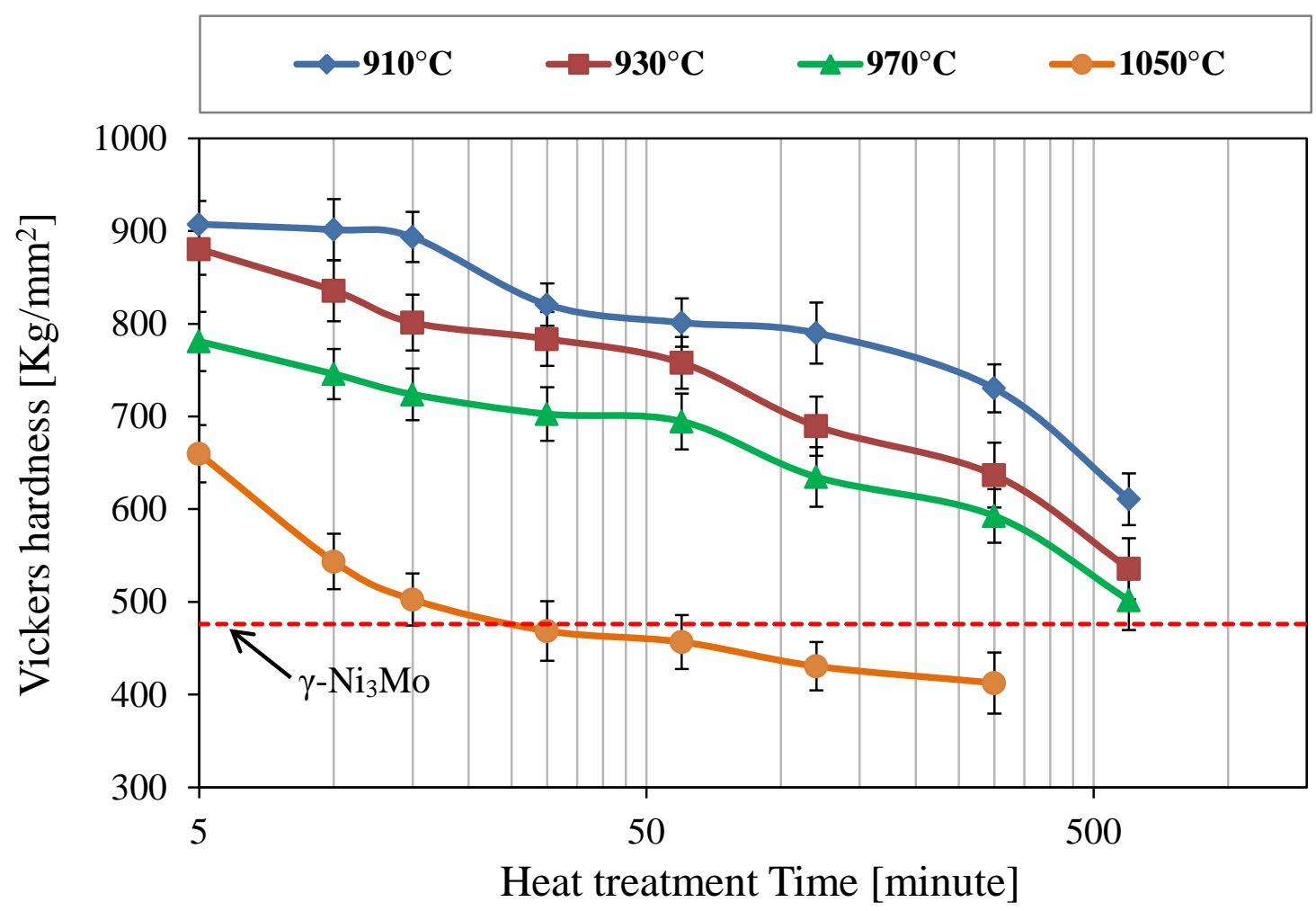

Figure 5.9 Microhardness of heat-treated samples plotted against heat-treatment time.

\subsection{Discussion}

The XRD patterns of the sample preparation and the formation of the equilibrium $\gamma-\mathrm{Ni}_{3} \mathrm{M}$ were discussed in Section 4.5. The $\delta$-NiMo phase was not detected at $910^{\circ} \mathrm{C}$ that could be because of the small volume fraction present. The solid-solution $\alpha$-Ni peaks shifted to the higher angles after $2 \mathrm{~h}$ at $910^{\circ} \mathrm{C}$ was evidence that the Mo concentration in $\alpha-\mathrm{Ni}$ was decreasing, and enhanced the formation of the $\delta$-NiMo phase. The microstructural development at $910^{\circ} \mathrm{C}$ is shown in Fig. 5.6a-c. The $\alpha$-Ni phase formed first then the $\delta$-NiMo started to precipitate along and within the grain boundaries of $\alpha-\mathrm{Ni}$. After $10 \mathrm{~h}$ of heat treatment, the microstructure developed into a pearlite-like structure of $\delta$-NiMo in the $\alpha$-Ni matrix as shown in Fig. 5.6c. This microstructural development raised the hardness to as high as about $907 \mathrm{Kg} / \mathrm{mm}^{2}$. 
The $\delta$-NiMo phase was detected at $970^{\circ} \mathrm{C}$, and $1050^{\circ} \mathrm{C}$ and $\alpha$-Ni peaks shifted to the higher angles after $2 \mathrm{~h}$ of heat treatment. At a heat-treatment of $970^{\circ} \mathrm{C}$, the $\delta$-NiMo began to precipitate along the grain boundaries of $\alpha-\mathrm{Ni}$. Upon prolonged heat-treatment, a mixture of fineline up $\delta$-NiMo particle (basket strands) in the $\alpha$-Ni matrix was observed, and it coarsened with time as shown in Fig. $5.7 \mathrm{c}-\mathrm{d}$. The phase transformation at $1050^{\circ} \mathrm{C}$ was similar to the one at $970^{\circ} \mathrm{C}$, except that small and large precipitated particles were revealed, and they did coarsen with time as seen in Fig. 5.8c-d. The lower the transformation temperature the finer the microstructure and the longer the transformation was allowed to proceed, the coarser the microstructure as shown in Figs 5.6 and 5.8. Also, hardness decreased with heat-treatment temperature as microstructure coarsened as seen in Fig. 5.9.

The development of the intermetallic $\delta$-NiMo phase is not understood yet, and there is not enough published data on its structural evolution. D. Schwam et al. [60] reported that in the Ni-47wt. \%Mo alloy, the $\delta$-NiMo phase was formed as intermittent lamella in $\alpha$-Ni solid solution matrix. In the $\alpha-\mathrm{Ni}$ solid-solution matrix $\mathrm{Ni}_{2} \mathrm{Mo}, \beta-\mathrm{Ni}_{4} \mathrm{Mo}$, and $\gamma-\mathrm{Ni}_{3} \mathrm{Mo}$ were observed that made the microstructure of Ni-Mo alloy very complicated. Because of that complexity, most of the studies in the Ni-Mo system have been done using transmission electron microscopy.

\subsection{Summary}

Bulk Ni-25at.\%Mo alloy was prepared using mechanical alloying and powder metallurgy methods. The bulk samples then were aged at $600^{\circ} \mathrm{C}$ for $100 \mathrm{~h}$ to form the equilibrium $\gamma-\mathrm{Ni}_{3} \mathrm{Mo}$ phase. After that, the microstructural evolution and the corresponding microhardness of the product of reverse peritectoid transformation of $\gamma-\mathrm{Ni}_{3} \mathrm{Mo}$ to $\alpha$-Ni and $\delta$-NiMo phases were studied. The reverse peritectoid transformations were performed at temperatures ranging from $910^{\circ} \mathrm{C}$ to $1050^{\circ} \mathrm{C}$ for up to $10 \mathrm{~h}$. The transformation to the $\alpha-\mathrm{Ni}$ phase always occurred first 
followed by the precipitation of the $\delta$-NiMo phase both along and within grain boundaries, with structures ranging from pearlite-like at the lower transformation temperatures to peanut-like at the higher transformation temperatures. Schematic diagram of the phase transformation of Ni25at.\%Mo alloy during heat treatment between $910^{\circ} \mathrm{C}-1050^{\circ} \mathrm{C}$ and different heat treatment times is shown in Fig. 5.10. The microhardness increased very rapidly peaking after five minutes before dropping with heat-treatment time as the microstructure coarsened.

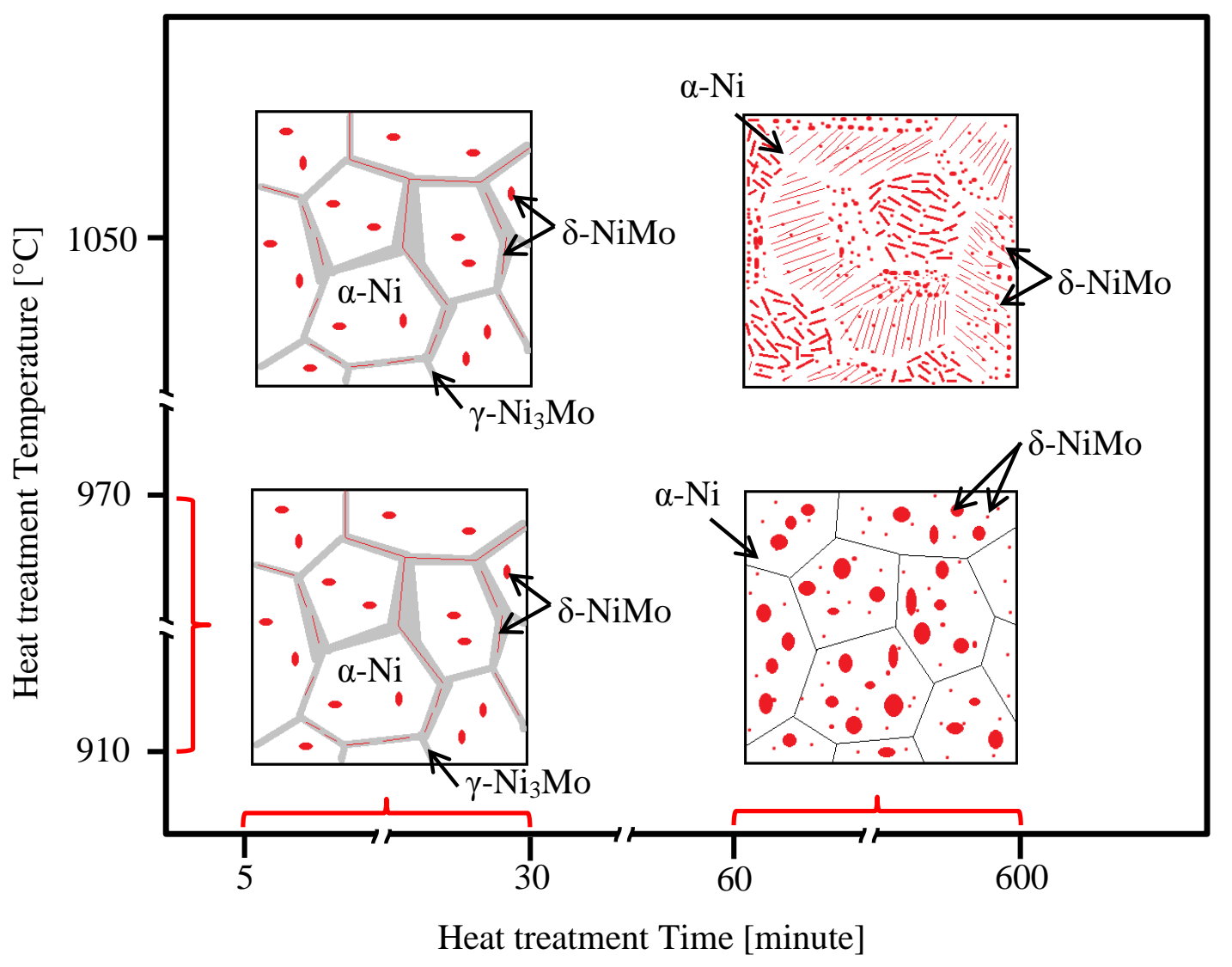

Figure 5.10 Schematic diagram summarizing the phase transformation of $\gamma-\mathrm{Ni}_{3} \mathrm{Mo}$ (Ni-25at.\%Mo alloy) during heat treatment between $910^{\circ} \mathrm{C}-1050^{\circ} \mathrm{C}$ (y-axis) and different heat treatment time (x-axis). 
Chapter Six

\section{Transformation of Supersaturated $\alpha$-Ni Solid Solution in the Peritectoid Two Phase Region}

\subsection{Abstract}

A supersaturated solid solution $(\alpha-\mathrm{Ni})$ of stoichiometric $\mathrm{Ni}_{3} \mathrm{Mo}$ composition was produced using mechanical alloying and powder metallurgy methods and isothermally aged between $910^{\circ} \mathrm{C}$ and $1050^{\circ} \mathrm{C}$ for up to $10 \mathrm{~h}$. Regardless of aging temperature, samples aged for short times exhibited small precipitates of $\delta$-NiMo phase along and within grain boundaries of $\alpha$ Ni phase. The volume of precipitates increased and coarsened with aging temperature and time. Initial hardness was high but dropped with aging time as the precipitated particles coarsened.

\subsection{Introduction}

The nature of the Ni-Mo system phase diagram makes it possible to process a supersaturated alloy out of the peritectoid composition of Ni-25at.\%Mo. This makes it possible for the alloy to be aged in the two-phase high-temperature region above the peritectoid isotherm similar to the traditional aging below the eutectic or eutectoid isotherm. It is of interest to study the microstructural evolution during the aging process and the associated mechanical properties. Bulk samples of the supersaturated alloy were prepared by first mechanically alloying elemental powders of the $\mathrm{Ni}_{3} \mathrm{Mo}$ composition, followed by cold compaction, sintering, and quenching. The processing steps for the alloy are schematically shown in Fig. 6.1 and the details can be found in an earlier report [67]. While there have been some studies on the structural development of $\gamma$ $\mathrm{Ni}_{3} \mathrm{Mo}[50,54,55,67]$ and $\beta-\mathrm{Ni}_{4} \mathrm{Mo}[30,74,75]$ from $\alpha-\mathrm{Ni}$ solid solution and $\delta$-NiMo [76-78], no previous studies were found in the two-phase region. 
The subject of this work was the microstructural evolution and the related microhardness resulting from the transformation of supersaturated solid solution $\alpha-\mathrm{Ni}$ to equilibrium $\alpha-\mathrm{Ni}+\delta$ NiMo.

\subsection{Experimental Procedures}

Reduced elemental blend of Ni-25at.\%Mo was mechanically alloyed for $10 \mathrm{~h}$. The mechanical alloying was carried out in a SPEX 8000M Mixer/Mill@ in a tungsten carbide medium. The milled powders then were cold-compacted and sintered in a tube furnace at $1300^{\circ} \mathrm{C}$ for $25 \mathrm{~h}$. The cold compaction and the sintering routines were repeated for a total of $100 \mathrm{~h}$ sintering followed by quenching (step 1 and 2 in Fig. 6.1). Sintered samples then were cut and isothermally aged in salt baths at temperatures ranging from $910^{\circ} \mathrm{C}$ to $1050^{\circ} \mathrm{C}$ for up to $10 \mathrm{~h}$ (step 3 in Fig. 6.1). X-ray diffraction was performed on samples before and after aging.

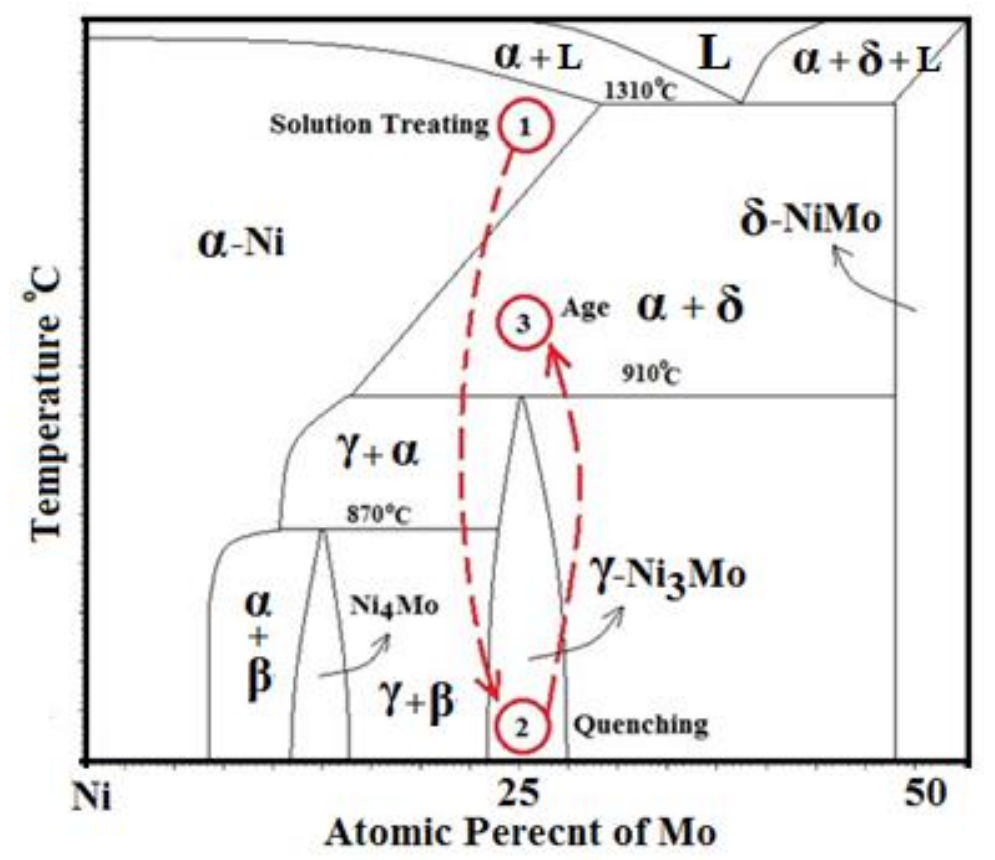

Figure 6.1 Partial phase diagram of Ni-Mo system with the heat-treatment steps: (1) sintering/solutionized at $1300^{\circ} \mathrm{C}$ for total $100 \mathrm{~h}$; (2) quenching; (3) aging at temperatures between $910^{\circ} \mathrm{C}-1050^{\circ} \mathrm{C}$ for up to $10 \mathrm{~h}$ followed by quenching. 
Optical and scanning electron microscopes (SEM) were performed on sintered and aged samples. Vickers microhardness values were measured for all samples using a LECO DM-400 with a 100 gf and 5 second dwell time.

\subsection{Results}

X-ray diffraction profiles of blended Ni-Mo powder, 10h mechanically alloyed powder and sintered bulk samples are shown in Fig. 4.2a-c. Representative XRD profiles of aged samples at $910^{\circ} \mathrm{C}, 970^{\circ} \mathrm{C}$, and $1050^{\circ} \mathrm{C}$ are shown in Figs. 6.2 to 6.4. As expected, the two phases $\alpha-\mathrm{Ni}$ and $\delta$-NiMo were identified with $\alpha-\mathrm{Ni}$ being the dominant phase at all aging temperatures. The $\alpha$-Ni peaks at all heat treatment temperatures were doubled after 5 min of transformation, but disappeared thereafter.

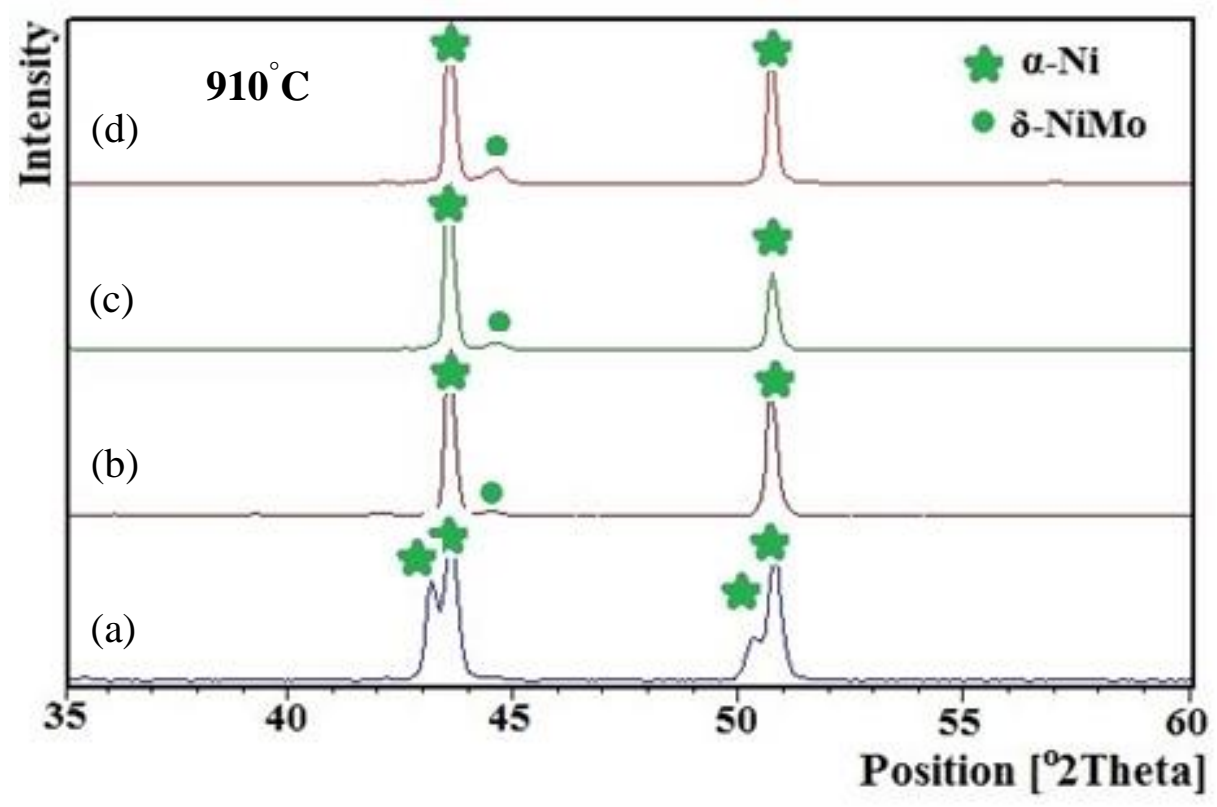

Figure 6.2 XRD patterns of Ni-25at.\%Mo alloy aged at $910^{\circ} \mathrm{C}$ for: (a) $5 \mathrm{~min}$, (b) $30 \mathrm{~min}$, (c) $2 \mathrm{~h}$, and (d) $10 \mathrm{~h}$. 


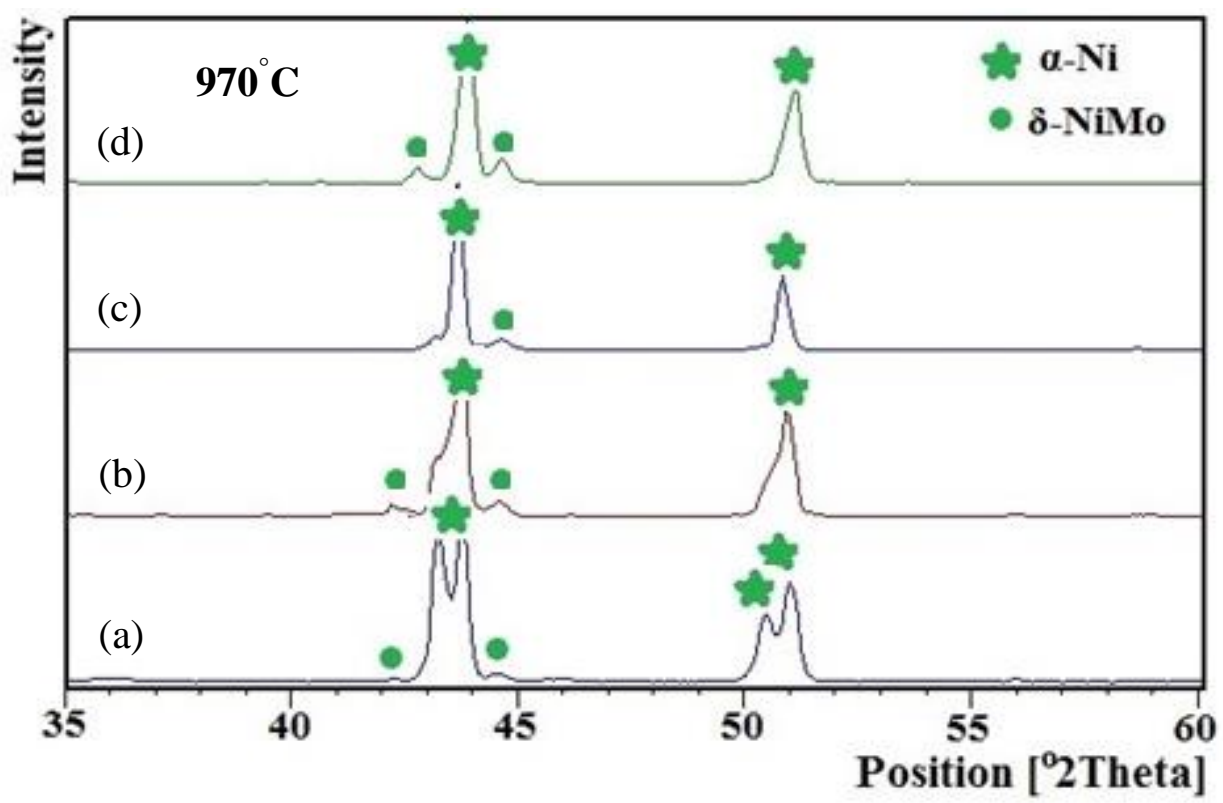

Figure 6.3 XRD patterns of Ni-25at.\%Mo alloy aged at $970^{\circ} \mathrm{C}$ for: (a) $5 \mathrm{~min}$, (b) $30 \mathrm{~min}$, (c) $2 \mathrm{~h}$, and (d) $10 \mathrm{~h}$.

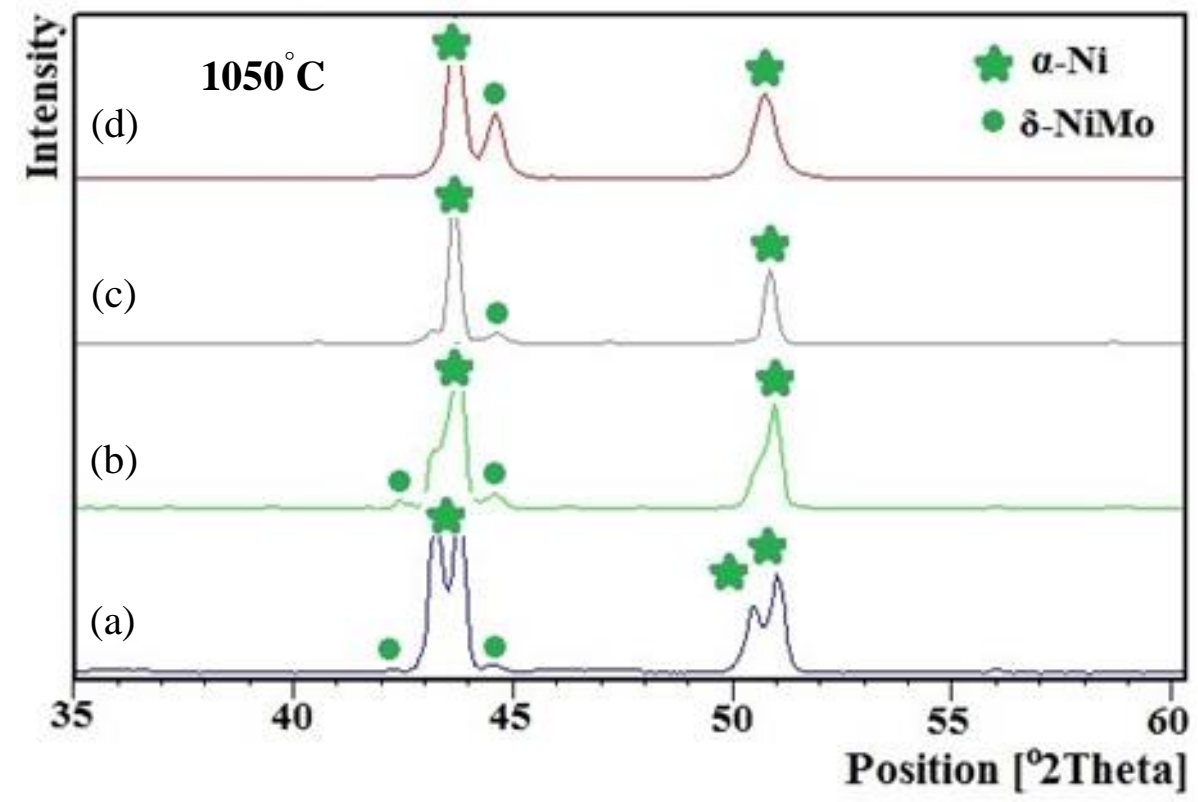

Figure 6.4 XRD patterns of Ni-25at.\%Mo alloy aged at $1050^{\circ} \mathrm{C}$ for: (a) $5 \mathrm{~min}$, (b) $30 \mathrm{~min}$, (c) $2 \mathrm{~h}$, and (d) 5 h. 
The microstructure of the sintered and supersaturated $\alpha-\mathrm{Ni}$ is shown in Fig. 6.5. It had annealing twins and equiaxed grains, nearly $110 \mu \mathrm{m}$ in diameter. Backscattered SEM microstructures for samples aged at $910^{\circ} \mathrm{C}, 970^{\circ} \mathrm{C}$, and $1050^{\circ} \mathrm{C}$ are shown in Figs. 6.6 to 6.8. At $910^{\circ} \mathrm{C}$, the precipitates were difficult to discern after 5 min (Fig. 6.6a). After $2 \mathrm{~h}$, they were still fine but had spread throughout the grains of $\alpha-\mathrm{Ni}$, and then coarsened after $10 \mathrm{~h}$ as seen in Fig.6.6b-c. The microstructural development in samples aged at $970^{\circ} \mathrm{C}$ and $1050^{\circ} \mathrm{C}$ was similar to that at $910^{\circ} \mathrm{C}$, except that coarsening was more rapid.

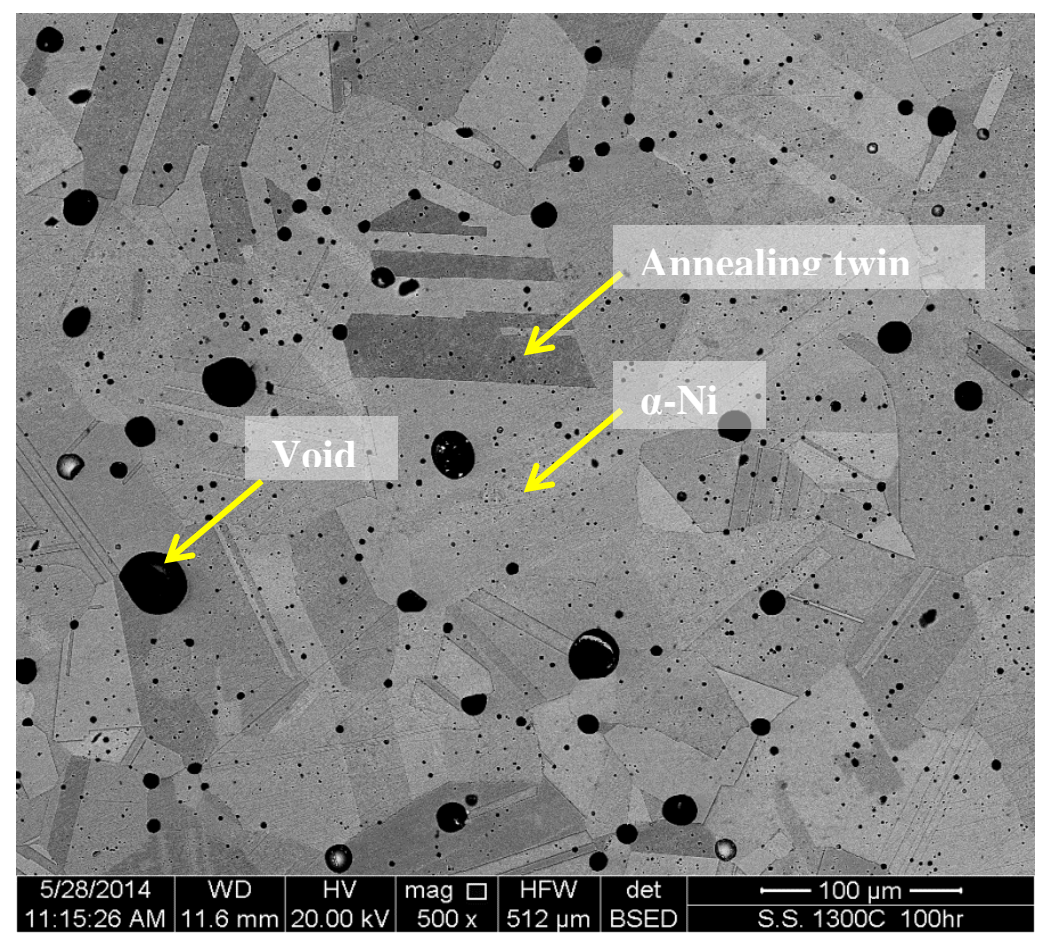

Figure 6.5 SEM micrograph of Ni-25at.\% Mo alloy sintered at $1300^{\circ} \mathrm{C}$ for a total $100 \mathrm{~h}$ followed by quenching consisting of annealing twins and equiaxed grains (the black regions are voids). Etchant: $\mathrm{FeCl}_{3}$ $5 \mathrm{~g}, \mathrm{HCl} 100 \mathrm{ml}$, and $10 \mathrm{ml} \mathrm{H}_{2} \mathrm{O}$. 

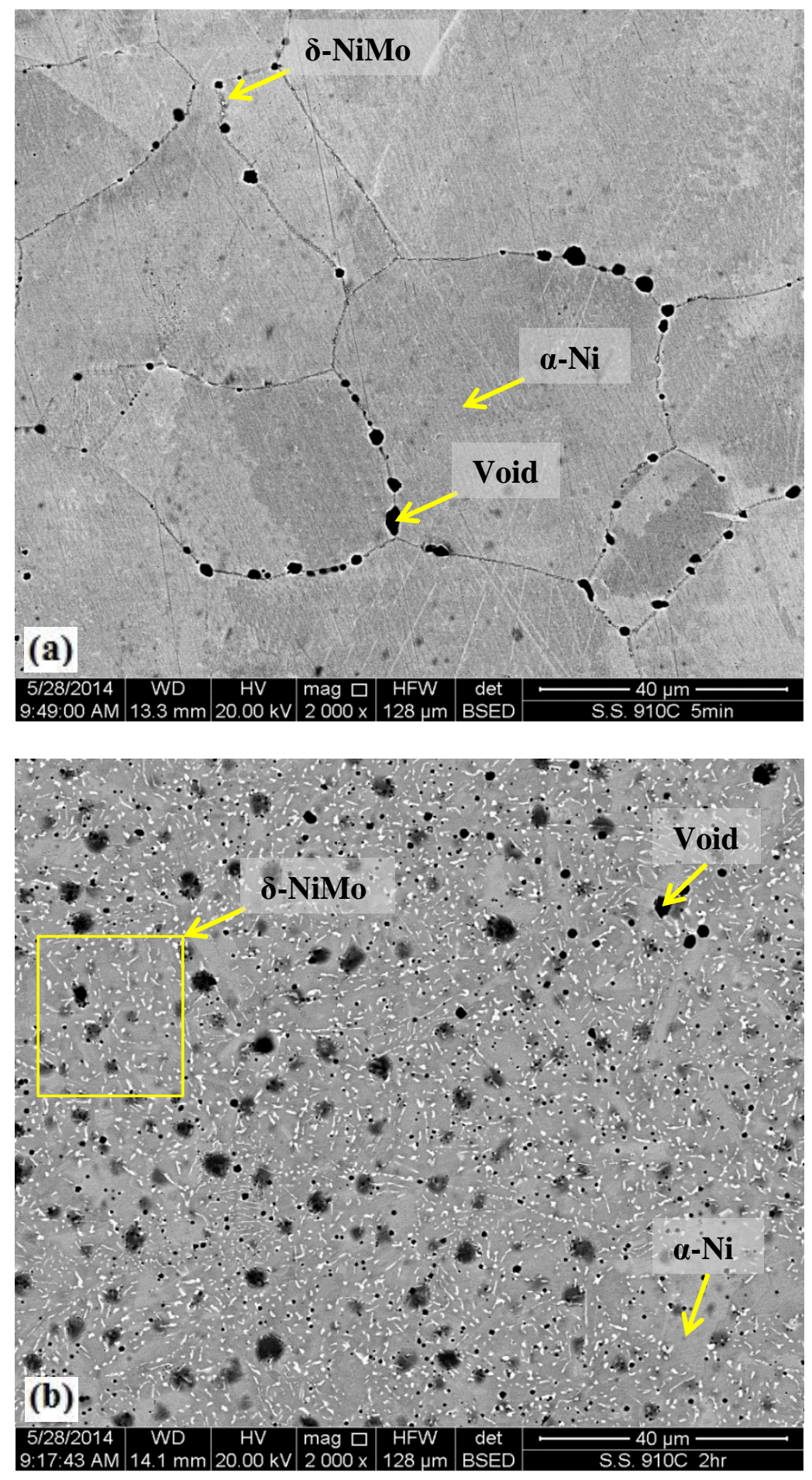


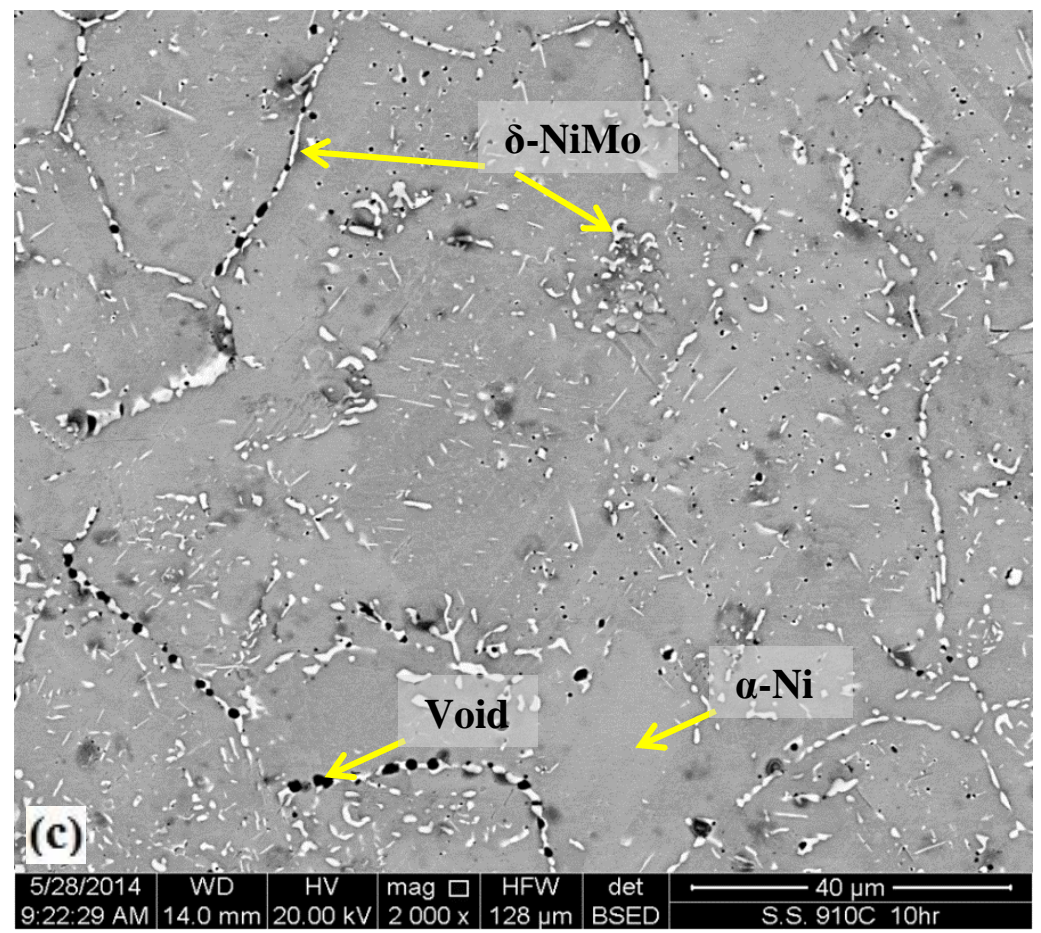

Figure 6.6 SEM micrographs of Ni-25at.\% Mo alloy aged at $910^{\circ} \mathrm{C}$ for: (a) $5 \mathrm{~min}$; (b) $2 \mathrm{~h}$; (c) $10 \mathrm{~h}$. The microstructures are consisting of precipitates of $\delta$-NiMo along and within the grain boundaries of $\alpha$-Ni (the black regions are voids). Etchant: $\mathrm{FeCl}_{3} 5 \mathrm{~g}, \mathrm{HCl} 100 \mathrm{ml}$, and $10 \mathrm{ml} \mathrm{H}_{2} \mathrm{O}$.

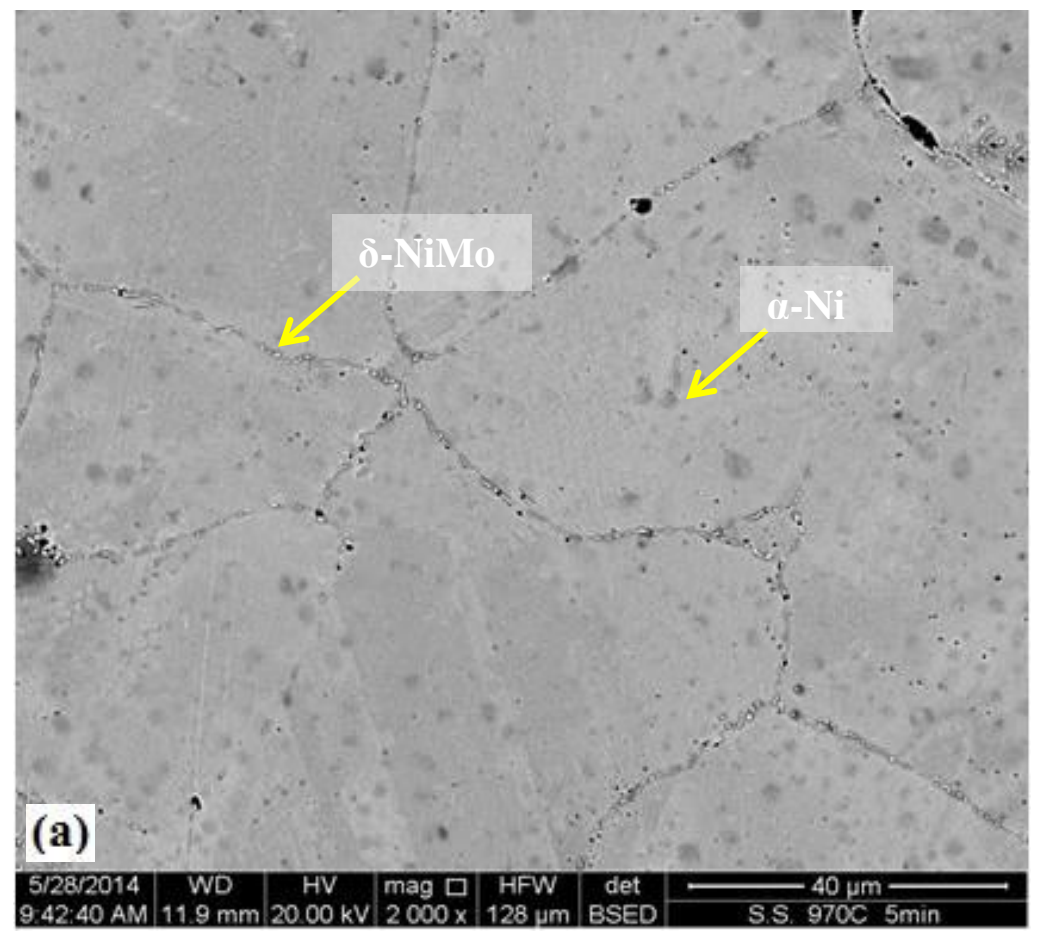




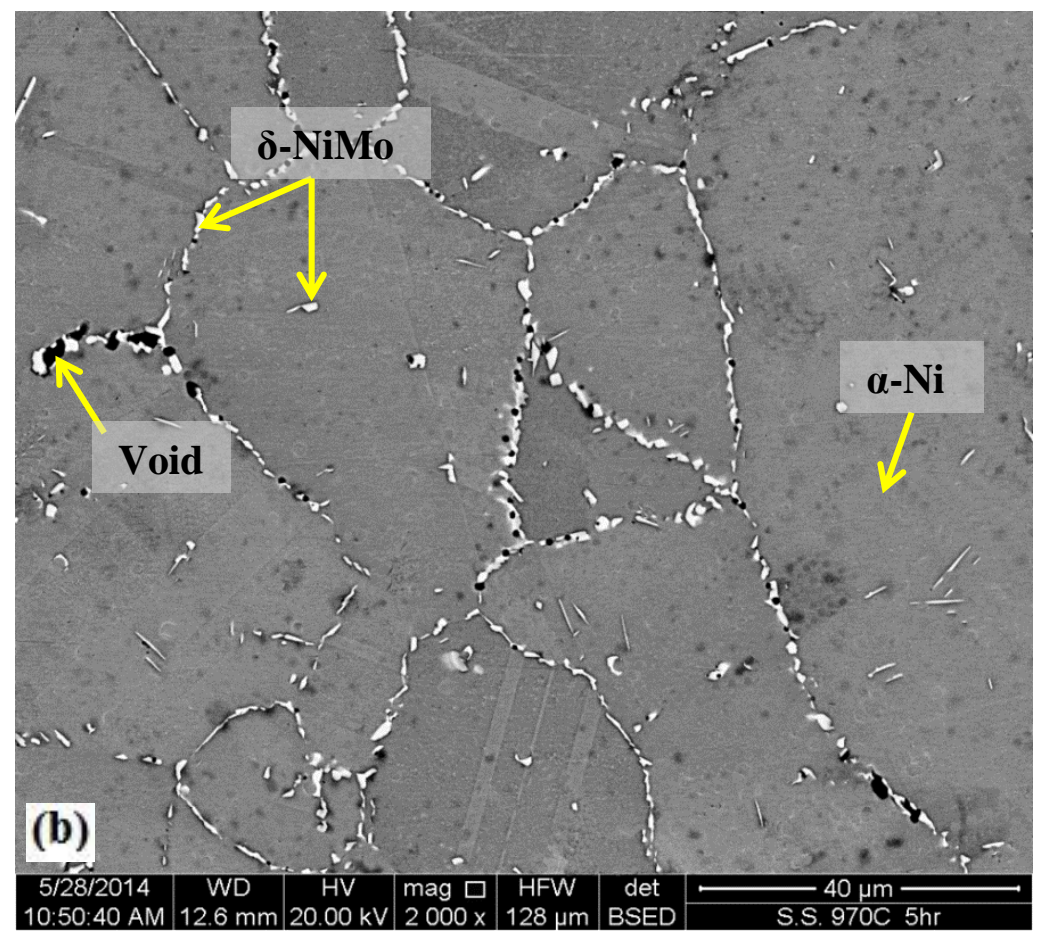

Figure 6.7 SEM micrographs of Ni-25at.\% Mo alloy aged at $970^{\circ} \mathrm{C}$ for: (a) $5 \mathrm{~min}$; (b) $5 \mathrm{~h}$. The microstructures are showing precipitates of $\delta$-NiMo along and within the grain boundaries of $\alpha$-Ni (the black regions are voids). Etchant: $\mathrm{FeCl}_{3} 5 \mathrm{~g}, \mathrm{HCl} 100 \mathrm{ml}$, and $10 \mathrm{ml} \mathrm{H}_{2} \mathrm{O}$.

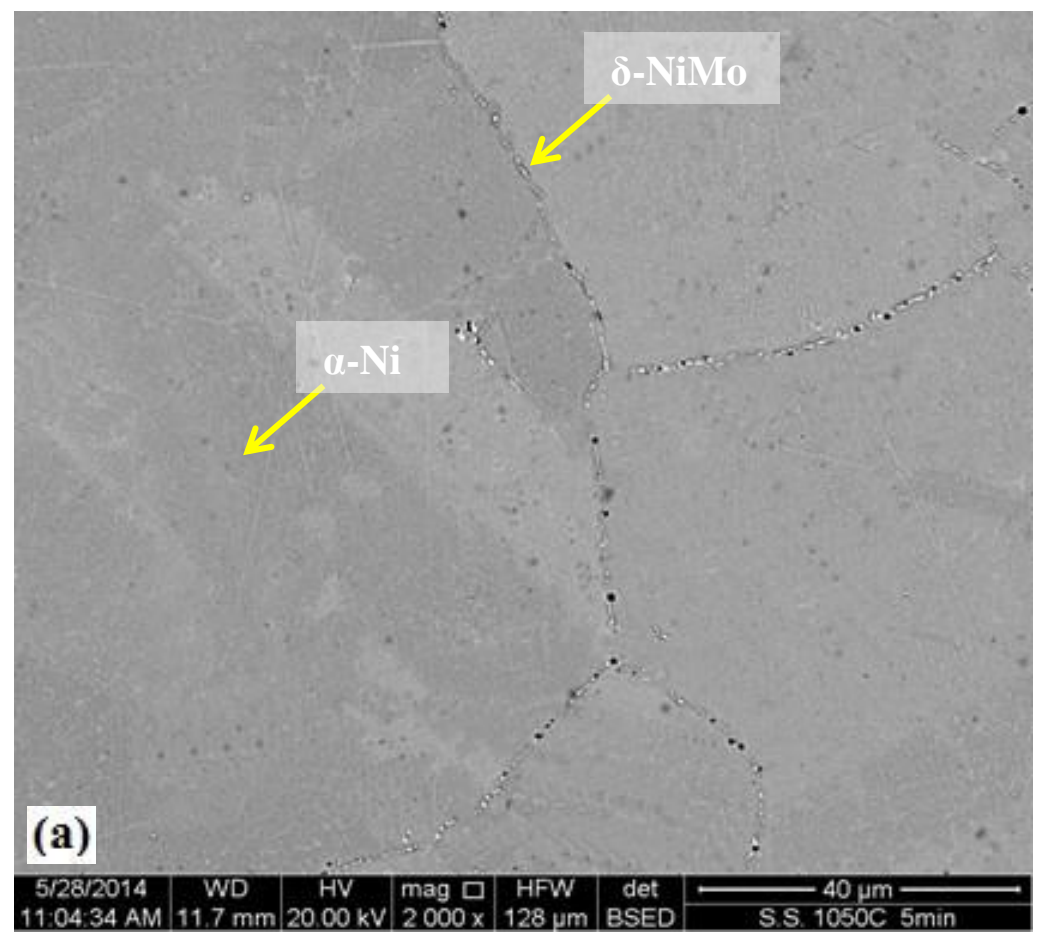



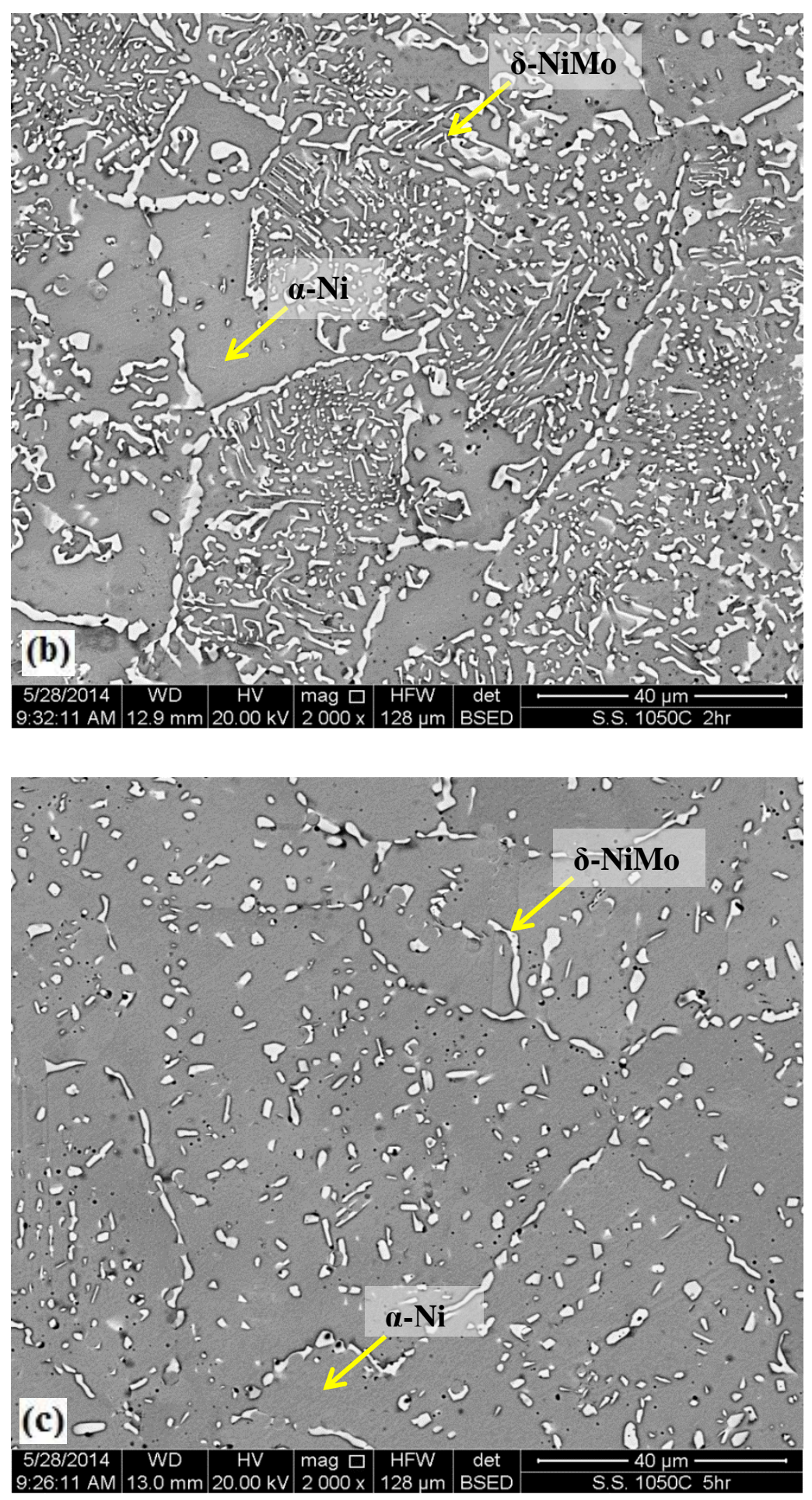

Figure 6.8 SEM micrographs of Ni-25at.\% Mo alloy aged at $1050^{\circ} \mathrm{C}$ for: (a) $5 \mathrm{~min}$; (b) $2 \mathrm{~h}$; (c) $5 \mathrm{~h}$. The microstructures are consisting of $\delta$-NiMo along and within the grain boundaries of $\alpha$-Ni (the black regions are voids). Etchant: $\mathrm{FeCl}_{3} 5 \mathrm{~g}, \mathrm{HCl} 100 \mathrm{ml}$, and $10 \mathrm{ml} \mathrm{H}_{2} \mathrm{O}$. 
Fig. 6.9 shows the result of Vicker's microhardness measurements on sintered/solutionized and aged samples. The curves were similar to traditional aging curves, in that hardness was higher for samples aged at lower temperatures and overaged with time. In this case, the sample aged at $910^{\circ} \mathrm{C}$ was the hardest while the one aged at $1050^{\circ} \mathrm{C}$ was the softest. The hardness of the sample aged at $910^{\circ} \mathrm{C}$ increased from $420 \mathrm{Kg} / \mathrm{mm}^{2}$ to a maximum of 710 $\mathrm{Kg} / \mathrm{mm}^{2}$ in 5 min before dropping

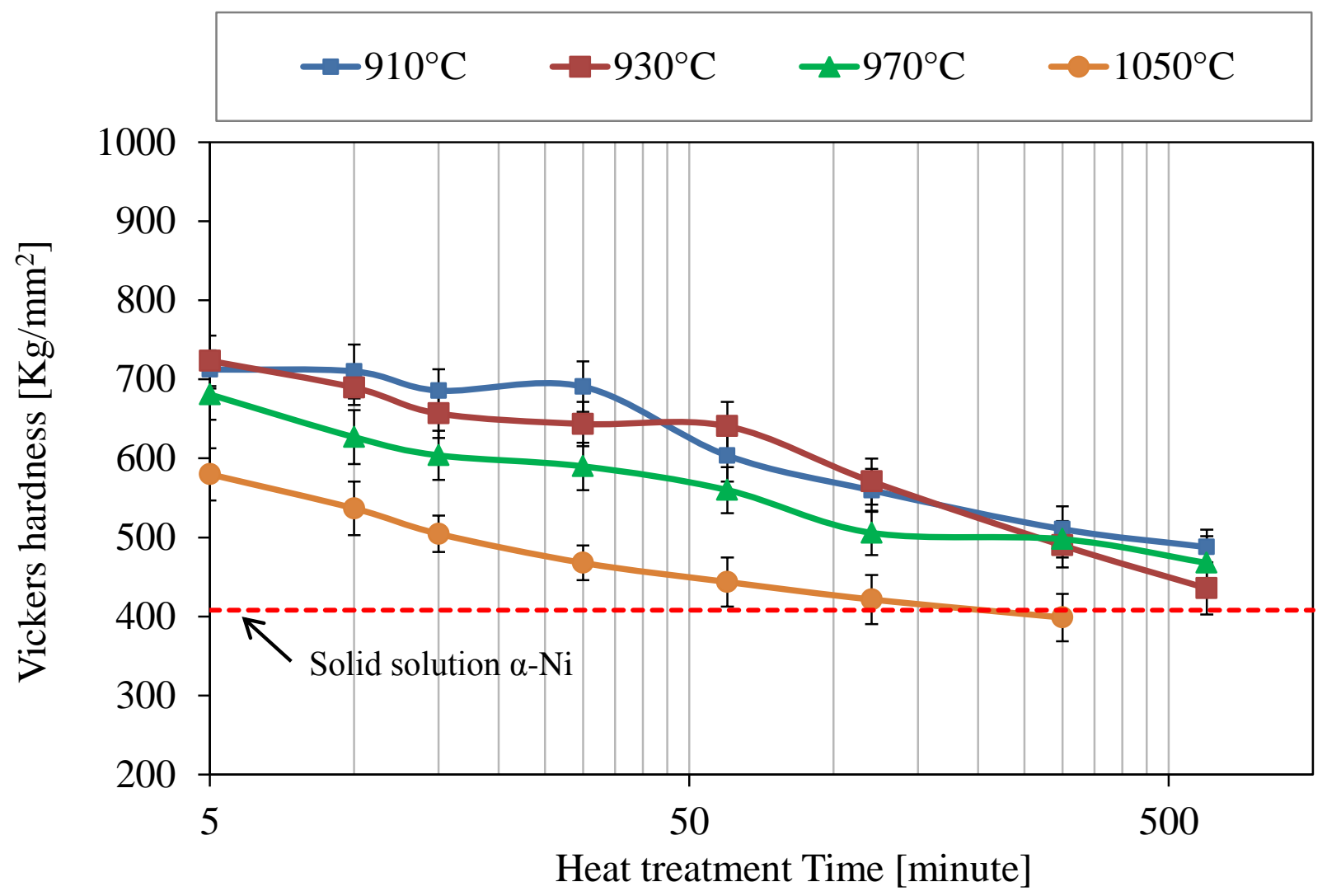

Figure 6.9 Microhardness of Ni-25at.\% Mo alloy aged plotted against aging time. 


\subsection{Discussion}

The XRD patterns of mechanically alloyed powder and sintered/solutionized sample was discussed in Section 4.5. Based on the XRD data, the solid-solution $\alpha$-Ni phase was the dominant phase in all aged samples. Besides that, a small amount of the intermetallic $\delta$-NiMo phase was detected. Based on the phase diagram of Ni-Mo system and in the two-phase region, the alloy composition (Ni-25at.\%Mo) is closer to the $\alpha$-Ni phase than the $\delta$-NiMo phase. For example, at $970^{\circ} \mathrm{C}$ in $\alpha-\mathrm{Ni}-\delta$-NiMo region, the percentages of $\alpha$-Ni and $\delta$-NiMo in the alloy were calculated to be $\sim 86 \%$ and $14 \%$ using the lever rule, respectively. Regardless of aging temperatures, after 5 min of transformation, the double peak was revealed at the $\alpha$-Ni phase but disappeared thereafter as shown in Figs 6.2 to 6.4. This could be the end point of spinodal decomposition. At such a high-temperature treatment microstructural coarsening was expected to be very rapid. At all aging temperatures, the microstructural development during aging began with the precipitation of $\delta$-NiMo phase along and within the grain boundaries of $\alpha$-Ni phase as shown in Figs. 6.6 to 6.8 . Upon prolonged aging, these precipitates coarsened with aging temperature as well. For instance, the effect of aging time can be seen in Fig. 6.8a-c. A sample aged at a lower temperature, i. e. $910^{\circ} \mathrm{C}$, was harder than the one aged at a higher temperature, i. e. $1050^{\circ} \mathrm{C}$. Like traditional aging curves, hardness increased and then overaged with time. Hardness decreased with aging temperature as well as time which was due to grain growth and precipitate coarsening. The average grain size of the samples before aging was around $110 \mu \mathrm{m}$, while after aging the average grain size increased by about $13.6 \%$ at $910^{\circ} \mathrm{C}, 31.8 \%$ at $970^{\circ} \mathrm{C}$, and $90.9 \%$ at $1050^{\circ} \mathrm{C}$. Besides

that, the precipitates size increased with aging times which led to losing coherency between precipitate particles and the matrix. That illustrates why hardness decreased with aging temperatures as well as time. 


\subsection{Summary}

The microstructural evolution during the aging of the supersaturated $\alpha-\mathrm{Ni}$ alloy was studied. Cut samples of the alloy were aged between temperatures of $910^{\circ} \mathrm{C}$ and $1050^{\circ} \mathrm{C}$ for up to 10h. The $\delta$-NiMo phase developed as precipitates along and within grain boundaries of the $\alpha-\mathrm{Ni}$ matrix, and then they coarsened with the transformation temperature and time. Schematic diagram of the phase transformation of $\mathrm{Ni}-25 \mathrm{at} . \% \mathrm{Mo}$ alloy during heat treatment between $910^{\circ} \mathrm{C}-1050^{\circ} \mathrm{C}$ and different heat treatment times is shown in Fig. 6.10. Hardness increased, peaked and then quickly decreased with the transformation temperature and time as the precipitates coarsened for aged samples. For the sample aged at $910^{\circ} \mathrm{C}$, the hardness increased from the pre-aging value of $420 \mathrm{Kg} / \mathrm{mm}^{2}$ to as high as $710 \mathrm{Kg} / \mathrm{mm}^{2}$.

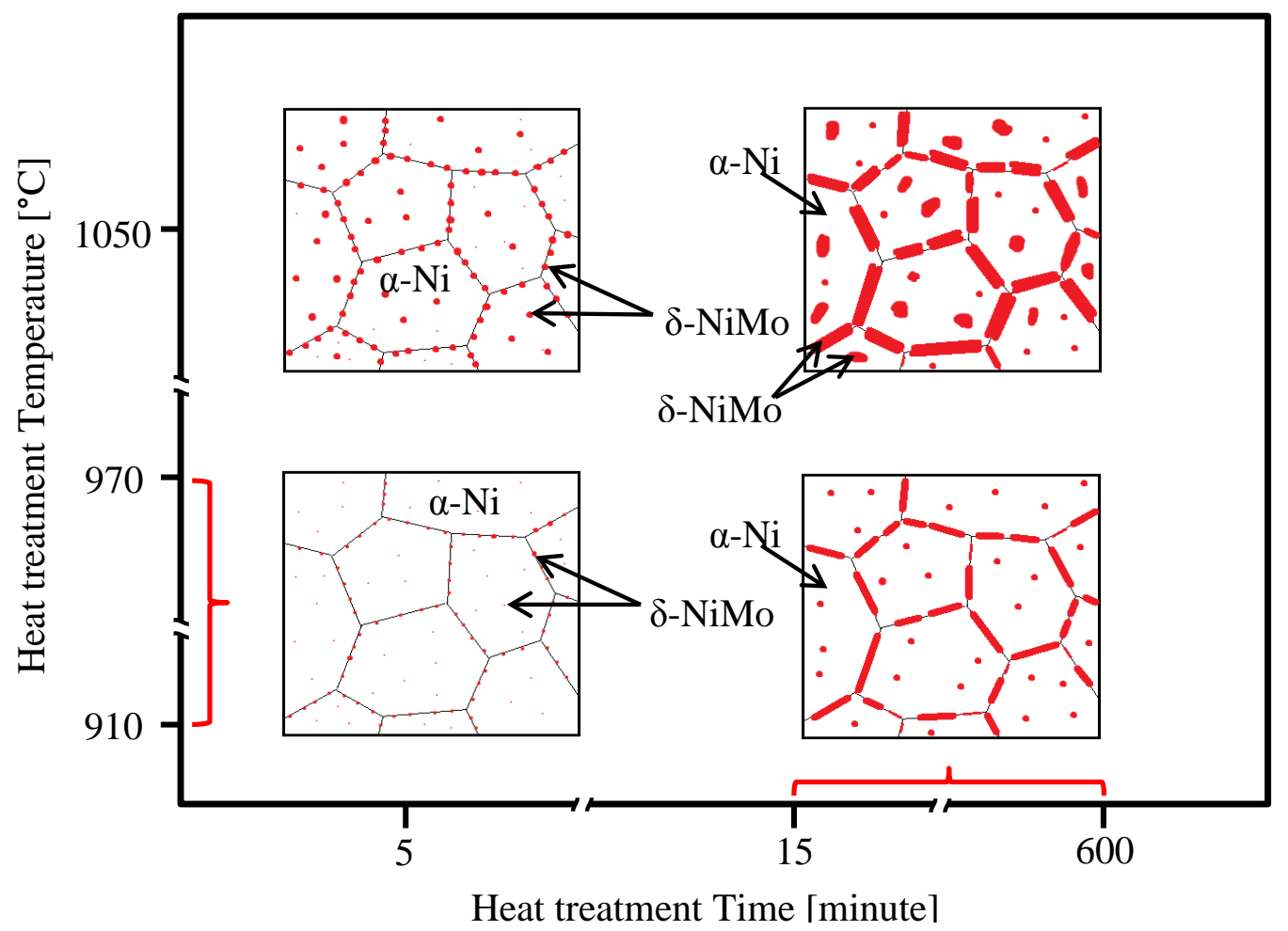

Figure 6.10 Schematic diagram summarizing the phase transformation of the supersaturated Ni-25at.\%Mo alloy during heat treatment between $910^{\circ} \mathrm{C}-1050^{\circ} \mathrm{C}$ (y-axis) and different heat treatment times (x-axis). 


\section{Thesis Summary}

High-energy ball milling and powder metallurgy methods were used to prepare bulk Ni25at.\%Mo alloy. Nickel and molybdenum powders were milled for $10 \mathrm{~h}$, cold-compacted, and sintered/solutionized at $1300^{\circ} \mathrm{C}$ for $25 \mathrm{~h}$ under hydrogen and argon gases flow followed by quenching. The cold compaction and the sintering routines were repeated for a total of $100 \mathrm{~h}$ sintering followed by quenching. The goal of these routines was to improve the density of the bulk samples, and the density was about $8.754 \mathrm{~g} / \mathrm{cc}$ ( $93.8 \%$ out of the theoretical density). The microstructural evolution and their related hardness in bulk supersaturated Ni-25at.\% Mo alloy were investigated in three different cases. The results of the three cases have led to the following conclusions:

\section{The first case:}

i. The microstructural development of $\gamma-\mathrm{Ni}_{3} \mathrm{Mo}$ phase during aging between $600^{\circ} \mathrm{C}$ and $900^{\circ} \mathrm{C}$ for up to $100 \mathrm{~h}$ from the supersaturated solid solution $\alpha-\mathrm{Ni}$ was studied.

ii. The equilibrium $\gamma-\mathrm{Ni}_{3} \mathrm{Mo}$ was formed at $600^{\circ} \mathrm{C}$ after $100 \mathrm{~h}$. The transformation began with the precipitation of $\mathrm{Ni}_{2} \mathrm{Mo}, \beta-\mathrm{Ni}_{4} \mathrm{Mo}$, and $\gamma-\mathrm{Ni}_{3} \mathrm{Mo}$ and then eventually the equilibrium $\gamma$ $\mathrm{Ni}_{3} \mathrm{Mo}$ became the dominant phase after $100 \mathrm{~h}$.

iii. At aging temperatures between $650^{\circ} \mathrm{C}$ and $850^{\circ} \mathrm{C}$, the transformation to the equilibrium $\gamma$ $\mathrm{Ni}_{3} \mathrm{Mo}$ was not completed because aging at these temperatures for $25 \mathrm{~h}$ was not sufficient to complete the transformation.

iv. The formation of the intermetallic $\delta$-NiMo phase was observed only at $900^{\circ} \mathrm{C}$ as a cellular structure after $2 \mathrm{~h}$ and a basket structure after $25 \mathrm{~h}$. 
v. In general, hardness increased by about $113.6 \%$, and overaging occurred with aging time. For example, at an aging temperature of $600^{\circ} \mathrm{C}$, hardness increased and peaked with the complete formation of $\gamma-\mathrm{Ni}_{3}$ Mo phase.

\section{The second case:}

i. The microstructural evolution of the $\alpha-\mathrm{Ni}$ and $\delta$-NiMo from $\gamma-\mathrm{Ni}_{3} \mathrm{Mo}$ was studied.

ii. Samples were first heat-treated at $600^{\circ} \mathrm{C}$ for $100 \mathrm{~h}$, to form the equilibrium $\gamma-\mathrm{Ni}_{3} \mathrm{Mo}$ phase. Subsequently, other heat treatments were performed at temperatures ranging from $910^{\circ} \mathrm{C}$ to $1050^{\circ} \mathrm{C}$ for up to $10 \mathrm{~h}$ followed by quenching.

iii. In all samples, the formation of the $\alpha-\mathrm{Ni}$ phase always occurred first and followed by the precipitation of the $\delta$-NiMo phase along and within grain boundaries.

iv. The equilibrium $\gamma-\mathrm{Ni}_{3} \mathrm{Mo}$ phase was not stable above the peritectoid temperature $910^{\circ} \mathrm{C}$.

v. The microhardness increased by about $90.5 \%$ very rapidly after 5 minutes and peaked with heat-treatment time as the microstructure coarsened.

\section{The third case:}

i. The microstructural evolution of supersaturated $\alpha-\mathrm{Ni}$ alloy in the two-phase region during aging was studied. After sintering/solutionizing followed by quenching the samples were aged at temperatures ranging from $910^{\circ} \mathrm{C}$ to $1050^{\circ} \mathrm{C}$ for up to $10 \mathrm{~h}$.

ii. The $\delta$-NiMo phase was developed as precipitates along and within the grain boundaries of the $\alpha-\mathrm{Ni}$ phase, and then they coarsened with aging temperature as well as time.

iii. Hardness increased by about $77.2 \%$, peaked, and then quickly decreased with aging temperature and time as the precipitates coarsened. 


\section{References}

1. DeHoff, R., Engineering of microstructures. Materials Research, 1999. 2(3): p. 111-126.

2. Thijs, L., et al., A study of the microstructural evolution during selective laser melting of Ti-6Al-4V. Acta Materialia, 2010. 58(9): p. 3303-3312.

3. Kruth, J.-P., et al., Selective laser melting of iron-based powder. Journal of Materials Processing Technology, 2004. 149(1): p. 616-622.

4. Murty, B. and S. Ranganathan, Novel materials synthesis by mechanical alloying/milling. International materials reviews, 2013.

5. Benjamin, J.S., Dispersion strengthened superalloys by mechanical alloying. Metallurgical transactions, 1970. 1(10): p. 2943-2951.

6. De Knijf, D., et al., The influence of ultra-fast annealing prior to quenching and partitioning on the microstructure and mechanical properties. Materials Science and Engineering: A, 2015. 627: p. 182-190.

7. Petrov, R., et al., Ultra-Fast Annealing of High Strength Steel. International Virtual Journal of Machines, Technologies, Materials, Scientific-technical Union of Mechanical Engineering, Bulgaria, Sofia, 2012. 8: p. 68-71.

8. Chen, C., et al., Precipitation hardening of high-strength low-alloy steels by nanometersized carbides. Materials Science and Engineering: A, 2009. 499(1): p. 162-166.

9. Wang, S. and M. Starink, Precipitates and intermetallic phases in precipitation hardening $\mathrm{Al}-\mathrm{Cu}-\mathrm{Mg}-(\mathrm{Li})$ based alloys. International Materials Reviews, 2013.

10. Shunk, F.A., M. Hansen, and K. Anderko, Constitution of binary alloys. 1969: McGrawHill.

11. Verlinden, B., Severe plastic deformation of metals. Metalurgija, 2005. 11(3): p. 165-182.

12. Valiev, R., Nanostructuring of metals by severe plastic deformation for advanced properties. Nature materials, 2004. 3(8): p. 511-516.

13. Lavernia, E.J., J. Ayers, and T.S. Srivatsan, Rapid solidification processing with specific application to aluminium alloys. International materials reviews, 2013.

14. Jacobson, L.A. and J. McKittrick, Rapid solidification processing. Materials Science and Engineering: R: Reports, 1994. 11(8): p. 355-408. 
15. Gladman, T., Precipitation hardening in metals. Materials science and technology, 1999. 15(1): p. 30-36.

16. Fine, M.E., Precipitation hardening of aluminum alloys. Metallurgical Transactions A, 1975. 6(4): p. 625-630.

17. Tsuji, N., et al., ARB (Accumulative Roll-Bonding) and other new Techniques to Produce Bulk Ultrafine Grained Materials. Advanced Engineering Materials, 2003. 5(5): p. 338344.

18. Valiev, R.Z., N. Krasilnikov, and N. Tsenev, Plastic deformation of alloys with submicron-grained structure. Materials Science and Engineering: A, 1991. 137: p. 35-40.

19. Tsuji, N., Ultrafine grained steels. Tetsu-to-Hagane(Journal of the Iron and Steel Institute of Japan)(Japan), 2002. 88(7): p. 359-369.

20. Valiev, R.Z. and T.G. Langdon, Principles of equal-channel angular pressing as a processing tool for grain refinement. Progress in Materials Science, 2006. 51(7): p. 881981.

21. Moumeni, H., S. Alleg, and J. Greneche, Structural properties of Fe 50 Co 50 nanostructured powder prepared by mechanical alloying. Journal of Alloys and Compounds, 2005. 386(1): p. 12-19.

22. Kim, J.-C. and I.-H. Moon, Sintering of nanostructured W-Cu alloys prepared by mechanical alloying. Nanostructured Materials, 1998. 10(2): p. 283-290.

23. Xueming, M. and J. Gang, Nanostructured WC-Co alloy prepared by mechanical alloying. Journal of alloys and compounds, 1996. 245(1): p. L30-L32.

24. Lavernia, E.J. and T.S. Srivatsan, The rapid solidification processing of materials: science, principles, technology, advances, and applications. Journal of Materials Science, 2010. 45(2): p. 287-325.

25. Klement, W., R. Willens, and P. Duwez, Non-crystalline structure in solidified goldsilicon alloys. 1960.

26. Versnyder, F.I. and M. Shank, The development of columnar grain and single crystal high temperature materials through directional solidification. Materials Science and Engineering, 1970. 6(4): p. 213-247. 
27. Bormann, R., F. Gärtner, and F. Haider, Determination of the free energy of equilibrium and metastable phases in the Cu-Zr system. Materials Science and Engineering, 1988. 97: p. 79-81.

28. Krishnamurthy, S. and F. Froes, Rapidly solidified titanium-eutectoid former alloys. International materials reviews, 1989. 34(6): p. 297-311.

29. Wilm, A., Physikalisch-metallurgische Untersuchungen über magnesiumhaltige Aluminiumlegierungen. Metallurgie: Zeitschrift für de gesamte Hüttenkunde, 1911. 8(8): p. 225-227.

30. Van Tendeloo, G., Short range order considerations and development of long range order in different Ni-Mo alloys. Materials Science and Engineering, 1976. 26(2): p. 209220.

31. Suryanarayana, C., Mechanical alloying and milling. Progress in materials science, 2001. 46(1): p. 1-184.

32. Gilman, P. and J. Benjamin, Mechanical alloying. Annual Review of Materials Science, 1983. 13(1): p. 279-300.

33. Fecht, H., et al., Nanocrystalline metals prepared by high-energy ball milling. Metallurgical Transactions A, 1990. 21(9): p. 2333-2337.

34. Aikin, B. and T. Courtney, The kinetics of composite particle formation during mechanical alloying. Metallurgical Transactions A, 1993. 24(3): p. 647-657.

35. Martin, C., D. Bouvard, and S. Shima, Study of particle rearrangement during powder compaction by the discrete element method. Journal of the Mechanics and Physics of Solids, 2003. 51(4): p. 667-693.

36. Upadhyaya, G., Powder metallurgy technology. 1997: Cambridge Int Science Publishing.

37. Wilkinson, D.S. and M. Ashby, Pressure sintering by power law creep. Acta Metallurgica, 1975. 23(11): p. 1277-1285.

38. Eksi, A. and M.K. Kulekci, Hardness and densification behaviour of copper and bronze powders compacted with uniaxial die and cold isostatic pressing processes. METALURGIJA-SISAK THEN ZAGREB-, 2004. 43(2): p. 129-134.

39. Ye, J., L. Ajdelsztajn, and J.M. Schoenung, Bulk nanocrystalline aluminum 5083 alloy fabricated by a novel technique: Cryomilling and spark plasma sintering. Metallurgical and Materials Transactions A, 2006. 37(8): p. 2569-2579. 
40. Zhan, Y., et al., $\mathrm{Cu}-\mathrm{Cr}-\mathrm{Zr}$ alloy matrix composite prepared by powder metallurgy method. Powder metallurgy, 2006. 49(3): p. 253-257.

41. Nagarathnam, K., et al., Development of 1000-Ton Combustion-Driven Compaction Press for Materials Development and Processing. ADVANCES IN POWDER METALLURGY AND PARTICULATE MATERIALS, 2007. 1: p. 03.

42. Kalpakjian, S. and S.R. Schmid, Manufacturing processes for engineering materials. 2010: Pearson education.

43. Crapps, J., et al., Development of the hot isostatic press manufacturing process for monolithic nuclear fuel. Nuclear Engineering and Design, 2013. 254: p. 43-52.

44. German, R.M., Sintering theory and practice. Solar-Terrestrial Physics (Solnechnozemnaya fizika), 1996: p. 568.

45. Guo, Z. and W. Sha, Quantification of Precipitation Hardening and Evolution of Precipitates. Materials Transactions, 2002. 43(6): p. 1273-1282.

46. Kelly, A., Precipitation hardening. 1963: Pergamon Press.

47. Aniyeri, A. and N. Nagarajan, Studies of age-hardening heat treatment on duralumin brick blocks for aerospace applications.

48. Smallman, R.E., Modern physical metallurgy. 2013: Elsevier.

49. Yamamoto, M., et al., Structural Changes during Isothermal Annealing of the Quenched Ni 3 Mo Alloy (I). Transactions of the Japan Institute of Metals, 1970. 11(2): p. 120-126.

50. Ruedl, E. and S. Amelinckx, The substructure of Ni3Mo due to ordering. Materials Research Bulletin, 1969. 4(6): p. 361-368.

51. Das, S., et al., Short range order in Ni-Mo, Au-Cr, Au-V and Au-Mn alloys. Acta metallurgica, 1973. 21(7): p. 913-928.

52. Martin, P. and J. Williams, Long range order in Ni 3 Mo based ternary alloys-II. Coherent phase solvii. Acta Metallurgica, 1984. 32(10): p. 1695-1702.

53. Martin, P. and J. Williams, Long range order in Ni3Mo based ternary alloys-I. Isothermal aging response. Acta Metallurgica, 1984. 32(10): p. 1681-1693.

54. Schryvers, D., G. Van Tendeloo, and S. Amelinckx, On the ordering mechanism of Ni3Mo a high resolution electron microscopy study. Physica status solidi (a), 1985. 87(2): p. 401-415. 
55. Kulkarni, U. and S. Banerjee, Phase separation during the early stages of ordering in Mi 3 Mo. Acta Metallurgica, 1988. 36(2): p. 413-424.

56. Mishra, N. and S. Ranganathan, Electron microscopy and diffraction of ordering in a Ni25wt.\% Mo alloy. Materials Science and Engineering: A, 1992. 150(1): p. 75-85.

57. Tawancy, H., Long-range ordering behaviour and mechanical properties of Ni-Mo-based alloys. Journal of materials science, 1995. 30(2): p. 522-537.

58. Martin, P. and J. Williams, Long range order in Ni $i_{3} M o$ based ternary alloys-II. Coherent phase solvii. Acta Metallurgica, 1984. 32(10): p. 1695-1702.

59. Tawancy, H., Precipitation of NiMo in a Ni-Mo base alloy. Journal of Materials Science, 1980. 15(10): p. 2597-2604.

60. Schwam, D. and S. Dirnfeld, Microstructure and crystallography of a directionally solidified Ni-NiMo eutectic alloy. Materials Science and Engineering: A, 1989. 122(2): p. 257-263.

61. Loverude, M.E., C.H. Kautz, and P.R. Heron, Helping students develop an understanding of Archimedes' principle. I. Research on student understanding. American Journal of Physics, 2003. 71: p. 1178.

62. Smith, W.F. and J. Hashemi, Foundations of materials science and engineering. 2006: Mcgraw-Hill Publishing.

63. Callister, W.D. and D.G. Rethwisch, Materials science and engineering: an introduction. Vol. 7. 2007: Wiley New York.

64. Pearson, W.B., A handbook of lattice spacings and structures of metals and alloys. 1967.

65. Khalfallah, I.a.A.A., Transformation of Supersaturated $\alpha$-Ni Solid Dolution in the Peritectoid Two-Phase Region, 2014: MS\&T 2014. p. 7.

66. Khalfallah, I.a.A.A., Bulk Processing of and Reverse Peritectoid Phase Transformation in Ni3Mo Alloy, 2014: MS\&T 2014 Supplemental Proceedings. p. 7.

67. Khalfallah, I. and A. Aning, Bulk Processing and Mechanical Properties of Ni3Mo. TMS 2014 Supplemental Proceedings, 2014: p. 999-1006.

68. Chakravarti, B., E. Starke Jr, and B. LeFevre, Order-induced strengthening in Ni4Mo. Journal of Materials Science, 1970. 5(5): p. 394-406.

69. Chakravarti, B., et al., Short range order and the development of long range order in Ni4Mo. Journal of Physics and Chemistry of Solids, 1974. 35(9): p. 1317-1326. 
70. Das, S. and G. Thomas, The metastable phase Ni2Mo and the initial stages of ordering in Ni-Mo alloys. Physica status solidi (a), 1974. 21(1): p. 177-190.

71. Mishra, N., C. Singh, and S. Ranganathan, Order hardening in nickel-molybdenum and nickel-tungsten alloys. Journal of materials science, 1992. 27(6): p. 1599-1607.

72. Carter, C.B. and M.G. Norton, Ceramic materials: science and engineering. 2007: Springer Science \& Business Media.

73. Martin, P. and J. Williams, Long range order in Ni3Mo based ternary alloys-I. Isothermal aging response. Acta Metallurgica, 1984. 32(10): p. 1681-1693.

74. Chakravarti, B., et al., Short range order and the development of long range order in Ni 4 Mo. Journal of Physics and Chemistry of Solids, 1974. 35(9): p. 1317-1326.

75. Spruiell, J. and E. Stansbury, X-ray study of short-range order in nickel alloys containing 10.7 and 20.0 at.\% molybdenum. Journal of Physics and Chemistry of Solids, 1965. 26(5): p. 811-822.

76. Jin, Y., et al., Crystal structure of $\delta$-NiMo phase in a ternary NiMoAl alloy. Materials Science and Engineering: A, 1997. 225(1): p. 78-84.

77. Jin, Y., Y. Han, and M. Chaturvedi, Electron microscopy study of the $\delta$-NiMo phase in a binary Ni-Mo alloy. Materials Letters, 1995. 23(1): p. 21-25.

78. Van Tendeloo, G. and S. Amelinckx, The domain structure of the $\delta$-phase alloy NiMo. Materials Research Bulletin, 1973. 8(6): p. 721-731. 